Prepared for the U.S. Department of Energy under Contract DE-AC05-76RL01830

\title{
Optimization of Rhodium-Based Catalysts for Mixed Alcohol Synthesis - 2012 Progress Report
}

\author{
MA Gerber KO Albrecht \\ MJ Gray BL Thompson
}

November 2012

Pacific Northwest

NATIONAL LABORATORY

Proudly Operated by Battelle Since 1965 


\title{
DISCLAIMER
}

This report was prepared as an account of work sponsored by an agency of the United States Government. Neither the United States Government nor any agency thereof, nor Battelle Memorial Institute, nor any of their employees, makes any warranty, express or implied, or assumes any legal liability or responsibility for the accuracy, completeness, or usefulness of any information, apparatus, product, or process disclosed, or represents that its use would not infringe privately owned rights. Reference herein to any specific commercial product, process, or service by trade name, trademark, manufacturer, or otherwise does not necessarily constitute or imply its endorsement, recommendation, or favoring by the United States Government or any agency thereof, or Battelle Memorial Institute. The views and opinions of authors expressed herein do not necessarily state or reflect those of the United States Government or any agency thereof.

\author{
PACIFIC NORTHWEST NATIONAL LABORATORY \\ operated by \\ BATTELLE \\ for the \\ UNITED STATES DEPARTMENT OF ENERGY \\ under Contract DE-AC05-76RL01830
}

Printed in the United States of America

Available to DOE and DOE contractors from the

Office of Scientific and Technical Information,

P.O. Box 62, Oak Ridge, TN 37831-0062;

ph: (865) 576-8401

fax: $(865) 576-5728$

email: reports@adonis.osti.gov

\footnotetext{
Available to the public from the National Technical Information Service,

U.S. Department of Commerce, 5285 Port Royal Rd., Springfield, VA 22161 ph: (800) 553-6847 fax: (703) 605-6900

email: orders@ntis.fedworld.gov

online ordering: http://www.ntis.gov/ordering.htm
}

This document was printed on recycled paper. 


\title{
Optimization of Rhodium-Based Catalysts for Mixed Alcohol Synthesis - 2012 Progress Report
}

\author{
MA Gerber \\ KO Albrecht \\ MJ Gray \\ BL Thompson
}

November 2012

Prepared for

the U.S. Department of Energy

under Contract DE-AC05-76RL01830

Pacific Northwest National Laboratory

Richland, Washington 99352 


\section{Summary}

The U.S. Department of Energy's (DOE) Pacific Northwest National Laboratory (PNNL) has been conducting research since 2005 to develop a catalyst for the conversion of synthesis gas (carbon monoxide $[\mathrm{CO}]$ and hydrogen $\left[\mathrm{H}_{2}\right]$ ) into mixed alcohols for use in liquid transportation fuels. At that time, no commercial catalysts were available, so initial research involved the screening of potential catalysts based on a review of the literature. The screening effort resulted in a decision to focus on catalysts containing rhodium ( $\mathrm{Rh})$ and manganese $(\mathrm{Mn})$. Subsequent research identified iridium (Ir) as a key promoter for this catalyst system. Since then, research has continued to improve the RhMnIr-based catalyst, optimizing the relative and total concentrations of the three metals, examining baseline catalysts on alternative supports, and examining the effects of additional promoters.

Testing continued in FY 2012 to further improve the Ir-promoted RhMn catalysts on both silica and carbon supports for producing mixed oxygenates from synthesis gas. This testing re-examined selected alternative silica and carbon supports to follow up on some uncertainties in the results with previous test results. Additional tests were conducted to further optimize the total and relative concentrations of Rh, $\mathrm{Mn}$, and Ir on selected silica and carbon supports, and to examine selected promoters and promoter combinations based on earlier results. To establish optimum operating conditions, the effects of the process pressure and the feed gas composition also were evaluated. Based on the results of these tests, a number of general conclusions can be reached.

Re-examination of several alternative silica supports showed that a Davisil 645 silica support had the best selectivity to $\mathrm{C}_{2}+$ oxygenates of those silica supports that produced higher $\mathrm{C}_{2}+$ oxygenate spacetime-yield (STYs). The Perlkat 97-1 and the earlier tested Merck Grade 7734 silica supports, while much less active in terms of achievable STYs, were much more selective to $\mathrm{C}_{2}+$ oxygenates. They generally require more total metals (up to 50\% more) to achieve the higher STYs achieved with Davisil 645 silicasupported baseline catalysts, but they can maintain levels of selectivity that are higher than that of Davisil 645 supported catalysts.

Re-examination of the alternative Hyperion carbon nanotube supports suggests that both the CS-05-063 and the CS-07-063 carbon supports produced better STYs than the Hyperion CS-02C-063 carbon support, although the CS-05C-063 carbon support had a lower selectivity to $\mathrm{C}_{2}+$ oxygenates than the other two supports. Incorporating $10 \%$ methanol in the impregnation solution consistently produced catalysts that could achieve significantly higher STYs without significantly affecting the converted carbon selectivity to $\mathrm{C}_{2}+$ oxygenates.

Test results with the Davisil 645 silica-supported catalysts showed that increasing the total metal contents of $\mathrm{Rh}, \mathrm{Mn}$, and Ir beyond their baseline concentrations $(5.56 \% \mathrm{Rh}, 1.69 \% \mathrm{Mn}$, and $1.03 \% \mathrm{Ir})$ to $1.5 \mathrm{X}$ and $2 \mathrm{X}$ the baseline concentrations would significantly increase $\mathrm{C}_{2}+$ oxygenate STYs. A similar trend occurred when the baseline metal concentrations were increased from $1.5 \mathrm{X}$ to $2 \mathrm{X}$ on the Merck Grade 7734 silica support.

Tests performed with Hyperion CS-02C-063 carbon-supported catalysts further examined the effects of $\mathrm{Rh}$ and Ir concentrations in RhMnIr/Hyperion CS-02C-063 carbon supports. The test results showed that increasing the Ir concentration can significantly improve both $\mathrm{C}_{2}+$ oxygenate STYs and the level of selectivity when $\mathrm{Rh}$ and $\mathrm{Mn}$ are maintained at constant concentrations. Alternatively, it appeared that 
increasing the Ir concentration while decreasing the Rh concentration in appropriate amounts could significantly increase the selectivity while maintaining the STY at comparable levels. A comparison of the STYs and corresponding levels of selectivity over a range of testing temperatures for all of the catalysts with different concentrations of $\mathrm{Rh}, \mathrm{Mn}$, and Ir tested to date suggests that the $1.5 \mathrm{X}$ baseline $\mathrm{Rh}$ and $\mathrm{Mn}$ concentrations, along with a 5.6X baseline Ir concentration, had the best overall performance on the Hyperion CS-02C-063 carbon support. It achieved a converted $\mathrm{CO}$ selectivity to $\mathrm{C}_{2}+$ oxygenates that ranged from 70 to $71 \%$ over an STY range from about 900 to $1320 \mathrm{~g} / \mathrm{kg}_{\text {cat }} / \mathrm{hr}$, while operating within a 240 to $250^{\circ} \mathrm{C}$ catalyst temperature range, a $1200 \mathrm{psig}$ reactor pressure, and a $7900 \mathrm{~L} / \mathrm{L}_{\mathrm{cat}} / \mathrm{hr}$ gas hourly space velocity using a feed gas with a nominal 2:1 $\mathrm{H}_{2}: \mathrm{CO}$ ratio and also containing $4 \% \mathrm{~N}_{2}$ and $4 \% \mathrm{CO}_{2}$.

The effect of $\mathrm{Mg}$ as an additional promoter was investigated for RhMnIr catalysts on both the Davisil 645 and Merck Grade 7734 supports. The results indicated that the addition of Mg significantly increased $\mathrm{CO}$ conversion. However, the effect of $\mathrm{Mg}$ addition on the $\mathrm{C}_{2}+$ oxygenate STYs was more difficult to ascertain because there was considerable scatter in these results when repeat tests were made using different batches of catalysts. The differences appeared to be the result of an interchange between the selectivity to $\mathrm{C}_{2}+$ hydrocarbon gases and liquids and the nonalcoholic $\mathrm{C}_{2}+$ oxygenates. One clear difference was that, when $\mathrm{Mg}$ was added to the catalyst, a separate organic liquid fraction, presumed to be mainly hydrocarbons in the $\mathrm{C}_{5}+$ range, was produced. Gas chromatography-mass spectrometry analysis of organic liquid samples produced from $\mathrm{Mg}$-promoted catalysts on both supports showed that about $70 \%$ of the organic liquid species were oxygenated species, apparently consisting mostly of $\mathrm{C}_{2}$ to $\mathrm{C}_{10}$ aldehydes and $\mathrm{C}_{4}$ to $\mathrm{C}_{20}$ acetates derived from $\mathrm{C}_{2}$ to $\mathrm{C}_{10}$ alcohols, with lesser quantities of $\mathrm{C}_{2}$ to $\mathrm{C}_{6}$ alcohols and $\mathrm{C}_{6}$ to $\mathrm{C}_{8}$ acetals. The acetals appear to be derived from $\mathrm{C}_{2}$ to $\mathrm{C}_{4}$ aldehydes and alcohols. These results at least partially explain why a decrease in the organic liquids was accompanied with by an increase in oxygenates in the aqueous phase.

Praseodymium, boron (B), gallium $(\mathrm{Ga})$, zinc + palladium $(\mathrm{Zn}+\mathrm{Pd})$, and zinc + iron $(\mathrm{Zn}+\mathrm{Fe})$ were examined as additional promoters on a partially optimized Hyperion CS-02C-063 carbon-supported RhMnIr catalyst, containing 2.11X the baseline concentrations of $\mathrm{Rh}$ and $\mathrm{Mn}$, and 3.64X the baseline concentration of Ir. The results showed that B- and Ga-promoted catalysts compare very favorably with the unpromoted catalyst. The main difference between these promoted catalysts and the unpromoted catalyst is that they both appear to achieve higher $\mathrm{C}_{2}+$ oxygenate STYs than the unpromoted catalyst at a similar temperature, while attaining comparable levels of selectivity to $\mathrm{C}_{2}+$ oxygenates. The catalysts promoted with $\mathrm{Zn}+\mathrm{Pd}$ and $\mathrm{Zn}+\mathrm{Fe}$ were not as good, both suffering from lower levels of selectivity at comparable conditions, although the STYs for the $\mathrm{Zn}+\mathrm{Pd}$-promoted catalysts compared favorably at comparable temperatures.

Tests to investigate the effect of system operating pressure on catalyst performance showed similar trends for both silica and carbon-supported catalysts of varying compositions, with carbon conversion undergoing a regular decrease of from 65 to $40 \%$ as the pressure decreased from 1200 to $400 \mathrm{psig}$. The selectivity to $\mathrm{C}_{2}+$ oxygenates decreased several percent with decreasing pressure over the entire pressure range, although very little change was observed with the silica-supported catalysts over the 1200 to 700 psig pressure range. The STYs generally followed the same trends as the CO conversion for all three catalysts. The $\mathrm{C}_{2}+$ alcohols made up a greater fraction of the total oxygenates as the pressure decreased over the entire range.

Two test series were conducted to investigate the effect of the $\mathrm{H}_{2}$ :CO ratio on the performance of two carbon-supported catalysts containing 2.11X the baseline concentrations of $\mathrm{Rh}$ and $\mathrm{Mn}$ and 3.64X the 
baseline concentration of $\mathrm{Ir}$, one promoted with $0.04 \% \mathrm{~B}$ and the other promoted with $0.01 \% \mathrm{Ga}$. The converted carbon selectivity to $\mathrm{C}_{2}+$ oxygenates increased by about 3 to $4 \%$ as the $\mathrm{H}_{2}$ : $\mathrm{CO}$ ratio decreased from 2:1 to 1.3:1, while the $\mathrm{C}_{2}+$ oxygenate STYs decreased between 18 and $24 \%$. Decreasing the $\mathrm{H}_{2}: \mathrm{CO}$ ratio also decreased the selectivity of the oxygenate products to $\mathrm{C}_{2}+$ alcohols, suggesting that hydrogenation of the other oxygenates to alcohols is less with the reduced hydrogen concentration in the gas.

Two tests investigated the effect of $4 \% \mathrm{CO}_{2}$ in the syngas using a Davisil 645 silica-supported catalyst containing $1 \mathrm{X}$ baseline concentrations of $\mathrm{Rh}, \mathrm{Mn}$, and $\mathrm{Ir}$, and $0.04 \% \mathrm{Mg}$ and a Merck Grade 7734 silica-supported catalyst containing $1.5 \mathrm{X}$ baseline concentrations of $\mathrm{Rh}, \mathrm{Mn}$, and $\mathrm{Ir}$ and $0.06 \% \mathrm{Mg}$. The results suggested that, when $\mathrm{CO}_{2}$ is reduced from 4 to $0 \%$ in the syngas, there appears to be a very modest 3 to $6 \%$ increase in the selectivity to $\mathrm{C}_{2}+$ oxygenates accompanied by an offsetting 10 to $14 \%$ decrease in the STY. 



\section{Acronyms/Abbreviations}

\begin{tabular}{|c|c|}
\hline $\mathrm{Al}_{2} \mathrm{O}_{3}$ & alumina \\
\hline $\mathrm{Au}$ & gold \\
\hline $\mathrm{Ba}$ & barium \\
\hline BET & Brunauer-Emmett-Teller \\
\hline $\mathrm{CO}$ & carbon monoxide \\
\hline $\mathrm{Cu}$ & copper \\
\hline DOE & U.S. Department of Energy \\
\hline $\mathrm{Fe}$ & iron \\
\hline FT & Fischer-Tropsch \\
\hline $\mathrm{Ga}$ & gallium \\
\hline $\mathrm{GC}$ & gas chromatograph \\
\hline GHSV & gas hourly space velocity \\
\hline GC-MS & gas chromatography-mass spectrometry \\
\hline $\mathrm{H}_{2}$ & hydrogen \\
\hline $\mathrm{HF}$ & hydrofluoric acid \\
\hline $\mathrm{HNO}_{3}$ & nitric acid \\
\hline HPLC & high-pressure liquid chromatograph \\
\hline ICP & inductively coupled plasma \\
\hline Ir & iridium \\
\hline $\mathrm{La}$ & lanthium \\
\hline $\mathrm{Li}$ & lithium \\
\hline Mo & molybdenum \\
\hline $\mathrm{Mn}$ & manganese \\
\hline $\mathrm{N}_{2}$ & nitrogen \\
\hline $\mathrm{Na}$ & sodium \\
\hline $\mathrm{NH}_{3}$ & ammonia \\
\hline $\mathrm{Pd}$ & palladium \\
\hline PNNL & Pacific Northwest National Laboratory \\
\hline $\mathrm{Pt}$ & platinum \\
\hline $\mathrm{Rh}$ & rhodium \\
\hline SCCM & standard cubic centimeters per minute \\
\hline $\mathrm{SiO}_{2}$ & silica \\
\hline STY & space-time-yield \\
\hline syngas & synthesis gas \\
\hline $\mathrm{V}$ & vanadium \\
\hline $\mathrm{Zn}$ & zinc \\
\hline
\end{tabular}




\section{Contents}

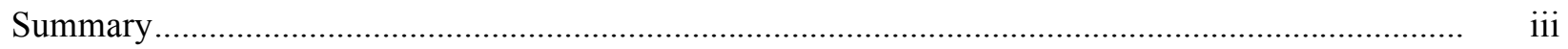

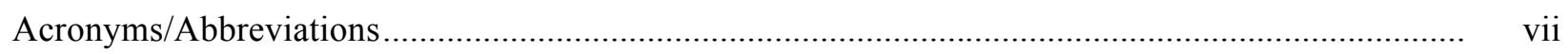

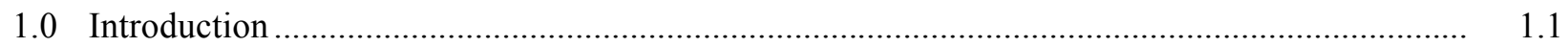

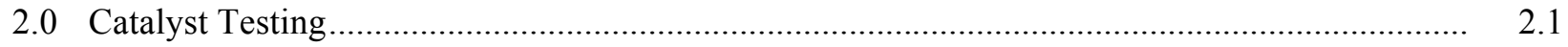

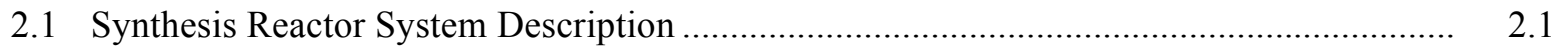

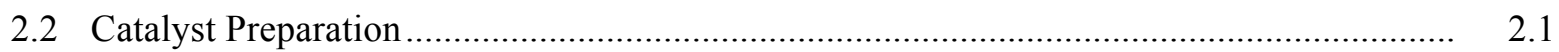

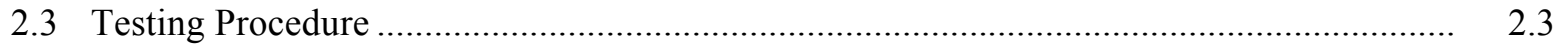

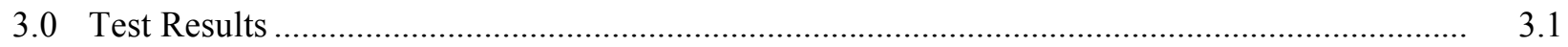

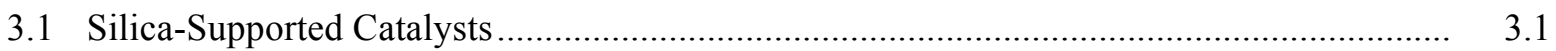

3.1.1 Evaluation of Alternative Silica Supports ........................................................... 3.1

3.1.2 Effect of Total Metal Concentration ................................................................. 3.3

3.1.3 Additional Promoters ................................................................................... 3.7

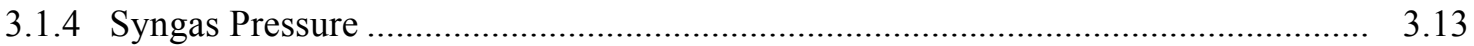

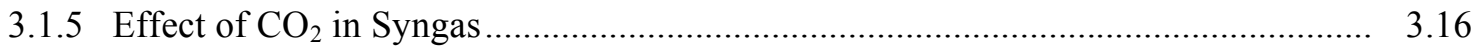

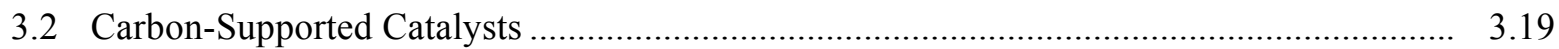

3.2.1 Alternative Carbon Nanotube Supports and Impregnation Solutions ..................... 3.19

3.2.2 Effect of Metal Concentrations ......................................................................... 3.20

3.2.3 Additional Promoters ............................................................................................. 3.23

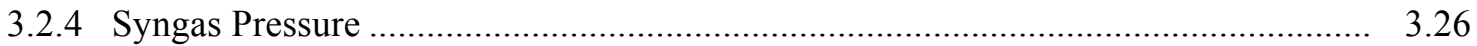

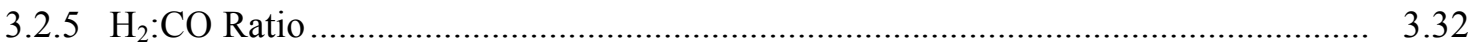

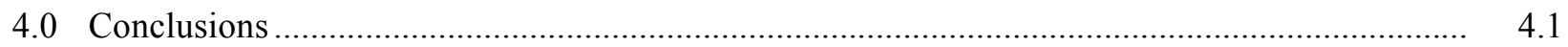

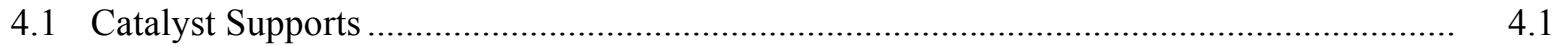

4.2 Effect of Metals Concentrations ........................................................................................

4.3 Evaluation of Promoters for the RhMnIr Catalysts ............................................................. 4.2

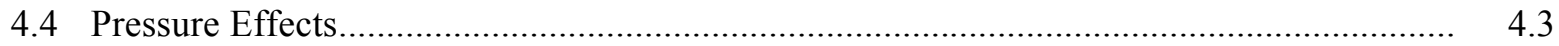

4.5 Gas Composition Effects ...................................................................................... 4.3

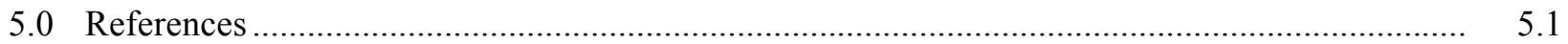




\section{Figures}

2.1 Simplified Diagram of the Reactor System Used to Test Catalysts ........................................ 2.2

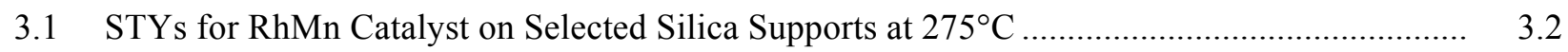

3.2 Converted Carbon Selectivity to Various Products for RhMnIr Catalysts on Selected Silica Supports

3.3 Effect of Catalyst Metal loading on CO Conversion for RhMnIr Catalysts on Selected Davisil 645 Silica Supports at $256^{\circ} \mathrm{C}$.

3.4 Effect of Catalyst Metal Loading on Converted Carbon Selectivity to Various Products for RhMnIr Catalysts on Davisil 645 Silica Supports at $256^{\circ} \mathrm{C}$.

3.5 Effect of Catalyst Metal Loading on STYs for RhMnIr Catalysts on Davisil 645 Silica Supports at $256^{\circ} \mathrm{C}$

3.6 Effect of Catalyst Metal Loading on CO Conversion for RhMnIr Catalysts on Merck Grade Silica Supports at $275^{\circ} \mathrm{C}$

3.7 Effect of Catalyst Metal Loading on Converted Carbon Selectivity to Various Products for RhMnIr Catalysts on Merck Grade Silica Supports at $275^{\circ} \mathrm{C}$

3.8 Effect of Catalyst Metal Loading on STYs for RhMnIr Catalysts on Merck Grade Silica Supports at $275^{\circ} \mathrm{C}$

3.9 Comparison of $\mathrm{C}_{2}+$ Oxygenate Selectivity and STYs for RhMnIr Catalysts on Select Silica Supports.

3.10 Effect of Promoters on CO Conversion for RhMnIr Catalysts on Davisil 645 Silica Supports at $275^{\circ} \mathrm{C}$

3.11 Effect of Promoters on Converted Carbon Selectivity to Various Products for RhMnIr Catalysts on Davisil 645 Silica Supports at $275^{\circ} \mathrm{C}$

3.12 Effect of Promoters on STYs for RhMnIr Catalysts on Davisil 645 Silica Supports at $275^{\circ} \mathrm{C}$

3.13 Effect of Promoters on CO Conversion for RhMnIr Catalysts on Merck Grade 7734

Silica Supports at $250^{\circ} \mathrm{C}$ and $260^{\circ} \mathrm{C}$.

3.14 Effect of Promoters on Converted Carbon Selectivity to Various Products for RhMnIr Catalysts on Merck Grade 7734 Silica Supports at $250^{\circ} \mathrm{C}$ and $260^{\circ} \mathrm{C}$

3.15 Effect of Promoters on STYs for RhMnIr Catalysts on Merck Grade 7734 Silica Supports at $250^{\circ} \mathrm{C}$ and $260^{\circ} \mathrm{C}$.

3.16 Distribution of Organic Liquid Product Hydrocarbons and Oxygenates 1.5X Baseline RhMnIr Catalyst Containing 6\% Mg on a Merck Grade 7734 Silica Support.

3.17 Effect of Syngas Pressure on CO Conversion for a 1X RhMnIr, 0.04\% Mg/Davisil Silica-Supported Catalyst at $265^{\circ} \mathrm{C}$

3.18 Effect of Syngas Pressure on Converted Carbon Selectivity for a 1X RhMnIr, $0.04 \% \mathrm{Mg} /$ Davisil Silica-Supported Catalyst at $265^{\circ} \mathrm{C}$

3.19 Effect of Syngas Pressure on STYs for a 1X RhMnIr, 0.04\% Mg/Davisil SilicaSupported Catalyst at $265^{\circ} \mathrm{C}$

3.20 Effect of Syngas Pressure on Carbon Distribution of the Oxygenates to $\mathrm{C}_{2}+$ Alcohols for a $1 \mathrm{X}$ RhMnIr, $0.04 \% \mathrm{Mg} /$ Davisil Silica-Supported Catalyst at $265^{\circ} \mathrm{C}$ 
3.21 Effect of $\mathrm{CO}_{2}$ in Syngas on CO Conversion for a $1 \mathrm{X}$ RhMnIr, 0.04\% Mg/Davisil

Silica-Supported Catalyst at $265^{\circ} \mathrm{C}$

3.22 Effect of $\mathrm{CO}_{2}$ in Syngas on Selectivity of the Oxygenates to $\mathrm{C}_{2}+$ Alcohols for a $1 \mathrm{X}$ RhMnIr, $0.04 \% \mathrm{Mg} /$ Davisil Silica-Supported Catalyst at $265^{\circ} \mathrm{C}$

3.23 Effect of $\mathrm{CO}_{2}$ in Syngas on STYs for a $1 \mathrm{X}$ RhMnIr, 0.04\% Mg/Davisil Silica-Supported Catalyst at $265^{\circ} \mathrm{C}$.

3.25 Effect of Impregnation using 10\% MeOH Solution on STY for 2.11X RhMnIr on

Various Carbon Supports at $275^{\circ} \mathrm{C}, 1200 \mathrm{psig}$, and $7500 \mathrm{~g} / \mathrm{kg}_{\mathrm{cat}} / \mathrm{hr}$

3.26 Effect of Metal Concentrations on STYs for RhMnIr/Hyperion CS-02C-63 Catalysts at $275^{\circ} \mathrm{C}, 1200 \mathrm{psig}$, and $7500 \mathrm{~g} / \mathrm{kg}_{\mathrm{cat}} / \mathrm{hr}$

3.27 Effect of Metal Concentrations on Converted Carbon Selectivity for RhMnIr/Hyperion CS02C-63 Catalysts at $275^{\circ} \mathrm{C}, 1200 \mathrm{psig}$, and $7500 \mathrm{~g} / \mathrm{kg}_{\text {cat }} / \mathrm{hr}$

3.28 Comparison of the $\mathrm{C}_{2}+$ Oxygenates versus $\mathrm{C}_{2}+$ Oxygenate STYs for Tests Conducted with Catalysts Containing Different Metal Concentrations on Hyperion CS-02C-063 Carbon Supports

3.29 Effect of Promoters on CO Conversion for RhMnIr Catalysts on Hyperion CS-02C-063 Carbon Supports at $260^{\circ} \mathrm{C}$ and 1200 psig....

3.30 Effect of Promoters on Converted Carbon Selectivity for RhMnIr Catalysts on Hyperion CS-02C-063 Carbon Supports at $260^{\circ} \mathrm{C}, 1200 \mathrm{psig}$, and $7500 \mathrm{GHSV}$

3.31 Effect of Promoters on STYs for RhMnIr Catalysts on Hyperion CS-02C-063 Carbon Supports at $260^{\circ} \mathrm{C}, 1200 \mathrm{psig}$, and $7500 \mathrm{GHSV}$.

3.32 Comparison of the $\mathrm{C}_{2}+$ Oxygenates versus $\mathrm{C}_{2}+$ Oxygenates STYs for Tests Conducted with Catalysts Containing Different Promoters.

3.33 Effect of Syngas Pressure on CO Conversion for a 1.5X Rh, 2X Mn, 5.6X Ir/Hyperion CS-02C-063 Carbon-Supported Catalyst at $256^{\circ} \mathrm{C}$

3.34 Effect of Syngas Pressure on Converted Carbon Selelctivity for a 1.5X Rh, 2X Mn, 5.6X Ir/Hyperion CS-02C-063 Carbon-Supported Catalyst at $256^{\circ} \mathrm{C}$

3.35 Effect of Syngas Pressure on Converted Carbon Selelctivity for a 1.5X Rh, 2X Mn, 5.6X Ir/Hyperion CS-02C-063 Carbon-Supported Catalyst at $256^{\circ} \mathrm{C}$

3.36 Effect of Syngas Pressure on STYs for a 1.5X Rh, 2X Mn, 5.6X Ir/Hyperion CS-02C-063 Carbon-Supported Catalyst at $256^{\circ} \mathrm{C}$

3.37 Effect of Syngas Pressure on Selectivity of the Oxygenates to $\mathrm{C}_{2}+$ Alcohols for a 1.5X Rh, 2X Mn, 5.6X Ir/Hyperion CS-02C-063 Carbon-Supported Catalyst at $256^{\circ} \mathrm{C}$

3.38 Effect of Syngas Pressure on Selectivity of the Oxygenates to $\mathrm{C}_{2}+$ Alcohols for a 2.11X RhMn, 3.64X Ir, 1.1\% Pr/Hyperion CS-02C-063 Carbon-Supported Catalyst at $256^{\circ} \mathrm{C}$

3.39 Effect of Syngas Pressure on Converted Carbon Selectivity for a 2.11X RhMn, 3.64X Ir, $1.1 \% \mathrm{Pr} /$ Hyperion CS-02C-063 Carbon-Supported Catalyst at $256^{\circ} \mathrm{C}$

3.40 Effect of Syngas Pressure on STYs for a 2.11X RhMn, 3.64X Ir, 1.1\% Pr/Hyperion CS-02C-063 Carbon-Supported Catalyst at $256^{\circ} \mathrm{C}$

3.41 Effect of Syngas Pressure on Selectivity of the Oxygenates to $\mathrm{C}_{2}+$ Alcohols for a 2.11X RhMn, 3.64X Ir, 1.1\% Pr/Hyperion CS-02C-063 Carbon-Supported Catalyst at $256^{\circ} \mathrm{C}$ 
3.42 Effect of the $\mathrm{H}_{2}$ :CO Ratio on the STYs for a 2.11X RhMn, 3.64X Ir, 0.04\% B/

Hyperion CS-02C-063 Catalyst

3.43 Effect of the $\mathrm{H}_{2}$ : $\mathrm{CO}$ Ratio on the Converted Carbon Selectivity to $\mathrm{C}_{2}+$ Oxygenates and the Oxygenate Selectivity to $\mathrm{C}_{2}+$ Alcohols for a 2.11X RhMn, 3.64X Ir, 0.04\% B/Hyperion CS-02C-063 Catalyst.

3.44 Effect of the $\mathrm{H}_{2}$ :CO Ratio on the Converted Carbon Selectivity to $\mathrm{C}_{2}+$ Oxygenates and the Oxygenate Selectivity to $\mathrm{C}_{2}+$ Alcohols for a 2.11X RhMn, 3.64X Ir, 0.01\% Ga Hyperion CS-02C-063 Catalyst

3.45 Effect of the $\mathrm{H}_{2}$ :CO Ratio on the STYs for a 2.11X RhMn, 3.64X Ir, $0.01 \% \mathrm{Ga} /$ Hyperion CS-02C-063 Catalyst 


\subsection{Introduction}

The U.S. Department of Energy's (DOE) Pacific Northwest National Laboratory (PNNL) is conducting research on the conversion of synthesis gas (syngas) into mixed alcohols for use in liquid transportation fuels. Initiated in 2005, this research began with goals to identify and confirm the performance of any catalysts that were commercially available at that time, as part of DOE's effort to demonstrate mixed alcohol synthesis via indirect liquefaction. No commercially available catalysts were identified, although one company would offer a modified methanol synthesis catalyst for testing. In the absence of commercially available catalysts, the project scope was expanded to examine a variety of noncommercial catalysts and to test the most promising candidates in a bench-scale system. Potential catalysts were divided into the six general classes described below:

- Modified methanol catalysts (e.g. modified copper [Cu]/zinc [Zn]- and $\mathrm{Cu} /$ manganese [Mn]-based catalysts)

- Modified molybdenum (Mo) sulfide catalysts

- Modified Mo oxide catalysts

- Rhodium (Rh)-based catalysts

- Modified Fischer-Tropsch (FT) catalysts.

Representative catalysts for each class were obtained or prepared and tested under conditions that would optimize $\mathrm{C}_{2}+$ space-time-yields (STYs) at a common operating pressure (1200 psig). Ten catalysts representative of the different catalyst classes were evaluated along with a modified methanol catalyst provided by a catalyst manufacturer in 2006 and early 2007 (Gerber et al. 2007). $\mathrm{C}_{2}+$ oxygenate STY was the primary basis of comparison with consideration given to reasonable converted carbon selectivity to $\mathrm{C}_{2}+$ oxygenates. These criteria presupposed that nonalcoholic oxygenates could be hydrogenated further to alcohols in a subsequent step.

Only the modified FT and Rh-based catalysts achieved $\mathrm{C}_{2}+$ oxygenate STYs that were greater than $400 \mathrm{~g} / \mathrm{L}_{\text {cat }} / \mathrm{hr}$. However, FT catalysts, which were modified to improve oxygenate yields, had less than $10 \%$ carbon selectivity to $\mathrm{C}_{2}+$ oxygenates, instead, mainly producing FT liquids and hydrocarbon gases.

The two tested Rh-based catalysts, $\mathrm{Rh} / \mathrm{Mn} /$ silica $\left(\mathrm{SiO}_{2}\right)$ and $\mathrm{Rh} / \mathrm{Mn} / \mathrm{Fe} / \mathrm{SiO}_{2}$, were both very active with the latter achieving a $\mathrm{C}_{2}+$ oxygenate STY of about $400 \mathrm{~g} / \mathrm{L}_{\text {cat }} / \mathrm{hr}\left(\sim 870 \mathrm{~g} / \mathrm{kg}_{\text {cat }} / \mathrm{hr}\right)$, and converted carbon selectivity of $\sim 24 \%$ to $\mathrm{C}_{2}+$ oxygenates. This $\mathrm{Rh}$ catalyst also was unique because it produced very few $\mathrm{C}_{1}$ oxygenates or FT liquids. Based on these results, catalyst tests, beginning in FY 2007, focused on the silica-supported, Rh-based catalyst to examine the effects of 21 promoters other than iron $(\mathrm{Fe})$ on catalyst performance. All of these catalysts used the same Rh:Mn:M atomic ratio (M represents the metal promoter) except one that used lithium (Li) as the promoter. The results of these tests identified several promoters that showed promise for improving the $\mathrm{C}_{2}+$ oxygenates STY and/or improving the selectivity of the $\mathrm{C}_{2}+$ oxygenates to alcohols (Gerber et al. 2008).

During FY 2009, the objective of the testing program shifted to optimization of the silica-supported, RhMn-based catalysts that were reported by Gerber et al. (2010). Optimization involved examination of different total metals concentrations and atomic ratios of $\mathrm{Rh}$ and $\mathrm{Mn}$ as well as that of some of the more 
promising promoters identified in the earlier tests (iridium [Ir] and Li). In addition, limited catalyst screening continued to examine additional promoters that had not been tested previously.

Catalyst optimization continued during FY 2010 on further catalyst optimization and screening. During FY 2010, catalyst optimization tests continued with further examination of the concentration effects of promising catalyst promoters as well as the effects of catalyst support alternatives to the Davisil 645 silica that was used in most testing up to that time (Gerber et al. 2012a). Limited testing to evaluate selected catalyst preparation techniques also were conducted during FY 2010.

Testing of alternative catalyst supports examined the performance of alternative silica support materials with the Ir-promoted $\mathrm{RhMn} / \mathrm{SiO}_{2}$ catalyst. Research continued to a limited extent on the further optimization of the catalyst composition for the silica- and carbon-supported catalysts. Research also began to evaluate the effects of adding more promoters to the RhMnIr catalyst to improve converted carbon selectivity to $\mathrm{C}_{2}+$ oxygenates, while maintaining high STYs (Gerber et al. 2012b).

Testing during FY 2012 re-examined selected alternative silica and carbon supports to follow up on some uncertainties in the results with previous test results. Additional tests were conducted to further optimize the total and relative concentrations of $\mathrm{Rh}, \mathrm{Mn}$, and Ir on selected silica and carbon supports, and to examine selected promoters and promoter combinations based on earlier results. The effects of key operating parameters, pressure, and the feed gas composition also were evaluated to establish the optimum operating conditions. 


\subsection{Catalyst Testing}

\subsection{Synthesis Reactor System Description}

The bench-scale tubular reactor system used to test catalysts is designed to operate at pressures up to $1200 \mathrm{psig}$ and temperatures up to $400^{\circ} \mathrm{C}$. This system is shown in Figure 2.1. The catalyst chamber is $1.67 \mathrm{~cm}$ long and has a $0.635 \mathrm{~cm}$ inner diameter. It usually is filled to a depth of $0.39 \mathrm{~cm}$ with porous metal frit that holds the catalyst in place. A $0.159 \mathrm{~cm}$ outer diameter thermocouple sheath is extended through the center of the reactor, creating an annulus-shaped catalyst chamber. Two thermocouples inside the sheath are spaced so one thermocouple is located at the center of the catalyst bed and the other is just upstream. The catalyst temperature during a test is based on the temperature measured by the thermocouple at the center of the catalyst bed. The reactor is heated with hot oil to obtain better temperature control; this approach more efficiently removes the heat of reaction, thus preventing a thermal excursion when the carbon conversion is too high.

The syngas fed to the reactor is metered through a mass flow controller. The system also meters the reducing gas $\left(10 \%\right.$ hydrogen $\left[\mathrm{H}_{2}\right]$ in nitrogen $\left.\left[\mathrm{N}_{2}\right]\right)$ during catalyst reduction. The raw product gas leaving the reactor is passed through one of two cold traps to condense liquids at $0^{\circ} \mathrm{C}$ and through a backpressure regulator that controls the system pressure. Gas flow is redirected from one trap to the other to isolate the former trap for liquid sample recovery.

The nominal feed rate to the reactor is determined by calibrating the mass flow controllers at system pressure before the tests. A Bios DryCal flow meter located downstream of the back-pressure regulator is used for this calibration. Flow-meter readings are corrected for standard pressure and temperature. The flow meter also is used to monitor product gas flow rate downstream of the liquid sample cold traps during each test.

Dry product gas grab samples for analysis in a gas chromatograph (GC) are obtained downstream of the back-pressure regulator in a line separate from that containing the bubble flow meter, as shown in Figure 2.1. The reactor inlet, catalyst bed, cold sample trap, and ambient temperatures, and the upstream gas and ambient pressures are monitored during tests.

Gas cylinders containing a specified syngas mixture are used in most of the tests. The gas mixture nominally $4 \%$ each carbon dioxide $\left(\mathrm{CO}_{2}\right)$ and $\mathrm{N}_{2}$ with the balance consisting of $\mathrm{H}_{2}$ and carbon monoxide (CO) $\left(2: 1 \mathrm{H}_{2}: \mathrm{CO}\right.$ volume ratio). The capability to separately meter $\mathrm{CO}, \mathrm{H}_{2}$, and $\mathrm{N}_{2}$ was added to the feed gas manifold so mixtures with and without $\mathrm{CO}_{2}$ in the syngas could be explored as well as different $\mathrm{H}_{2}: \mathrm{CO}$ ratios.

\subsection{Catalyst Preparation}

Catalysts tested during this portion of the testing program were based on a baseline catalyst composition of $5.56 \% \mathrm{Rh}, 1.69 \% \mathrm{Mn}$, and, if included, $1.03 \% \mathrm{Ir}$, which was used for most experiments in earlier research. Most catalyst preparations consisted of a single-step impregnation procedure using the incipient wetness technique. The appropriate quantities of a rhodium nitrate solution $(10 \mathrm{wt} \% \mathrm{Rh}$ concentration in solution), manganese nitrate tetrahydrate, and if used, a dihydrogen hexachloroiridium (IV) hydrate solution (14\% Ir) were combined with enough deionized water to bring the total volume of 
the impregnation solution to $90 \%$ of the water adsorption pore volume of the support. If additional promoters were used, they were added as soluble compounds (usually a nitrate salt) to the impregnation solution containing the other three metals.

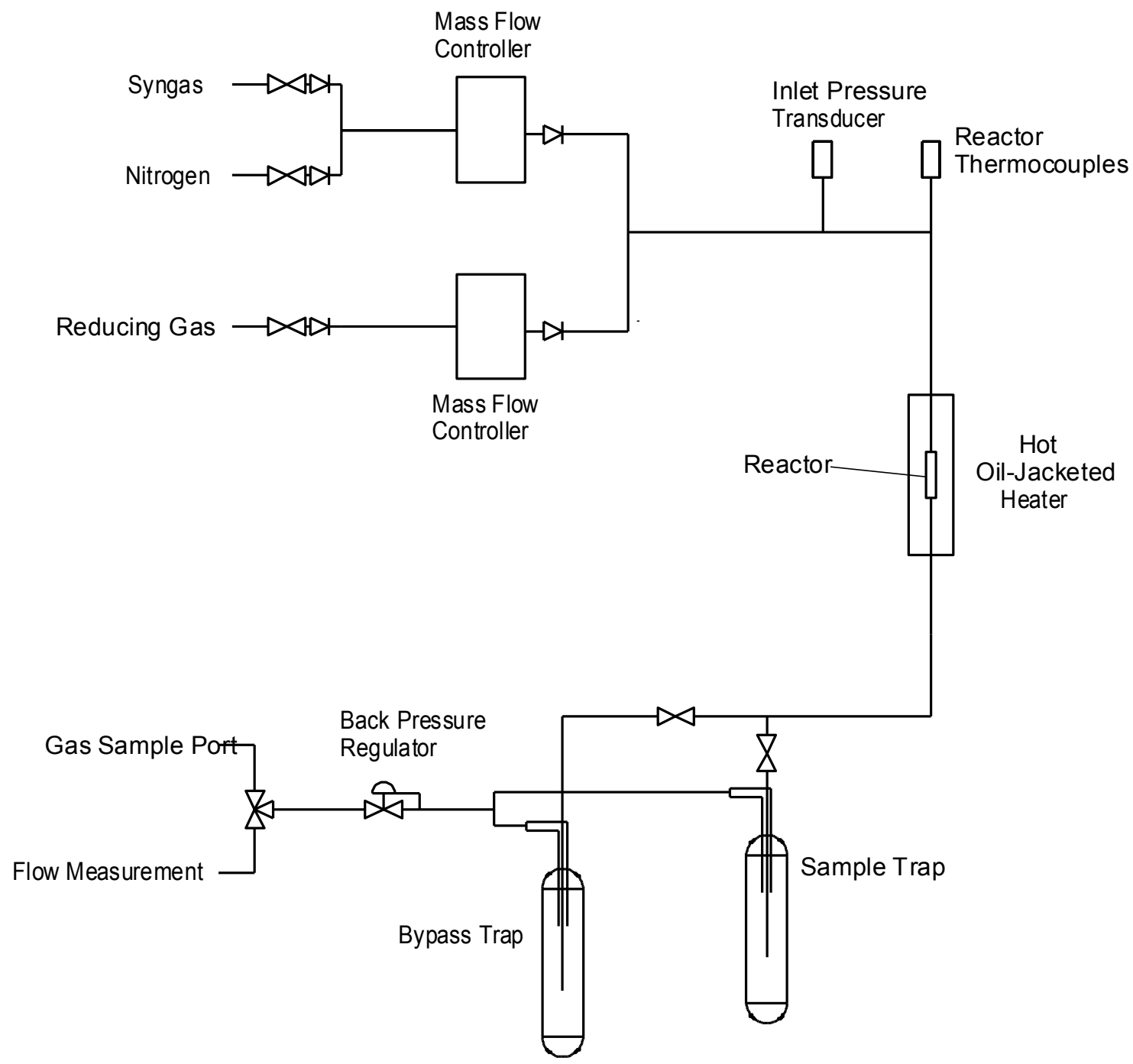

Figure 2.1. Simplified Diagram of the Reactor System Used to Test Catalysts

The solution was impregnated onto the silica in drop-wise fashion on a vibrating table to keep the support solids in motion during impregnation. The impregnated catalysts were dried under an infrared lamp while being shaken until a steady weight was achieved, and then they were dried overnight at $110^{\circ} \mathrm{C}$ in a drying oven. Some of the catalysts containing Rh, Mn, and Ir in tests to optimize the metal concentrations were prepared using two impregnations with drying between impregnations to investigate the effect of the order of metal addition on catalyst performance. Each impregnation solution volume, containing the appropriate metal concentrations, was equal to $90 \%$ of the water adsorption pore volume of the support. The dried catalysts impregnated on inorganic supports were calcined at $400^{\circ} \mathrm{C}$ in air using a muffle furnace. Catalysts supported on carbon were not calcined prior to reduction unless otherwise noted. 
Before conducting the tests, the calcined catalysts were loaded into the reactor and reduced using a $10 \% \mathrm{H}_{2}$-in- $\mathrm{N}_{2}$ gas mixture. All catalysts were heated in the reducing atmosphere to $220^{\circ} \mathrm{C}$ at $2.5^{\circ} \mathrm{C} / \mathrm{min}$ ramp-up rate and held that temperature for 1 hour, then heated from $220^{\circ} \mathrm{C}$ to $260^{\circ} \mathrm{C}$ at a rate of $1{ }^{\circ} \mathrm{C} / \mathrm{min}$ and held at that temperature for 8 hours, and finally heated to $\sim 350^{\circ} \mathrm{C}$ at a rate of $1.5^{\circ} \mathrm{C} / \mathrm{min}$ and held at that temperature for 2 hours.

\subsection{Testing Procedure}

During a typical test series, a measured volume of catalyst was loaded into the reactor, and its net weight was determined. The packing density for catalyst supported on Davisil 645 and Hyperion CS-02C-063 were typically $0.46 \mathrm{~g} / \mathrm{mL} \pm 10 \%$. Many of the other catalyst supports were significantly different from these values, and the basis for comparisons was catalyst weight. The reactor was placed in the reactor system, and reduced in situ at atmospheric pressure. The reactor was cooled after catalyst reduction, and the desired syngas feed rate and pressure were established. The reactor was heated slowly to a temperature at which the reaction rate was significant and maintained at that temperature for at least 24 hours to allow the catalyst to age. The product stream was directed through one of the cold traps during this time. After aging the catalyst, the product stream was redirected through the other cold trap for a period sufficient for at least 10 bed volumes of gas feed (based on the operating pressure and gas feed rate) to pass through the cold trap. This period of time provides a representative gas sample and a sufficiently large liquid sample for subsequent analysis. The operating conditions were recorded before sampling with two or more grab samples of product gas obtained and analyzed in a GC along with a feed gas sample and a calibration gas sample. The liquid recovered from the cold trap was weighed and, if two phases were present, separated into an aqueous phase and an organic phase. The weighed organic phase was not analyzed and was assumed to have a composition comparable to hexane for purposes of a carbon balance. The weighed aqueous phase was analyzed using a high-pressure liquid chromatograph (HPLC) to quantify the $\mathrm{C}_{1}$ to $\mathrm{C}_{5}$ oxygenates, which principally were alcohols, carboxylic acids, aldehydes, esters, and any other products associated with significant peaks identified by the HPLC. After sampling, a new set of conditions (i.e., temperature and feed rate) was established, and another cold trap sample was collected at the new conditions. This procedure was repeated until a representative set of conditions was obtained to evaluate catalyst performance in terms of STY, carbon selectivity, and single-pass carbon conversion. In many cases, tests progressively advanced to higher temperatures with one or more space velocities examined during each test. In most tests, an earlier test condition was re-examined to determine whether further catalyst aging during testing affected the performance of the catalyst.

To calculate a representative average outlet flow rate during a sample collection period, a $\mathrm{N}_{2}$ balance was used with the calibrated feed flow rates. The product gas flow rate downstream of the cold trap was monitored and recorded for estimating the product gas flow rate and to provide a rough check on the accuracy of the calculated flow using a $\mathrm{N}_{2}$ balance. Carbon balances, measured using this method, were usually within approximately $\pm 6 \%$. 


\subsection{Test Results}

Catalyst testing conducted during FY 2012 continued the effort to further improve RhMnIr catalysts on both silica and carbon supports. This effort primarily focused on improving the formulation of the catalyst on each class of supports and examining the effects of selected operating parameters on catalyst performance. In general, the RhMnIr catalysts on each class of support behave very differently and respond differently to further optimization of the catalyst composition. For this reason, the results of testing are discussed separately for the silica and carbon-supported catalysts in the following sections.

\subsection{Silica-Supported Catalysts}

Tests performed during FY 2012 using silica-supported RhMnIr catalysts fell into five general areas: re-examination of the performance of select silica supports; further examination of the total metals concentration on the Davisil 645, Merck Grade 7734, and Merck Grade 7754 silica-supported catalysts; and further evaluation and optimization of promising third metal and third and fourth metal combinations added to RhMnIr catalysts. Examination of operating pressure and the syngas composition on catalyst performance also was performed on selected catalysts.

\subsubsection{Evaluation of Alternative Silica Supports}

Several alternative silica supports evaluated during FY 2011 had reasonably good performance when $\mathrm{Rh}$ and Mn were evaluated, but when Ir was added in a second impregnation, the results were inconclusive (Gerber et al. 2011). Tests performed during FY 2012 re-examined several of these silica supports but with Ir co-impregnated along with $\mathrm{Rh}$ and $\mathrm{Mn}$ on the supports at the $1 \mathrm{X}$ baseline concentrations $(5.56 \%$ $\mathrm{Rh}, 1.69 \% \mathrm{Mn}$, and $1.03 \% \mathrm{Ir}$ ). The catalysts were evaluated at sequentially higher temperatures during a test (nominally $240^{\circ} \mathrm{C}, 255^{\circ} \mathrm{C}, 275^{\circ} \mathrm{C}$, and $300^{\circ} \mathrm{C}$ ) and at $7500 \mathrm{~L} / \mathrm{L}_{\text {cat }} / \mathrm{hr}$ gas hourly space velocity (GHSV), except for the Engelhard Mod D silica, which also was retested at $256^{\circ} \mathrm{C}$ and $275^{\circ} \mathrm{C}$ but at 11000 GHSV because it had a much higher activity, achieving $56 \% \mathrm{CO}$ conversion at $275^{\circ} \mathrm{C}$ and the $7500 \mathrm{~L} / \mathrm{Lcat} / \mathrm{hr}$ GHSV (CO conversion was $21 \%$ at the higher GHSV). (Previous results suggest that the STYs and levels of selectivity were not significantly affected by the GHSV at CO conversions less than $\sim 40 \%$ ). The catalyst performance comparison with the different supports was made for the results at $275^{\circ} \mathrm{C}$.

The Perlkat 79-3, Engelhard Mod D, and Norpro SS61138 silica supports had relatively high $\mathrm{C}_{2}+$ oxygenates STYs although not as high as the Davisil 645 silica as shown in Figure 3.1. However, their overall levels of selectivity to $\mathrm{C}_{2}+$ oxygenates (Figure 3.2) were not better than the Davisil 645 silica-supported catalysts, leaving the Davisil silica as the preferred silica among the more active silica supports. The fraction of the $\mathrm{C}_{2}+$ oxygenates that were $\mathrm{C}_{2}+$ alcohols was significantly higher for the Engelhard Mod D and Perlkat 79-3 silica-supported catalysts.

The Perkat 97-1 silica-supported catalyst was significantly less active than the Davisil silica, having a $\mathrm{C}_{2}+$ oxygenate STY that was approximately one-quarter of that achieved with the Davisil silica-supported catalyst (186 g/ $\mathrm{kg}_{\text {cat }} / \mathrm{hr}$ vs. an average of $794 \mathrm{~g} / \mathrm{kg}_{\text {cat }} / \mathrm{hr}$, respectively), but it had a significantly higher selectivity of $60 \%$ to the $\mathrm{C}_{2}+$ oxygenates. This performance compared very favorably with the Merck 
Grade 7734 Silica-supported RhMn and RhMnIr (double-impregnated) catalysts evaluated in FY 2011, which has been shown to perform well at higher metals concentrations (discussed later in this report).

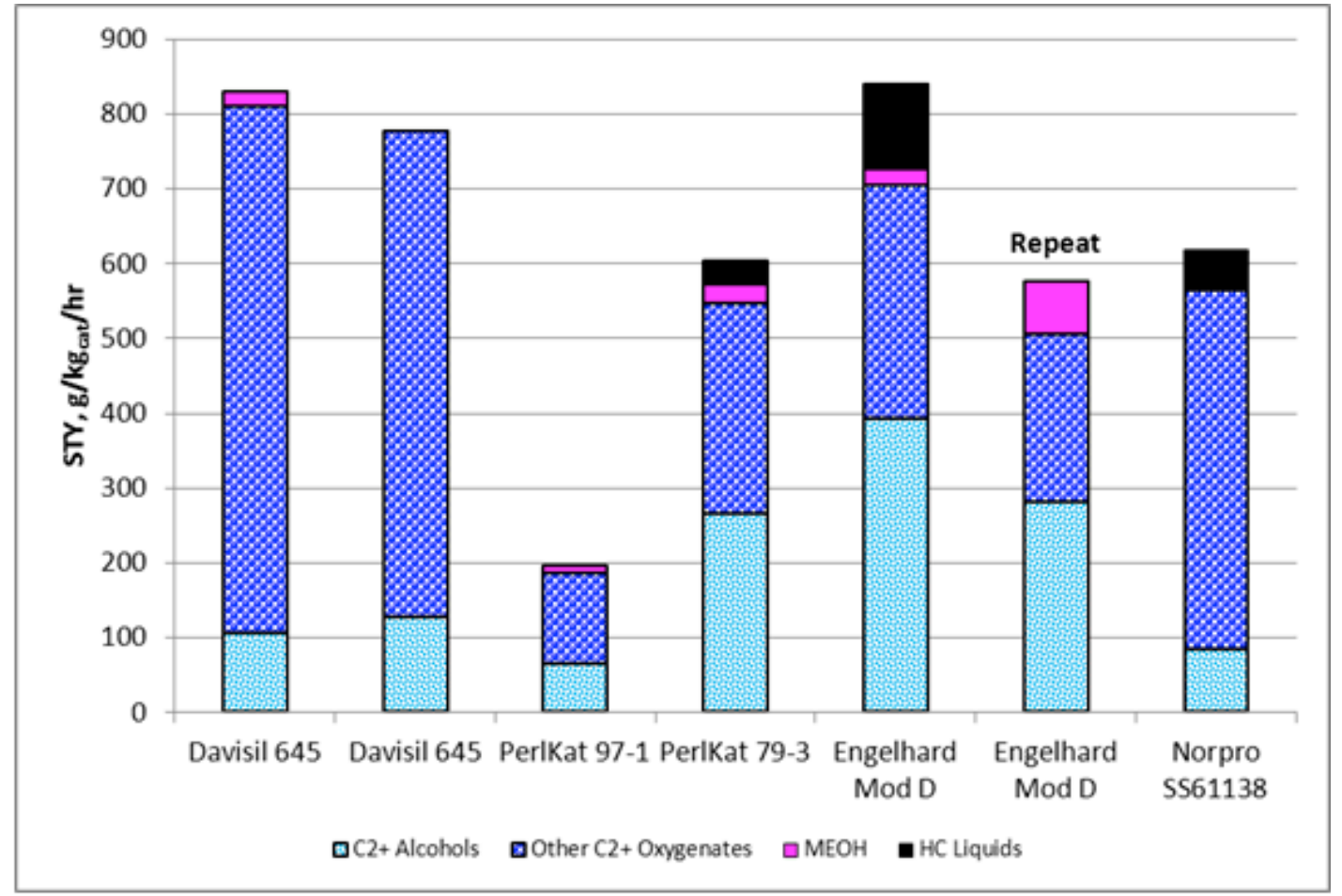

Figure 3.1. STYs for RhMn Catalyst on Selected Silica Supports at $275^{\circ} \mathrm{C}$

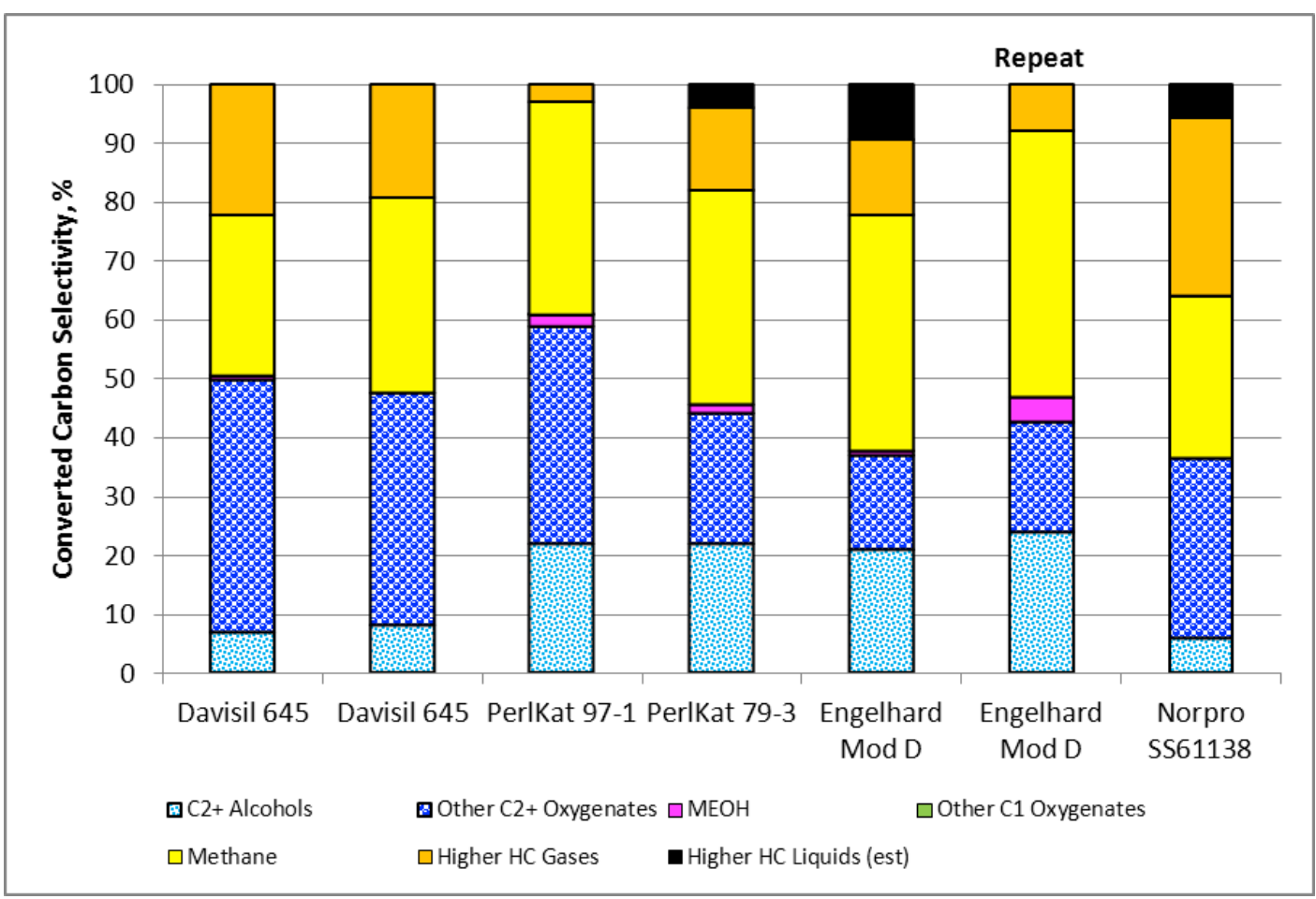

Figure 3.2. Converted Carbon Selectivity to Various Products for RhMnIr Catalysts on Selected Silica Supports 


\subsubsection{Effect of Total Metal Concentration}

During FY 2011, two test series were conducted to examine the effect of the $\mathrm{Rh}, \mathrm{Mn}$, and Ir concentrations on the Davisil 645 and Merck Grade 7734 supports, including total metals relative to a 1X baseline concentration of 5.56\% Rh, 1.69\% Mn, and 1.03\% Ir (Gerber et al. 2011). However, all of the catalysts were prepared using two impregnations - a first impregnation containing the $\mathrm{Rh}$ and $\mathrm{Mn}$ metal in the impregnation solution, and the second impregnation, following a drying step, containing the Ir metal in the solution. Test results with the double-impregnated catalysts were not very reproducible, thus making comparisons of different metal loadings difficult. During FY 2012, several test series were performed using each support and different total metals loading, but with all three metals co-impregnated on the support. In addition, two tests series were performed using the Merck Grade 7754 silica, which is a purer version of the 7734 silica. Catalysts were tested at incrementally higher temperatures starting at $225^{\circ} \mathrm{C}$ or $240^{\circ} \mathrm{C}$, depending on the temperature at which significant activity was indicated by a reduction in the outlet gas flow rate. Performance comparisons were made using a common temperature for each set of catalysts prepared with the same support (except where noted), with prior conditions achieved at lower, but not necessarily the same, temperatures.

Figure 3.3, Figure 3.4, and Figure 3.5 compare the performance of different catalyst loadings for the Davisil 645 silica support at a common temperature of $256^{\circ} \mathrm{C}$, except for the catalyst containing $2 \mathrm{X} \mathrm{RhMnIr}$, which was tested at $250^{\circ} \mathrm{C}$. As expected, increasing the total metals content at the same relative atomic ratios for $\mathrm{Rh}, \mathrm{Mn}$, and Ir resulted in higher $\mathrm{CO}$ conversion as shown in Figure 3.3. (It is noteworthy that the $2 \mathrm{X} \mathrm{RhMnIr}$ catalyst had a higher carbon conversion at $250^{\circ} \mathrm{C}$ than the corresponding 1.5X RhMnIr catalyst at $256^{\circ} \mathrm{C}$.) As shown in Figure 3.4, increasing the total metals loading from $1 \mathrm{X}$ to $2 \mathrm{X}$ at constant atomic ratios results in significantly decreased converted carbon selectivity to $\mathrm{C}_{2}+$ alcohols and other oxygenates. As a result, the $\mathrm{C}_{2}+$ oxygenate STY appears to reach a maximum at a $1.5 \mathrm{X}$ RhMnIr loading as shown in Figure 3.5, mainly because of the reduced selectivity at the 2X RhMnIr loading. However, this finding may be misleading because the $2 \mathrm{X} \mathrm{RhMnIr}$ catalyst was tested at $250^{\circ} \mathrm{C}$ instead of $256^{\circ} \mathrm{C}$. At a slightly higher temperature, the $2 \mathrm{X}$ RhMnIr catalyst would have experienced an even greater $\mathrm{CO}$ conversion that may or may not have been fully offset by a lower selectivity. In general, the catalysts prepared using Merck Grades 7734 and 7754 silica supports showed the same trends for CO conversion, converted carbon selectivity to $\mathrm{C}_{2}+$ oxygenates and total $\mathrm{C}_{2}+$ oxygenate STYs with increasing total metals as shown in Figure 3.6, Figure 3.7, and Figure 3.8. However, the selectivity of the Merck Grade 7754 supported catalyst was lower than that achieved with the Merck Grad 7734 silica support, when both contained 1.5X baseline metal concentrations, even though the STYs were comparable.

Figure 3.9 provides a comparison of the better performing catalysts in this series in terms of $\mathrm{C}_{2}+$ oxygenate STYs and corresponding levels of selectivity at all temperatures tested up to and including $275^{\circ} \mathrm{C}$. It can be seen that the Merck Grade 7734 with $1.5 \mathrm{X}$ baseline Rh, Mn, and Ir metal loadings provides the best levels of selectivity over a range of temperatures examined, achieving a $\mathrm{C}_{2}+$ oxygenate STY of about $700 \mathrm{~g} / \mathrm{kg}_{\text {cat }} / \mathrm{hr}$ at a converted carbon selectivity of $68 \%$ at $275^{\circ} \mathrm{C}$. 


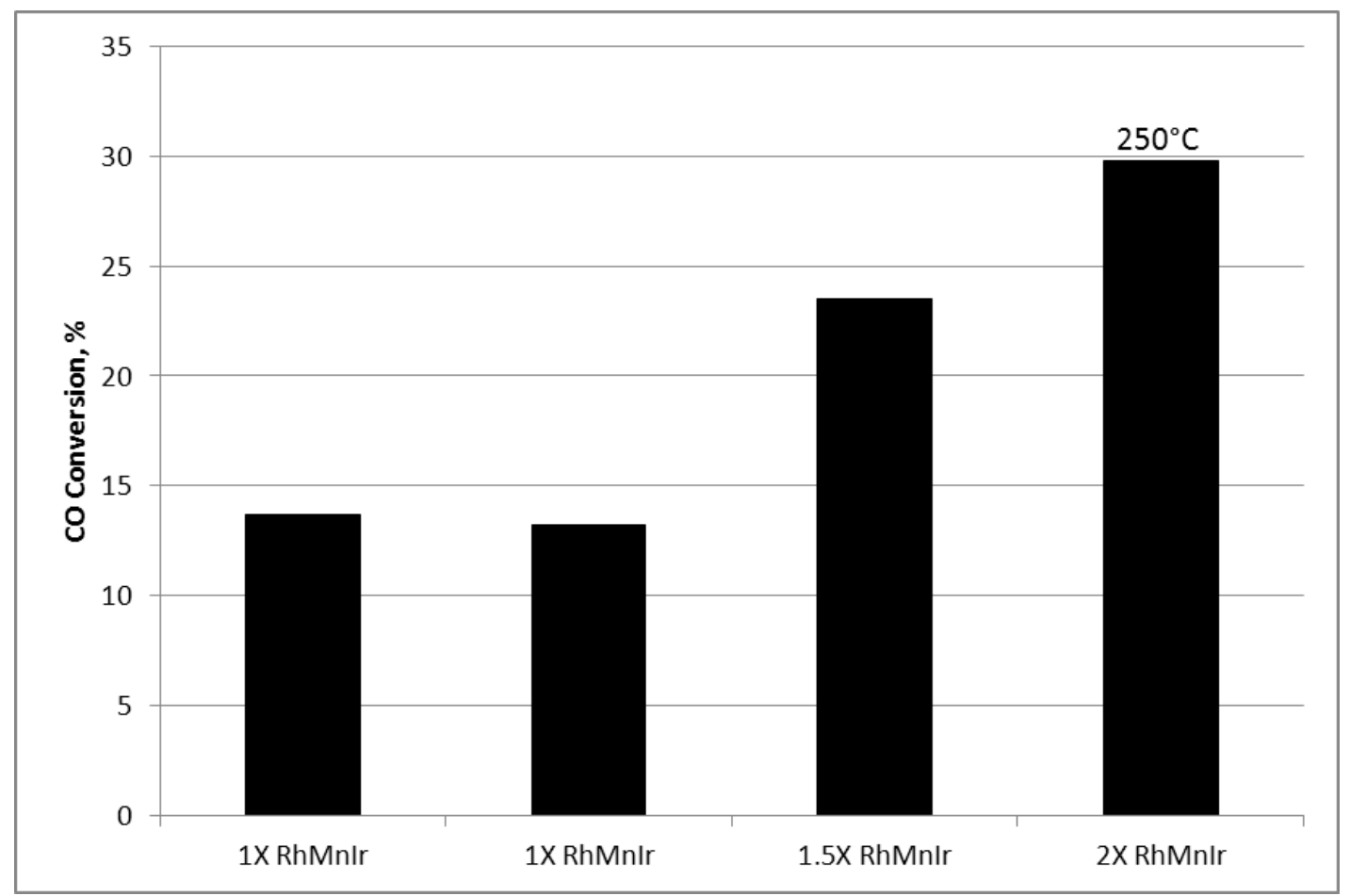

Figure 3.3. Effect of Catalyst Metal loading on CO Conversion for RhMnIr Catalysts on Selected Davisil 645 Silica Supports at $256^{\circ} \mathrm{C}$

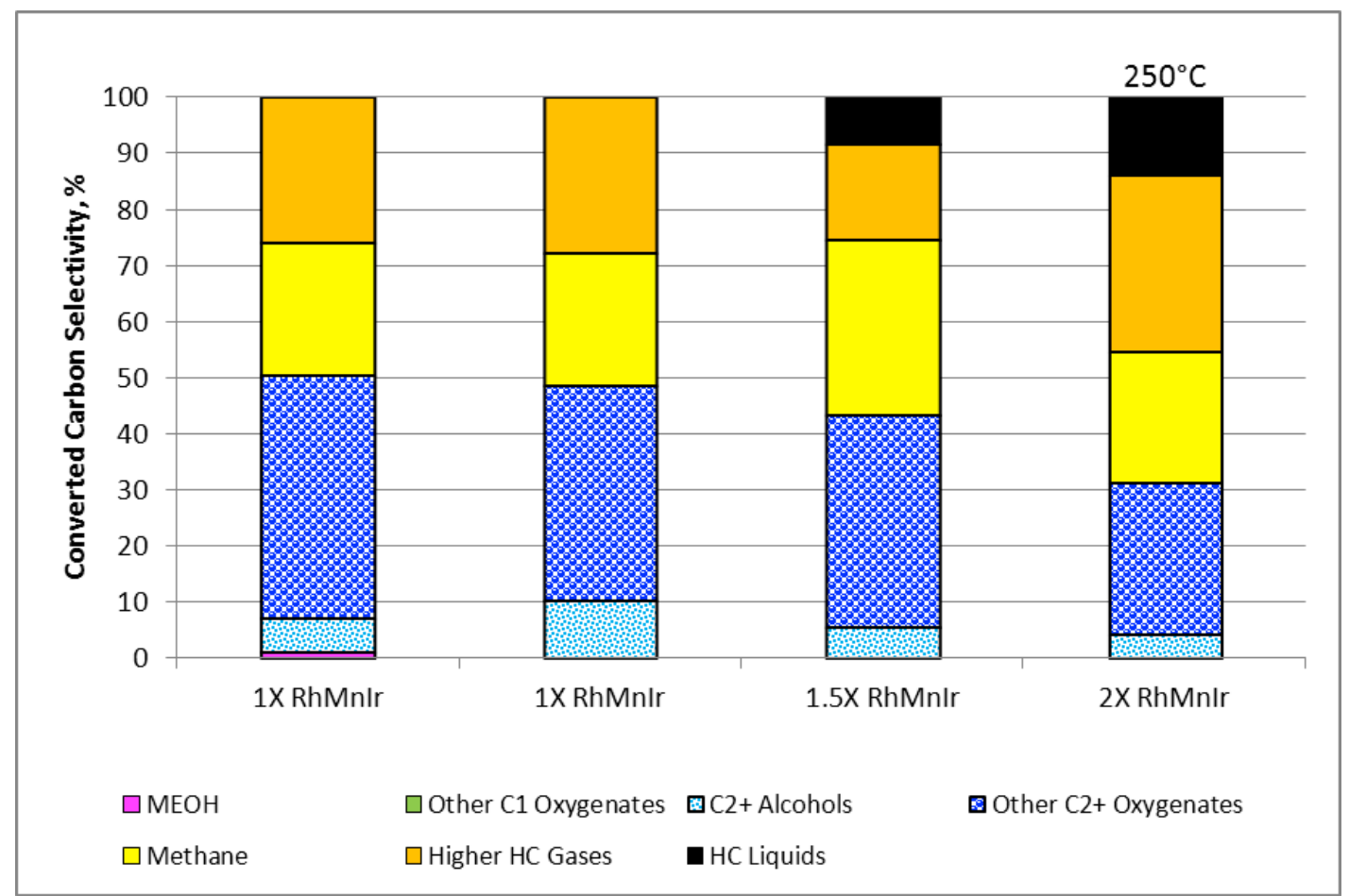

Figure 3.4. Effect of Catalyst Metal Loading on Converted Carbon Selectivity to Various Products for RhMnIr Catalysts on Davisil 645 Silica Supports at $256^{\circ} \mathrm{C}$ 


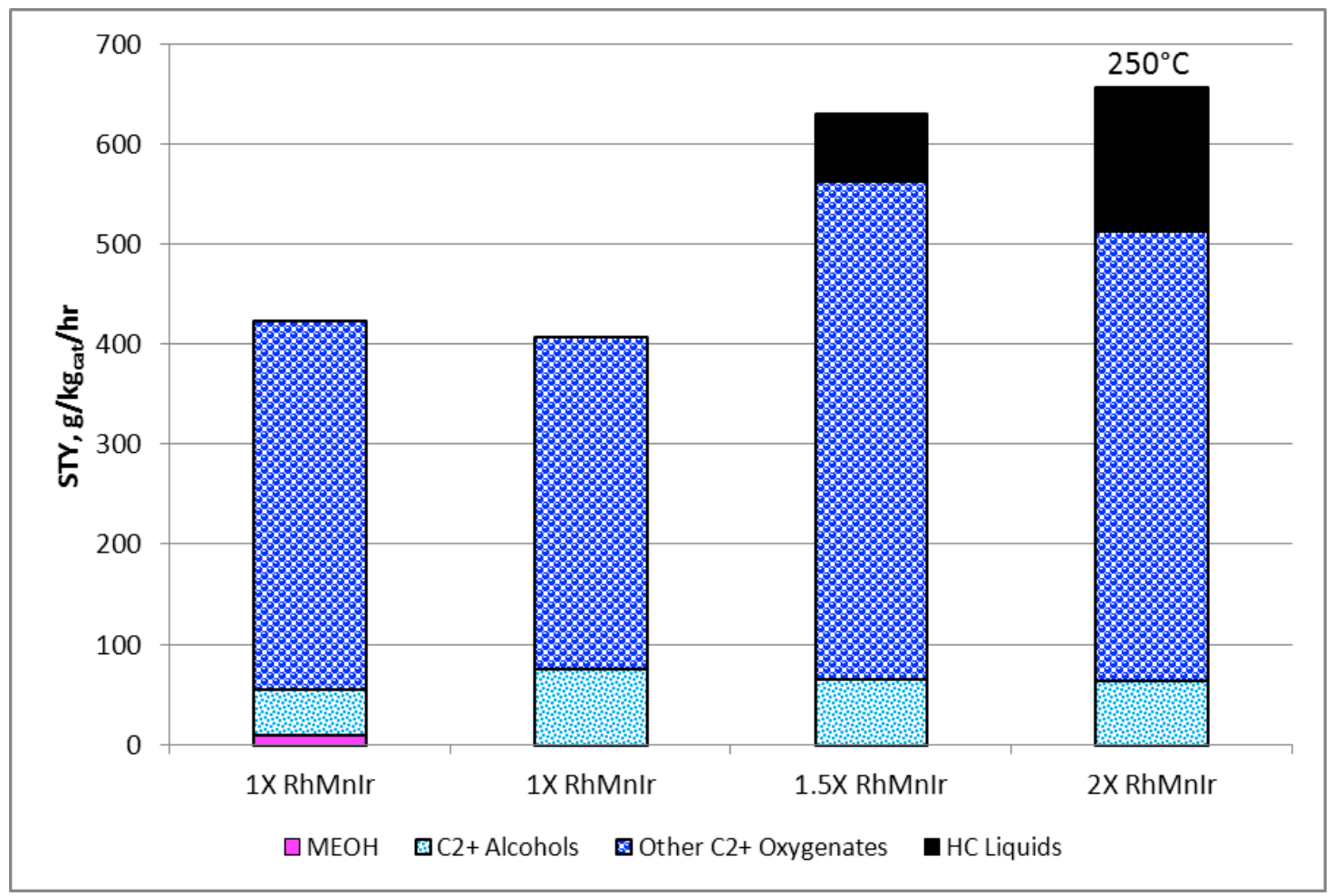

Figure 3.5. Effect of Catalyst Metal Loading on STYs for RhMnIr Catalysts on Davisil 645 Silica Supports at $256^{\circ} \mathrm{C}$

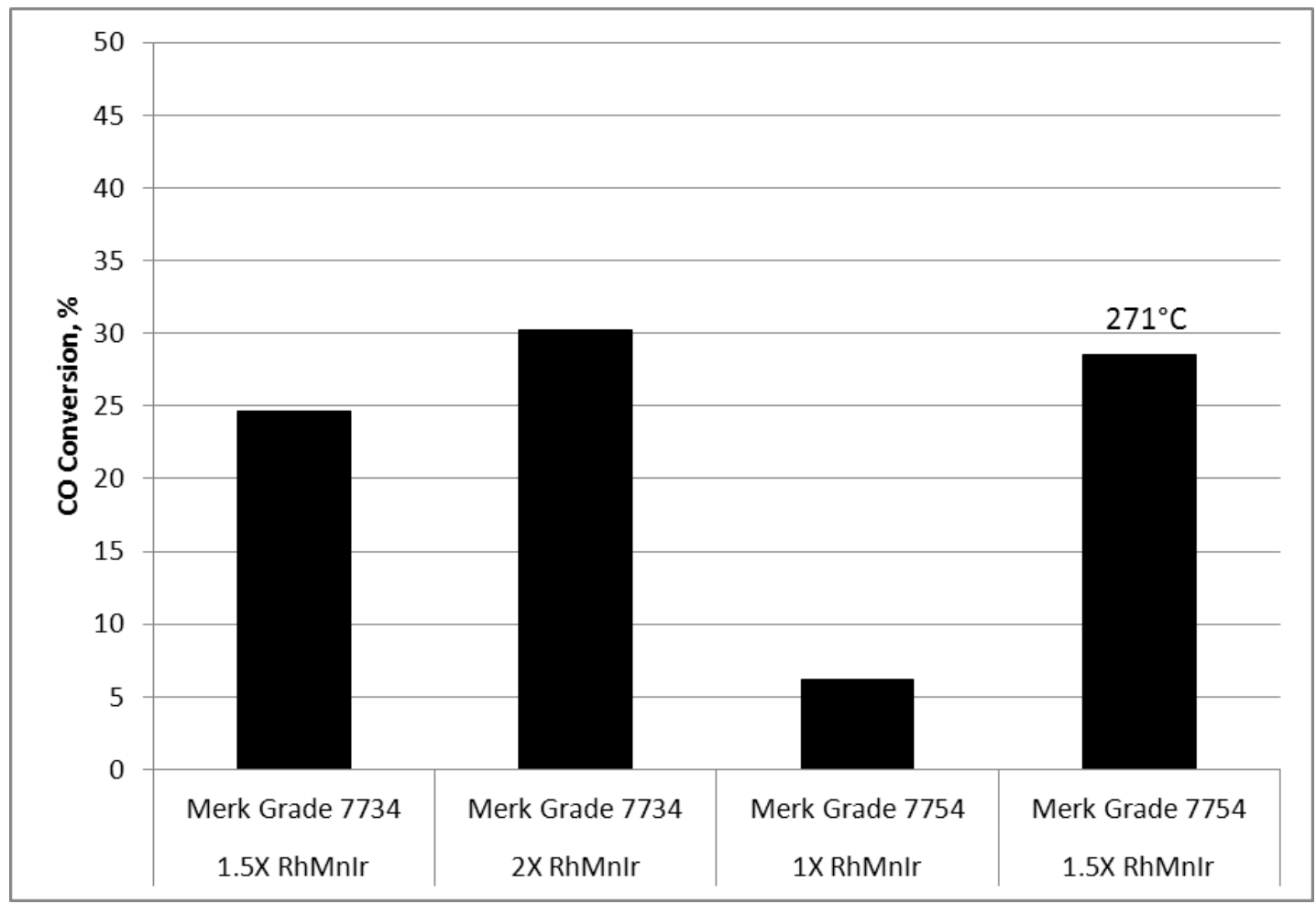

Figure 3.6. Effect of Catalyst Metal Loading on CO Conversion for RhMnIr Catalysts on Merck Grade Silica Supports at $275^{\circ} \mathrm{C}$ 


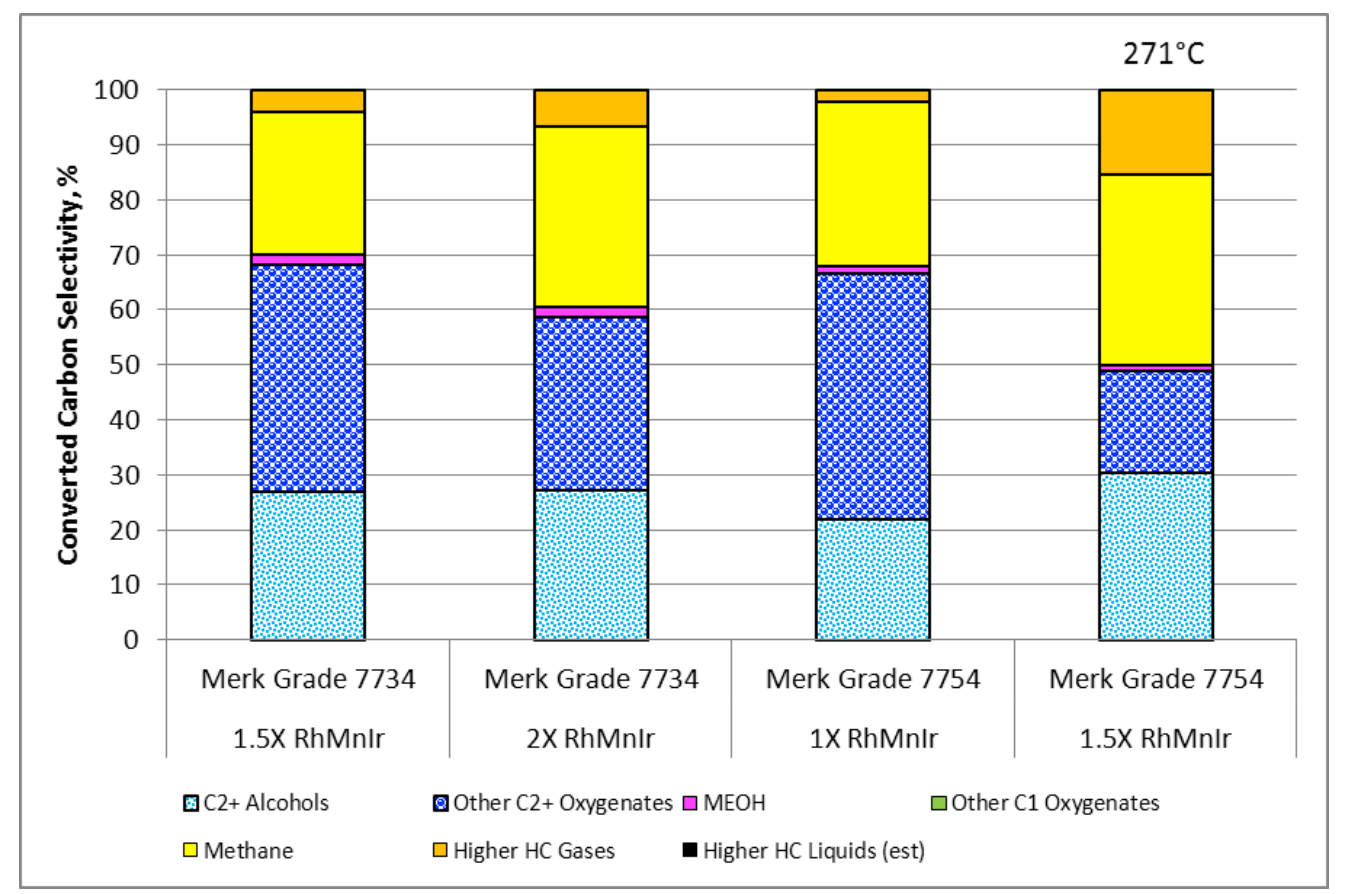

Figure 3.7. Effect of Catalyst Metal Loading on Converted Carbon Selectivity to Various Products for RhMnIr Catalysts on Merck Grade Silica Supports at $275^{\circ} \mathrm{C}$

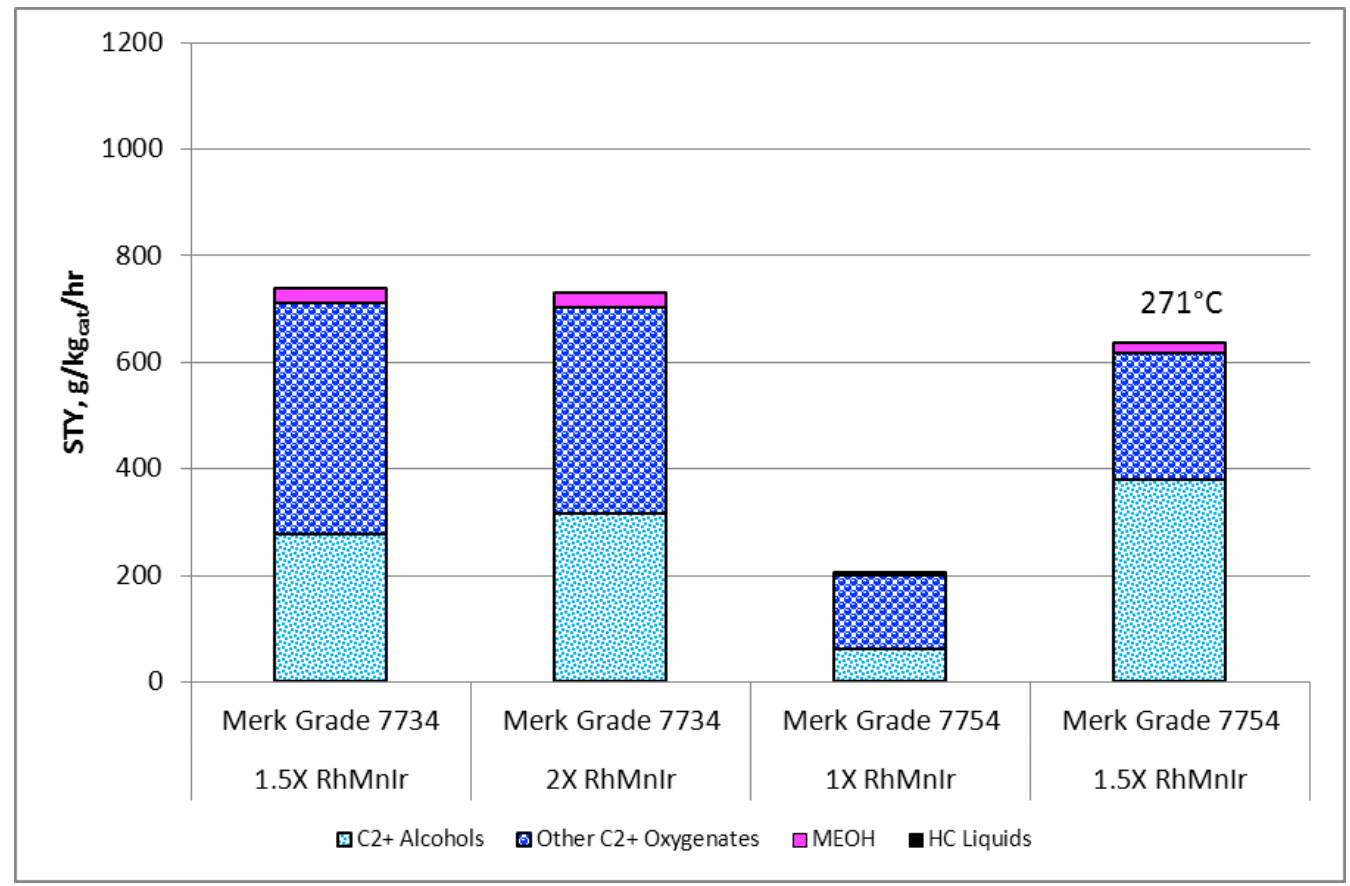

Figure 3.8. Effect of Catalyst Metal Loading on STYs for RhMnIr Catalysts on Merck Grade Silica Supports at $275^{\circ} \mathrm{C}$ 


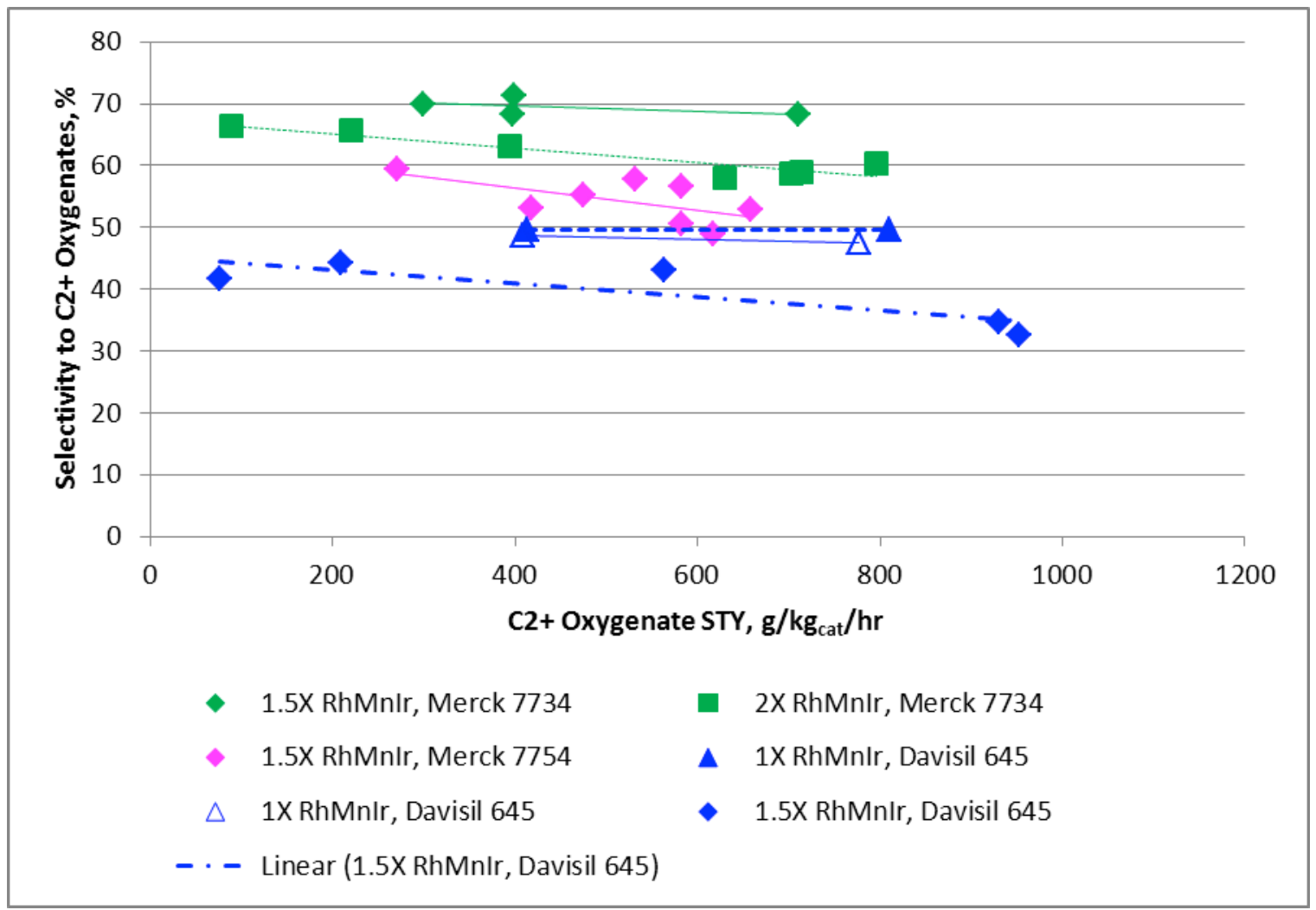

Figure 3.9. Comparison of $\mathrm{C}_{2}+$ Oxygenate Selectivity and STYs for RhMnIr Catalysts on Select Silica Supports

\subsubsection{Additional Promoters}

Several tests series were conducted to further investigate the addition of $\mathrm{Mg}$ promoter to the silicasupported RhMnIr catalysts. An earlier set of tests suggested that the individual addition of $\mathrm{Mg}$ to a $1 \mathrm{X}$ baseline RhMnIr catalyst supported on Davisil silica at a 0.33:1.0 Rh:metal atomic ratio increased both the $\mathrm{C}_{2}+$ oxygenate STY and selectivity over those achieved on the unpromoted catalysts (Gerber et al. 2011). The earlier test series was repeated using the same catalyst preparation and two other test series new-catalyst preparations having the same metals content. In addition, a test series was conducted using a catalyst with the same metal ratios but at $1.5 \mathrm{X}$ total metals content. Two other tests were conducted using the $1 \mathrm{X}$ baseline RhMnIr, promoted with $0.04 \% \mathrm{Mg}$ and also co-impregnated with $0.40 \% \mathrm{La}$ or with $0.05 \% \mathrm{Cu}$ plus $0.05 \% \mathrm{Zn}$ in addition to the $\mathrm{Mg}$.

Figure 3.10, Figure 3.11, and Figure 3.12 summarize the results of tests run at a common set of testing conditions $-275^{\circ} \mathrm{C}, 1200 \mathrm{psig}$, and $7000 \mathrm{~L} / \mathrm{L}_{\text {cat }} / \mathrm{hr} \mathrm{GHSV}$. The third catalyst in the figures is the one reported earlier (Gerber et al. 2011). The fourth catalyst in the figures is a repeat test using the same master batch of catalyst, while the next two catalysts were different catalyst preparations using the same recipe. 


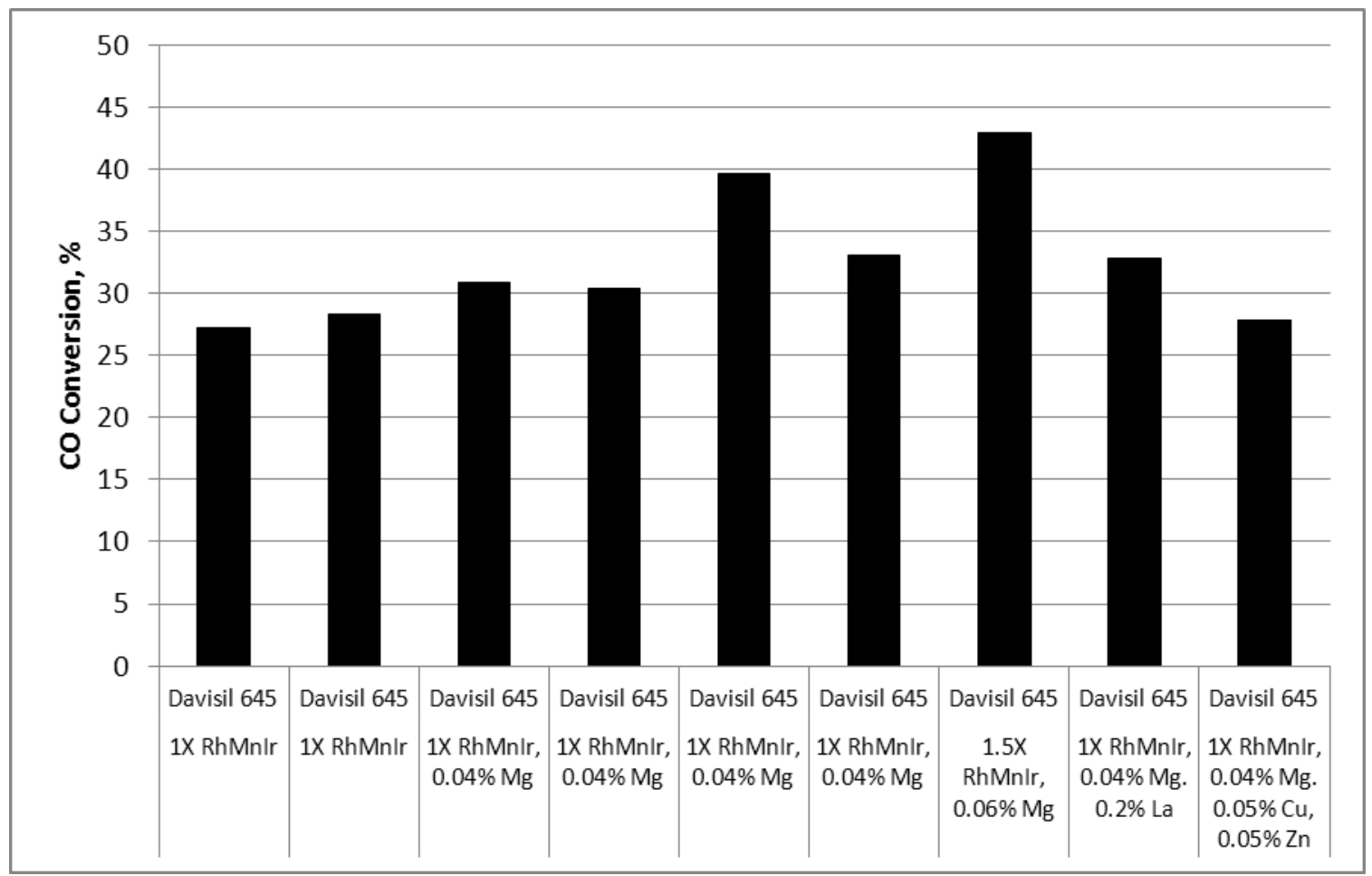

Figure 3.10. Effect of Promoters on CO Conversion for RhMnIr Catalysts on Davisil 645 Silica Supports at $275^{\circ} \mathrm{C}$

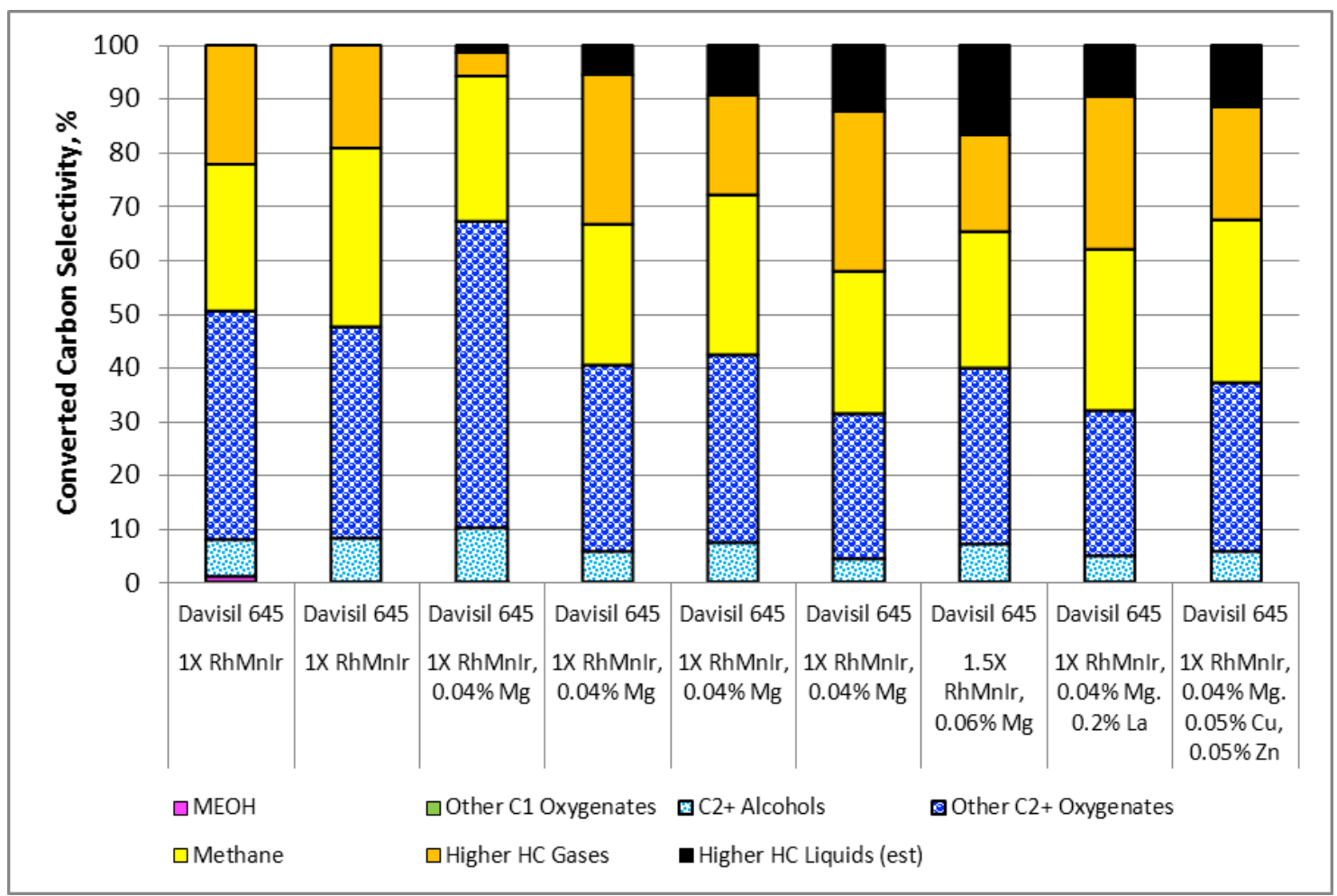

Figure 3.11. Effect of Promoters on Converted Carbon Selectivity to Various Products for RhMnIr Catalysts on Davisil 645 Silica Supports at $275^{\circ} \mathrm{C}$ 


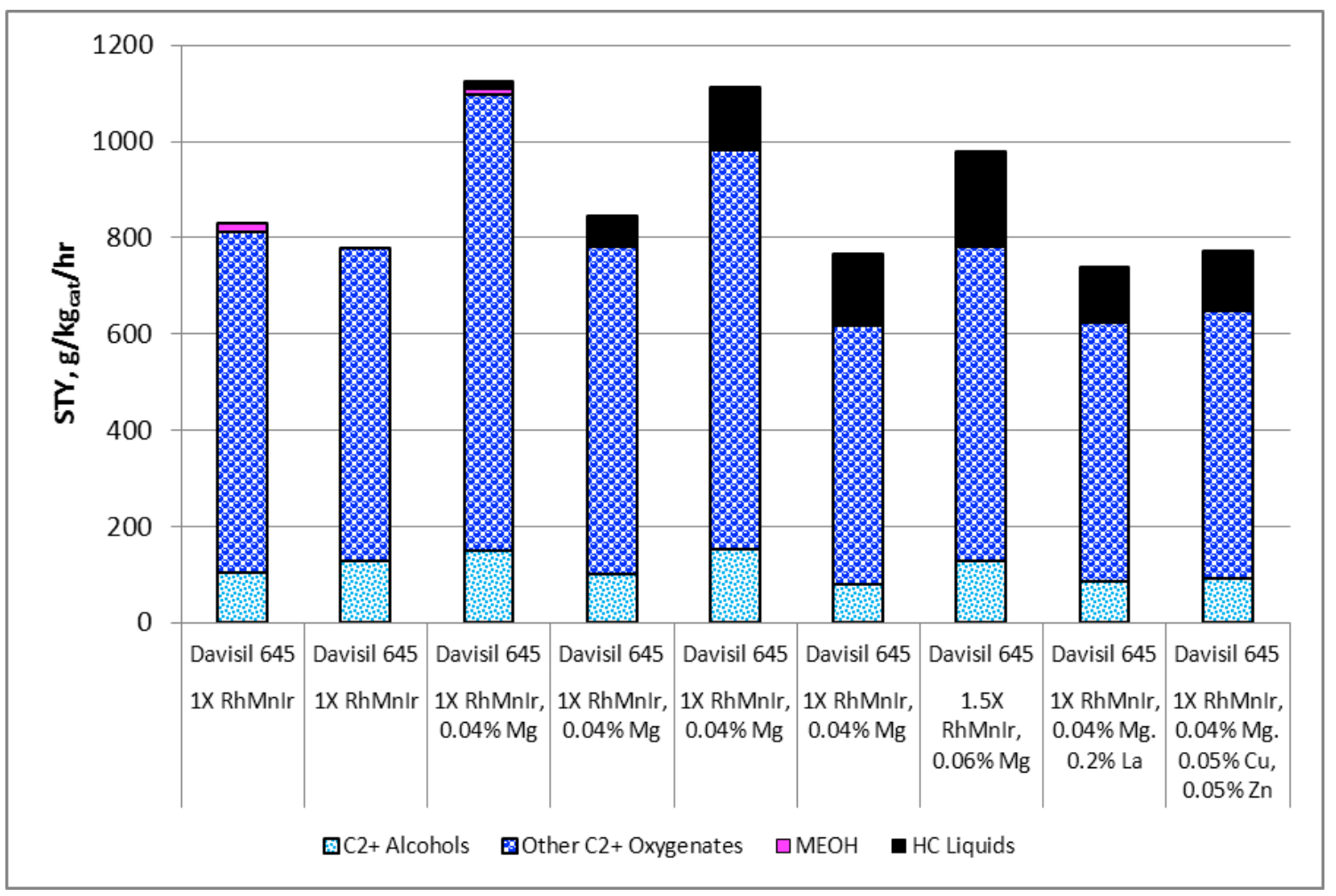

Figure 3.12. Effect of Promoters on STYs for RhMnIr Catalysts on Davisil 645 Silica Supports at $275^{\circ} \mathrm{C}$

Figure 3.10 shows the carbon conversion for the different catalyst compositions. It appears that there is a consistent trend of higher $\mathrm{CO}$ conversion when $\mathrm{Mg}$ is added to the catalyst and when the total metals content of the $\mathrm{Mg}$-promoted catalysts is increased. It also appears that the increased activity resulting from adding $\mathrm{Mg}$ is retained when $\mathrm{La}$ is included in the catalyst composition, but not when $\mathrm{Cu}+\mathrm{Zn}$ promoters are included.

Figure 3.11 shows a significant amount of scatter in the selectivity results for the catalysts containing $0.04 \% \mathrm{Mg}$, with the converted carbon selectivity to $\mathrm{C}_{2}+$ oxygenates ranging from $\sim 32$ to $\sim 68 \%$. This is much greater conversion than typically encountered, particularly for tests using the same master batch of catalyst. A comparable variation in the range of $\mathrm{C}_{2}+$ oxygenate STYs resulting from the different levels of selectivity is shown in Figure 3.12. The differences in $\mathrm{C}_{2}+$ oxygenate levels of selectivity appear to result from much greater selectivity to $\mathrm{C}_{2}+$ hydrocarbon gases and liquids at the expense of nonalcoholic $\mathrm{C}_{2}+$ oxygenates.

Given the variability in the previous test results with respect to selectivity for catalysts only promoted with $\mathrm{Mg}$, duplicate tests are also needed for catalysts involving the further addition of $\mathrm{La}$ or $\mathrm{Cu}+\mathrm{Zn}$ along with the $\mathrm{Mg}$ to better elucidate the effects of these metal additions on catalyst performance. The results of individual tests with these additional promoters are presented here only to document that their presence in catalysts does not provide any obvious benefit over the catalysts containing only $\mathrm{Mg}$.

Figure 3.13, Figure 3.14, and Figure 3.15 show comparable results for Mg-promoted catalysts using a $1.5 \mathrm{X}$ baseline RhMnIr composition (with $0.06 \% \mathrm{Mg}$ ) on Merck Grade 7734 supported silica. The first catalyst is an unpromoted catalyst shown for comparison at a common testing temperature of $250^{\circ} \mathrm{C}$. The 
second and third catalysts in the figures are from two different preparations of the 1.5X baseline RhMnIr catalyst promoted with co-impregnated $\mathrm{Mg}$ evaluated at the same temperature. The fourth, fifth, and six catalysts in the figures are the same as the first three (in order) but with results from testing at a common temperature of $260^{\circ} \mathrm{C}$. The last catalyst in the figures is the same as the sixth catalyst but evaluated at the same temperature with a higher $12000 \mathrm{~L} / \mathrm{L}_{\text {cat }} / \mathrm{hr}$ GHSV.

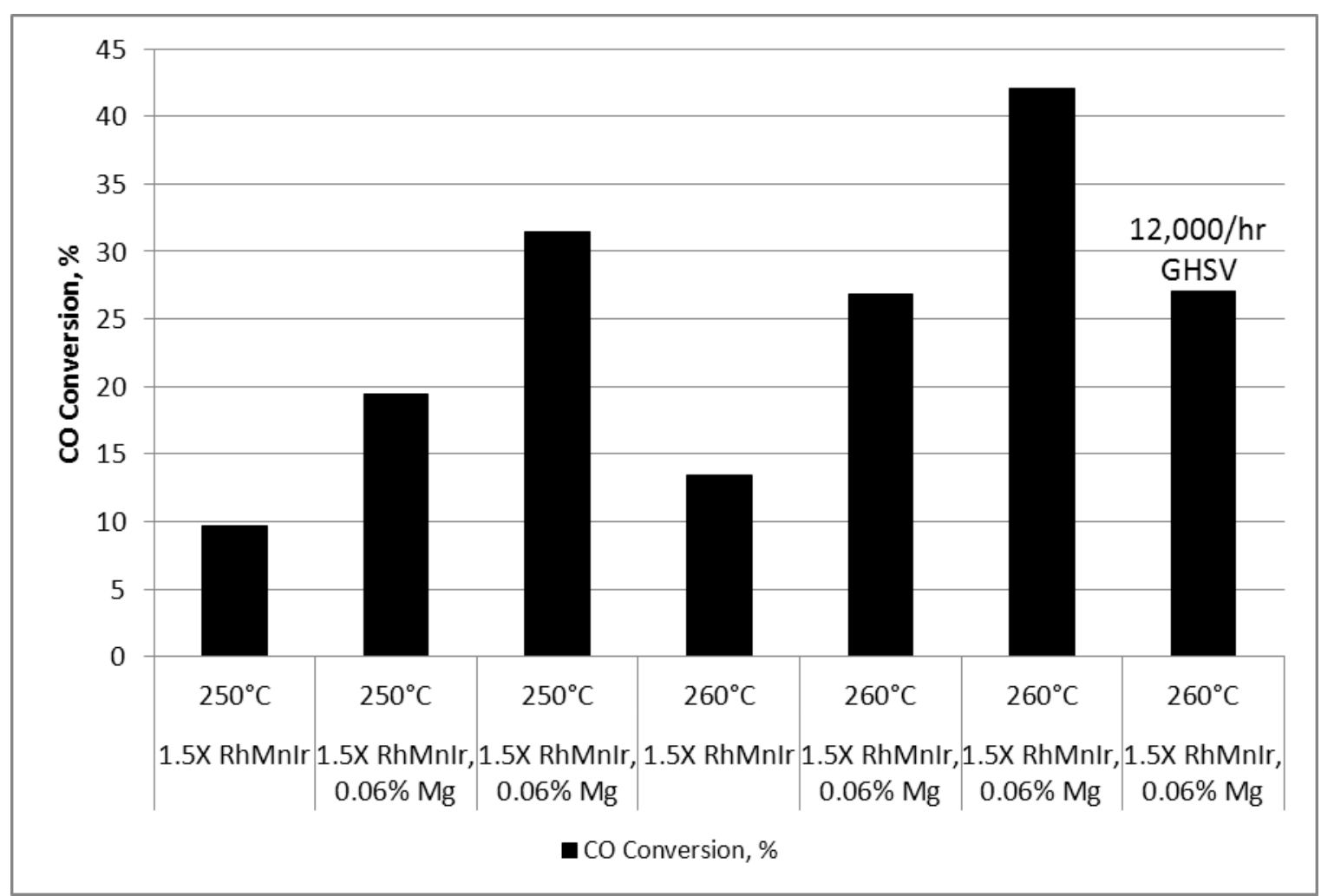

Figure 3.13. Effect of Promoters on CO Conversion for RhMnIr Catalysts on Merck Grade 7734 Silica Supports at $250^{\circ} \mathrm{C}$ and $260^{\circ} \mathrm{C}$ 


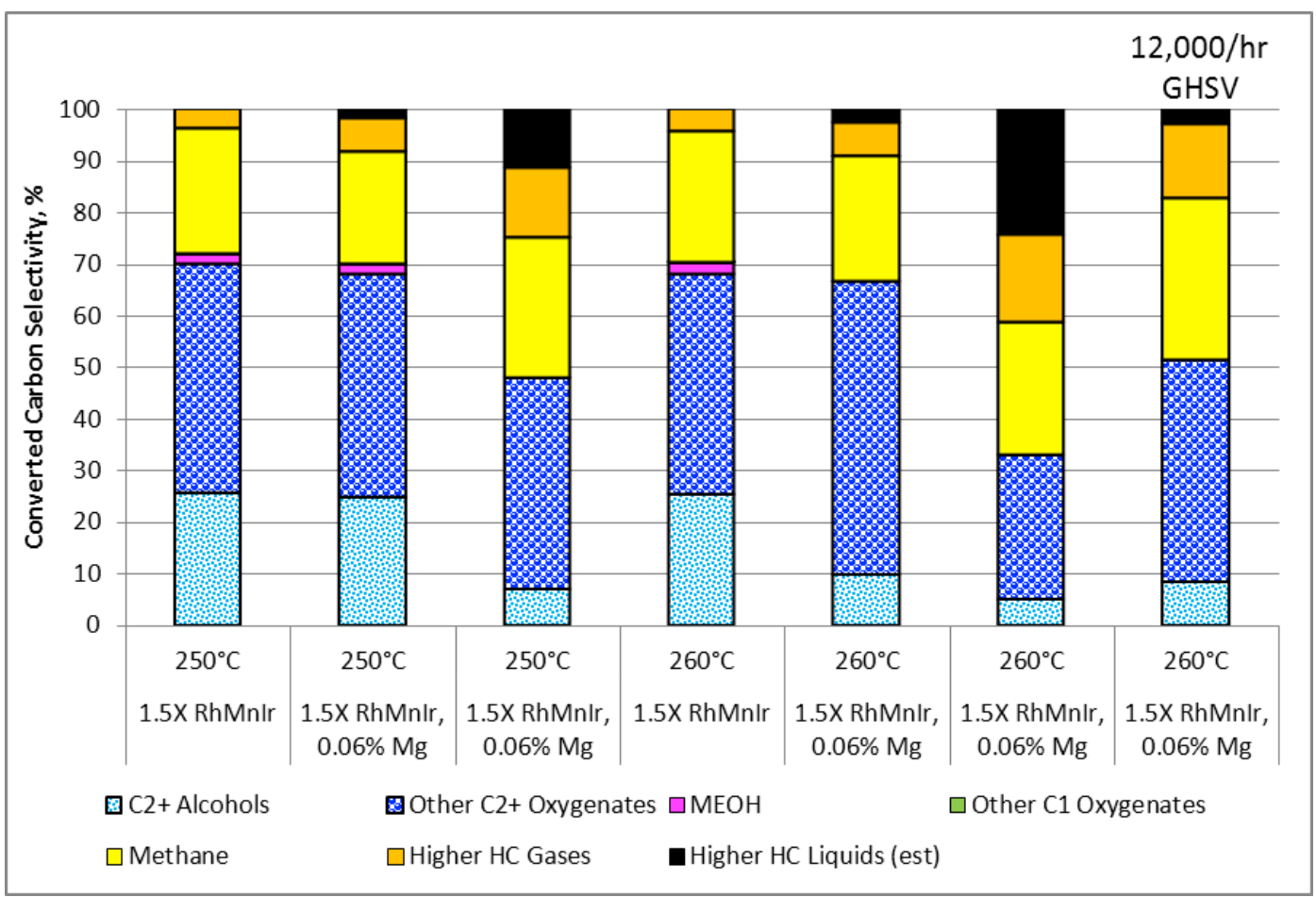

Figure 3.14. Effect of Promoters on Converted Carbon Selectivity to Various Products for RhMnIr Catalysts on Merck Grade 7734 Silica Supports at $250^{\circ} \mathrm{C}$ and $260^{\circ} \mathrm{C}$

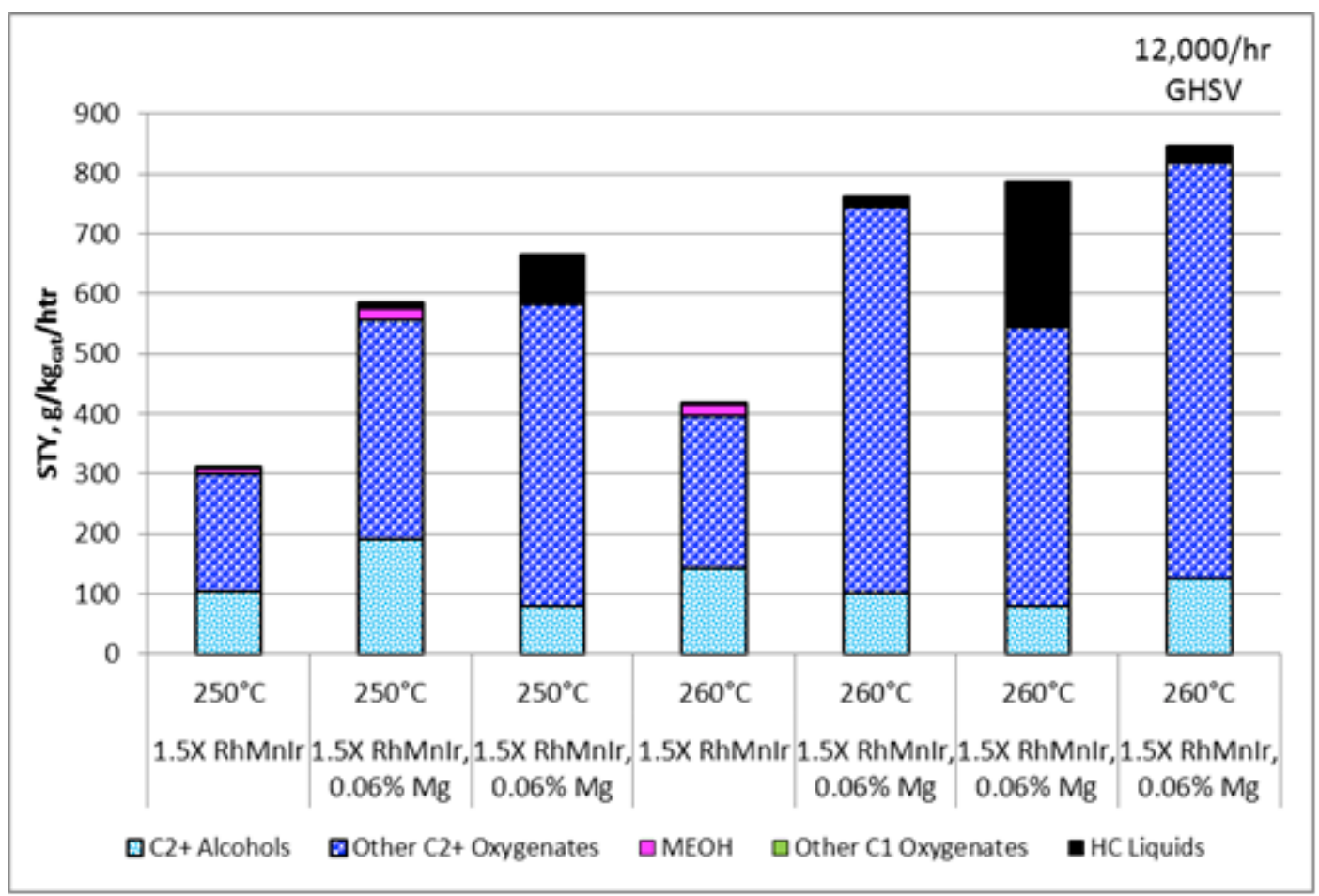

Figure 3.15. Effect of Promoters on STYs for RhMnIr Catalysts on Merck Grade 7734 Silica Supports at $250^{\circ} \mathrm{C}$ and $260^{\circ} \mathrm{C}$ 
As was the case for similarly made Davisil 645 silica-supported catalysts, there is considerable scatter in the data for the two Mg-promoted catalysts, with the second of the two catalysts (third in the figure) being $\sim 60 \%$ more active. Even so, it appears that adding the $\mathrm{Mg}$ significantly increased the $\mathrm{CO}$ conversion over that achieved on the unpromoted catalyst. The selectivity to $\mathrm{C}_{2}+$ oxygenates decreased with the addition of $\mathrm{Mg}$ and was accompanied by an increasing selectivity to $\mathrm{C}_{2}+$ hydrocarbon gases and hydrocarbon liquids, which is similar to the behavior of the Davisil-supported Mg-promoted catalysts, with the more active $\mathrm{Mg}$-promoted catalyst less selective the $\mathrm{C}_{2}+$ oxygenates than the other. A significant selectivity to the hydrocarbon liquid fraction also is noteworthy. When evaluated at $260^{\circ} \mathrm{C}, \mathrm{CO}$ conversion of the second catalyst was $42 \%$, while the selectivity to the $\mathrm{C}_{2}+$ hydrocarbon gases and liquid hydrocarbons increased significantly at the expense of the $\mathrm{C}_{2}+$ oxygenates. Retesting that catalyst at the same temperature but at a higher GHSV reduced the CO conversion to a more reasonable $27 \%$, accompanied by an almost complete elimination of the hydrocarbon liquid fraction. A liquid hydrocarbon sample from the test was analyzed using gas chromatography-mass spectrometry (GC-MS) to better understand what organic liquid species the catalyst produced. Using the peak area as the basis, $\sim 70 \%$ of the organic compounds in the liquid were oxygenate species, mainly consisting of $\mathrm{C}_{2}$ to $\mathrm{C}_{10}$ aldehydes and $\mathrm{C}_{4}$ to $\mathrm{C}_{20}$ esters. The $\mathrm{C}_{4}$ to $\mathrm{C}_{20}$ esters consisted almost entirely of acetates, and the majority of the acetates were derived mostly from $\mathrm{C}_{2}$ to $\mathrm{C}_{10}$ alcohols. Lesser quantities of $\mathrm{C}_{2}$ to $\mathrm{C}_{6}$ alcohols and $\mathrm{C}_{6}$ to $\mathrm{C}_{8}$ acetals, mainly consisting of combinations of $\mathrm{C}_{2}$ to $\mathrm{C}_{4}$ aldehydes and alcohols, also were found in the organic liquid sample. An aggregate breakdown in the liquid hydrocarbons and oxygenates in the organic liquid fraction by carbon number is shown in Figure 3.16. These results may at least partially explain the increased production of oxygenates (mainly acetic acid, acetaldehyde, ethanol, and ethyl acetate) found in the aqueous phase, when a higher GHSV reduced the amount of what were presumed to be hydrocarbon liquids. This also suggests that the term "hydrocarbon liquid" is a misnomer. A similar analysis of the organic liquid fraction resulting from the same catalyst composition, but supported on Davisil silica (1.5X RhMnIr, $0.06 \% \mathrm{Mg} /$ Davisil 645 silica), revealed a similar breakdown in the oxygen content (not shown), suggesting a common characteristic shared by Mg-promoted catalysts on both silica supports. 


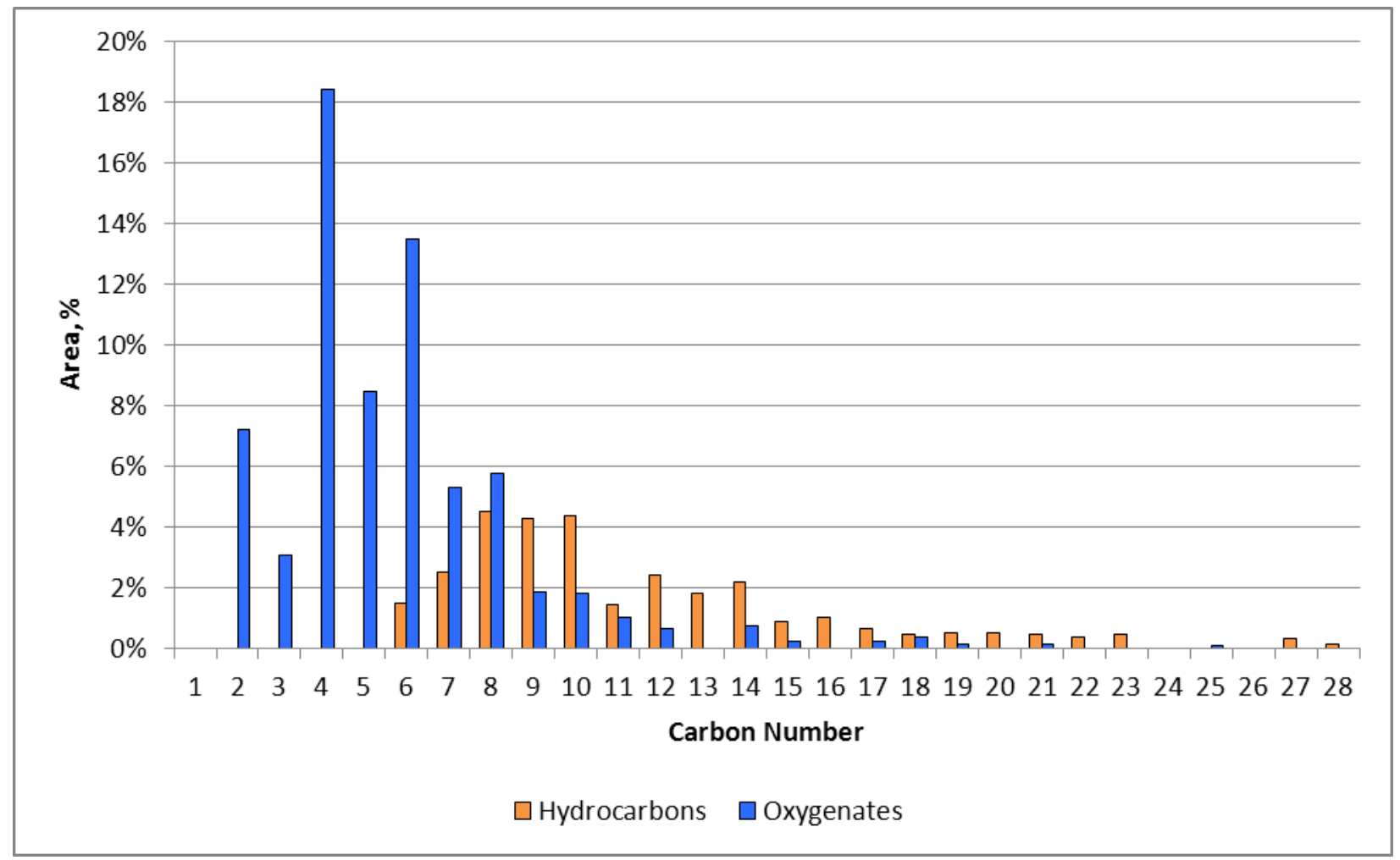

Figure 3.16. Distribution of Organic Liquid Product Hydrocarbons and Oxygenates 1.5X Baseline RhMnIr Catalyst Containing 6\% Mg on a Merck Grade 7734 Silica Support

\subsubsection{Syngas Pressure}

A series of test conditions were conducted to examine the effect of the syngas pressure on the performance of a $1 \mathrm{X} \mathrm{RhMnIr}, 0.04 \% \mathrm{Mg} /$ Davisil 645 catalyst. The test conditions were $265^{\circ} \mathrm{C}$, $7500 \mathrm{~L} / \mathrm{Lcat} / \mathrm{hr}$ GHSV, and syngas containing $4 \% \mathrm{CO}_{2}, 4 \% \mathrm{~N}_{2}$, and the balance a $\mathrm{H}_{2}$ and $\mathrm{CO}$ with a 2:1 $\mathrm{H}_{2}: \mathrm{CO}$ ratio. The pressures examined were 400,700 , and $1200 \mathrm{psig}$.

Figure 3.17 shows the effect of pressure on $\mathrm{CO}$ conversion. A power-law trend line fitted to the data using Microsoft Excel showed that the CO conversion was approximately first-order with respect to pressure. Figure 3.18 shows the effect of pressure on the converted carbon selectivity. Between 700 and $1200 \mathrm{psig}$, there was very little, if any, change in the selectivity to total hydrocarbons and total oxygenates, although there were more pronounced changes within the different hydrocarbon fractions with selectivity to methane coming at the expense of the selectivity to the higher hydrocarbon gases and liquids. Changes in the levels of selectivity to the $\mathrm{C}_{2}+$ alcohols and the other $\mathrm{C}_{2}+$ oxygenates were relatively minor over this range. Between 700 and 400 psig, the effects between the total hydrocarbons and total oxygenates were more significant, with greater selectivity to methane at the expense of the nonalcoholic $\mathrm{C}_{2}+$ oxygenates occurring as the pressure decreased. The total $\mathrm{C}_{2}+$ oxygenate $\mathrm{STY}$ increases in a manner very similar to the CO conversion as shown in Figure 3.19, because of the relatively modest effects of pressure on selectivity to the $\mathrm{C}_{2}+$ oxygenates over the pressure range considered. A power-law trend line fitted to the data showed that the STY was slightly greater than first-order with 
respect to pressure. The $\mathrm{C}_{2}+$ alcohols make up a relatively modest fraction of the total oxygenates, increasing from $\sim 14 \%$ at 1200 psig to $\sim 20 \%$ as the pressure is reduced to $400 \mathrm{psig}$, as shown in Figure 3.20 .

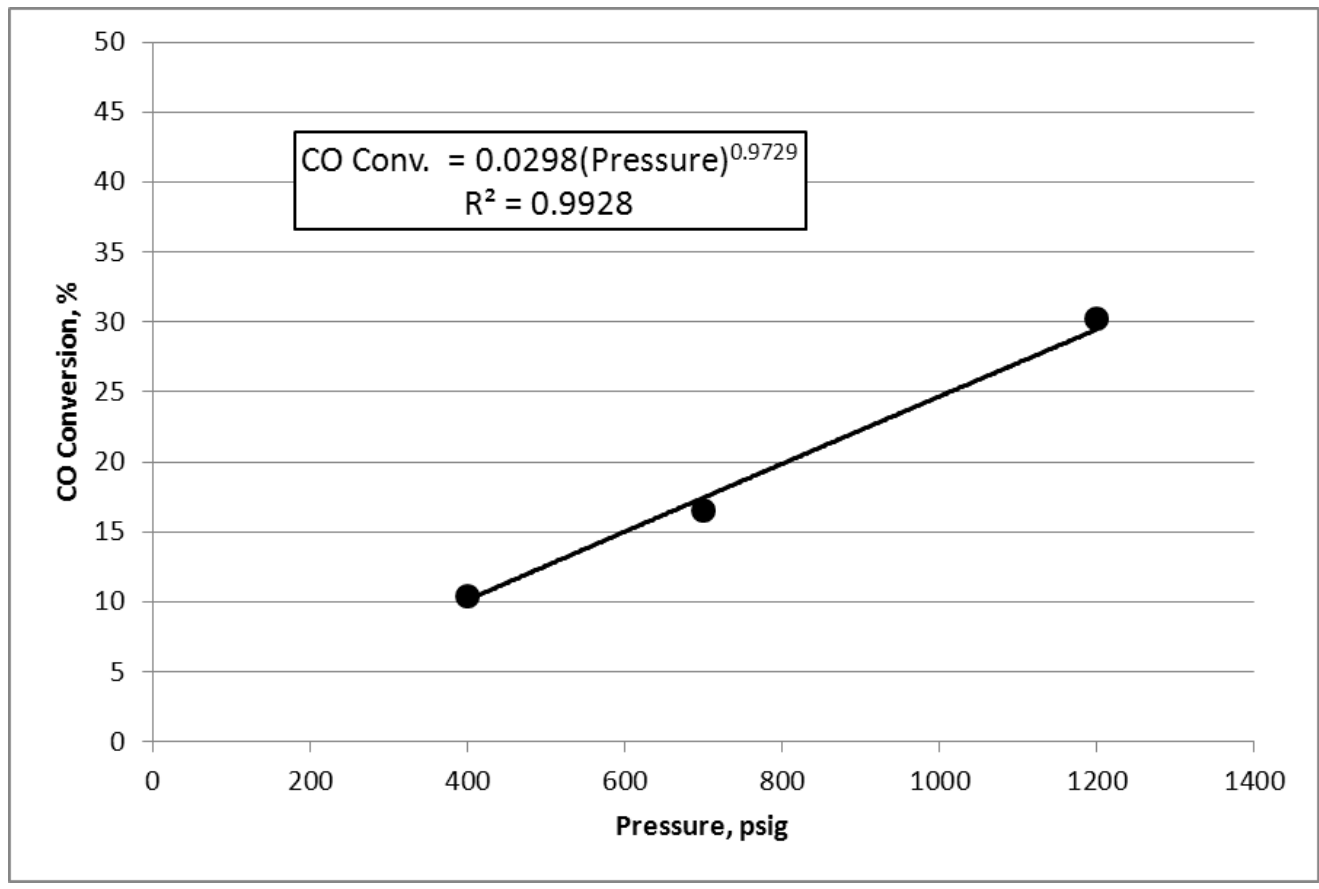

Figure 3.17. Effect of Syngas Pressure on CO Conversion for a $1 \mathrm{X}$ RhMnIr, 0.04\% Mg/Davisil Silica-Supported Catalyst at $265^{\circ} \mathrm{C}$ 


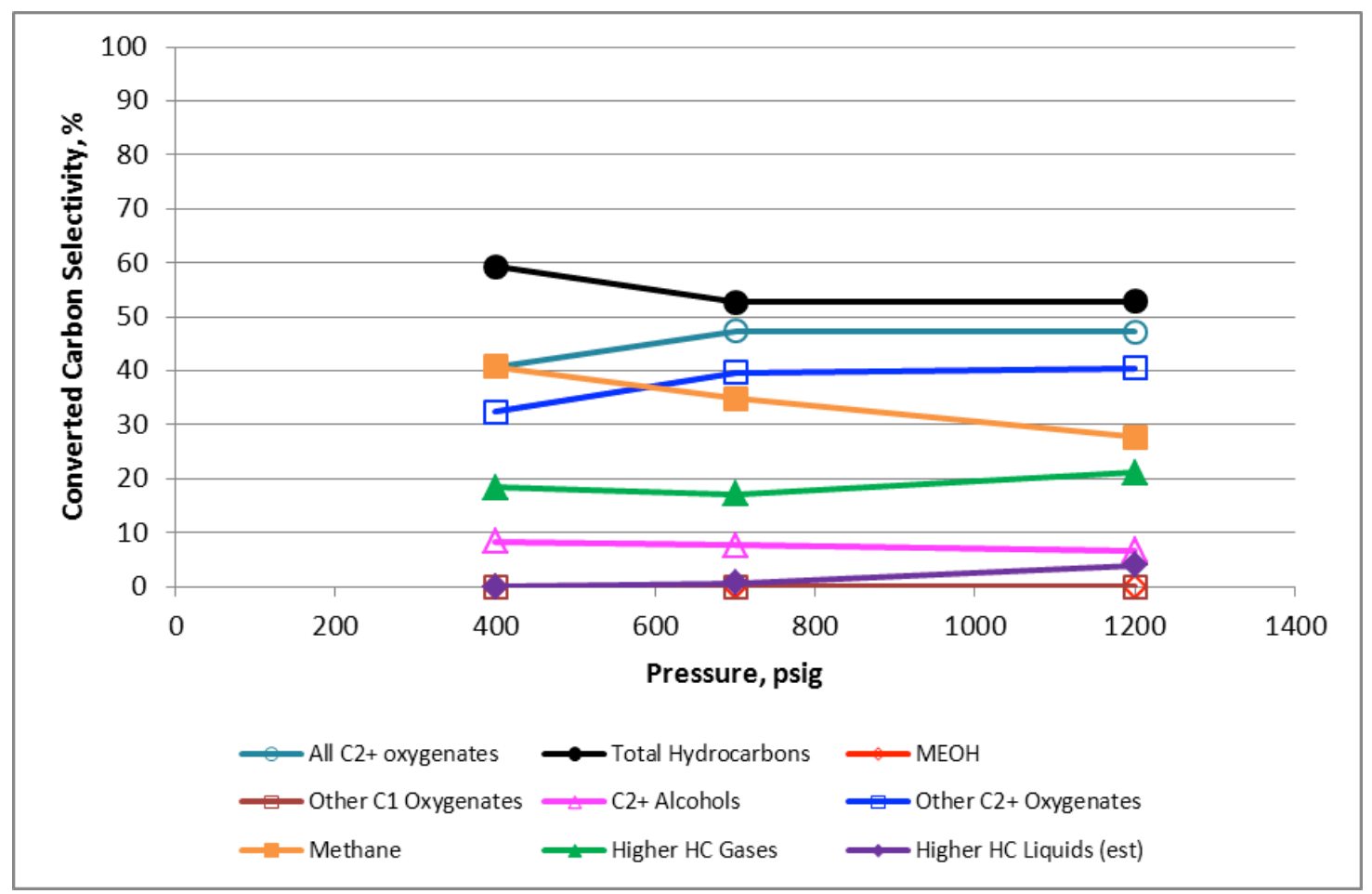

Figure 3.18. Effect of Syngas Pressure on Converted Carbon Selectivity for a $1 \mathrm{X}$ RhMnIr, $0.04 \% \mathrm{Mg} /$ Davisil Silica-Supported Catalyst at $265^{\circ} \mathrm{C}$

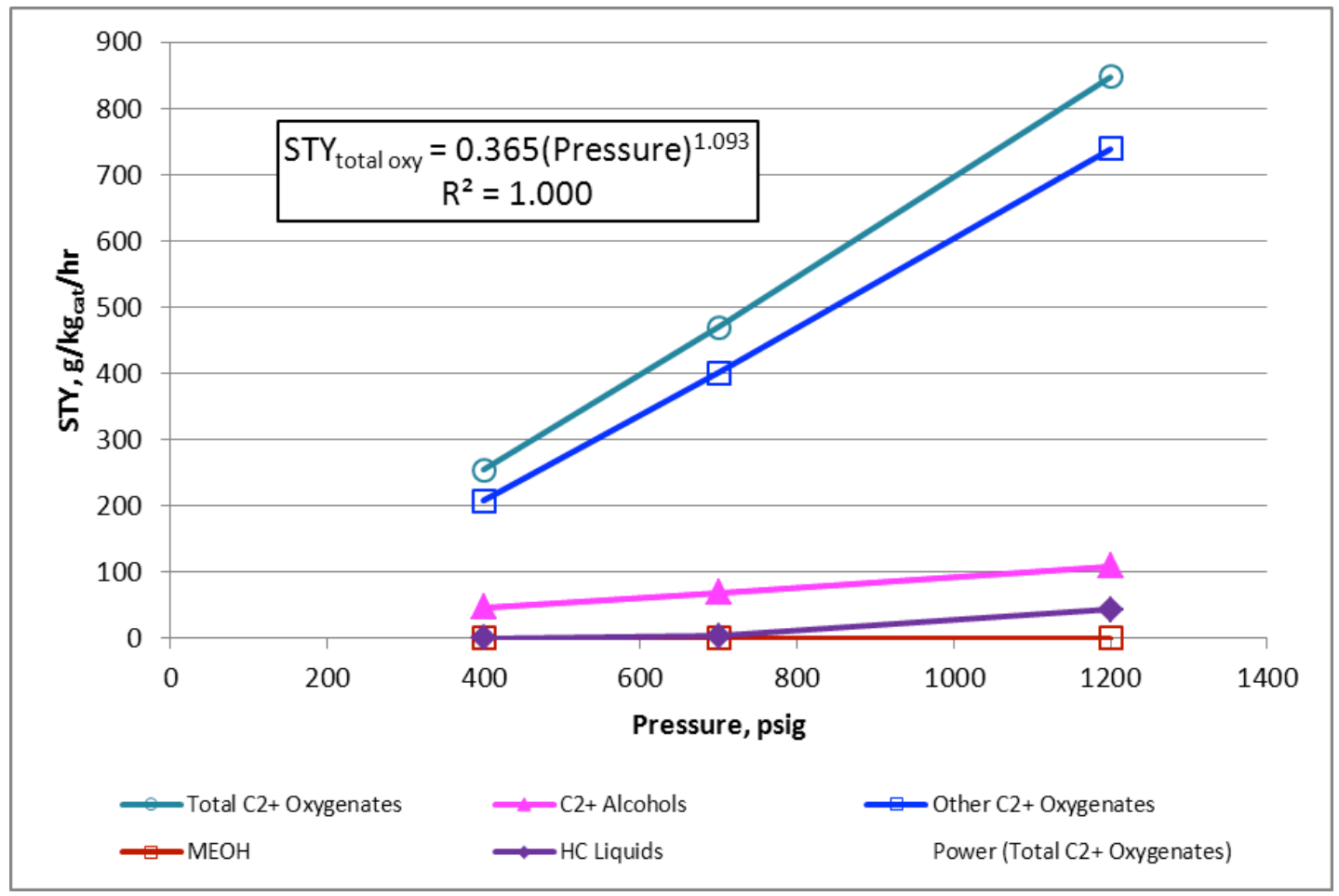

Figure 3.19. Effect of Syngas Pressure on STYs for a $1 \mathrm{X}$ RhMnIr, 0.04\% Mg/Davisil Silica-Supported Catalyst at $265^{\circ} \mathrm{C}$ 


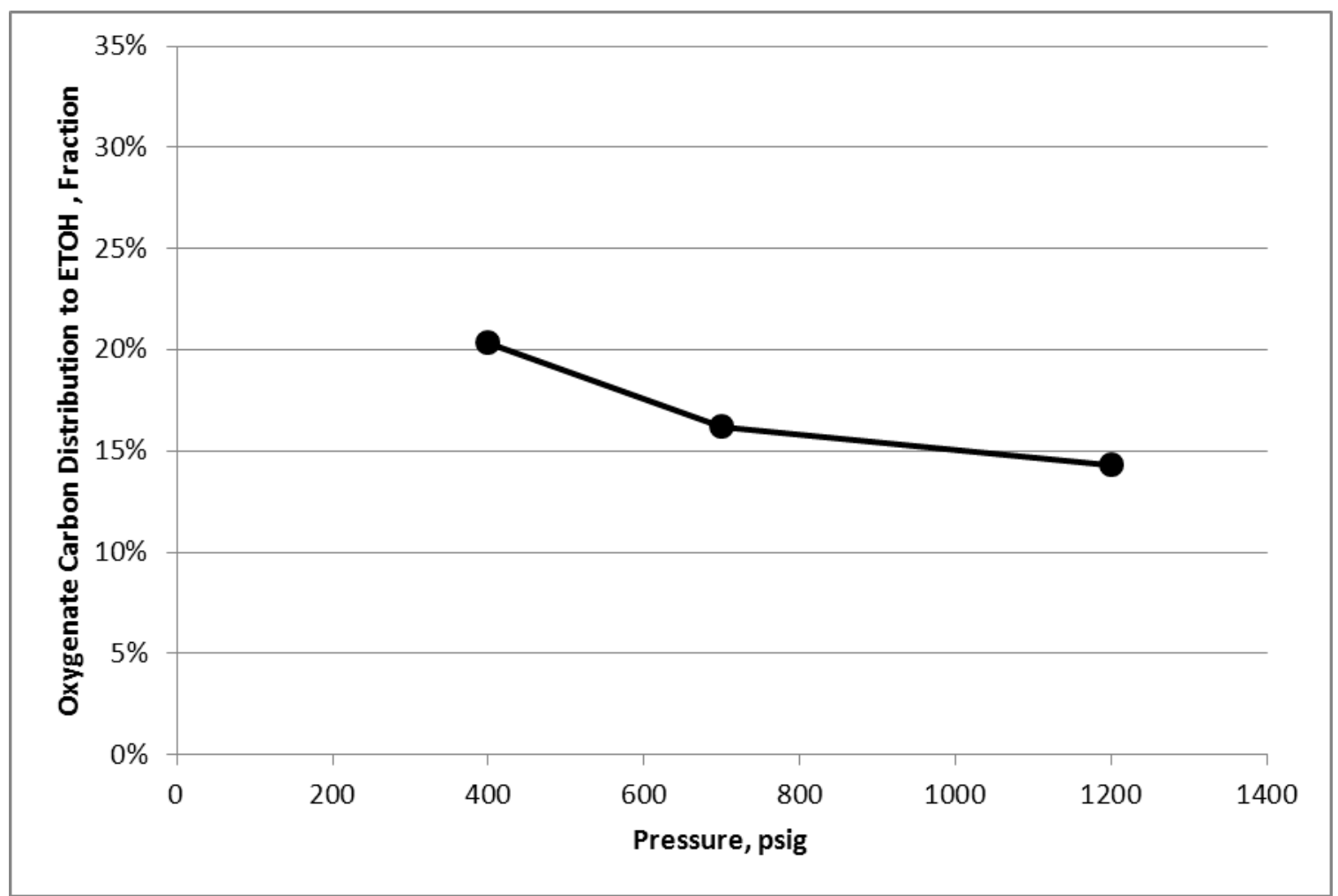

Figure 3.20. Effect of Syngas Pressure on Carbon Distribution of the Oxygenates to $\mathrm{C}_{2}+$ Alcohols for a 1X RhMnIr, $0.04 \% \mathrm{Mg} /$ Davisil Silica-Supported Catalyst at $265^{\circ} \mathrm{C}$

\subsubsection{Effect of $\mathrm{CO}_{2}$ in Syngas}

A series of tests under differing conditions were conducted to examine the effect of $4 \% \mathrm{CO}_{2}$ in the syngas on the performance of a $1 \mathrm{X}$ RhMnIr, $0.04 \% \mathrm{Mg} / \mathrm{Davisil} 645$ catalyst. The test conditions were $265^{\circ} \mathrm{C}, 7500 \mathrm{~L} / \mathrm{Lcat} / \mathrm{hr} \mathrm{GHSV}$, and syngas containing either $4 \% \mathrm{CO}_{2}$ and $4 \% \mathrm{~N}_{2}$ or $0 \% \mathrm{CO}_{2}$ and $8 \% \mathrm{~N}_{2}$, with the balance being $\mathrm{H}_{2}$ and $\mathrm{CO}$ in a 2:1 $\mathrm{H}_{2}: \mathrm{CO}$ ratio. The total syngas pressure was $1200 \mathrm{psig}$. Five sets of samples were collected to compare catalyst performance. The first set of samples using feed gas that contained $\mathrm{CO}_{2}$ was obtained after 4 days of testing at temperatures of $240^{\circ} \mathrm{C}$ and $256^{\circ} \mathrm{C}$. The second set of samples, using this same feed gas, was obtained after examining five more test conditions over a 6-day period at the same temperature $\left(265^{\circ} \mathrm{C}\right)$ but evaluating different GHSVs and pressures. The second set of samples was immediately followed by a third set of three consecutive samples obtained over a 4-day period using the syngas mixture that replaced the $\mathrm{CO}_{2}$ with additional $\mathrm{N}_{2}$.

Figure 3.21 shows the $\mathrm{CO}$ conversion for the two test conditions obtained with the syngas containing $\mathrm{CO}_{2}$ and the three tests using syngas not containing $\mathrm{CO}_{2}$. There appears to be a slight decrease of $1.4 \%$ in the $\mathrm{CO}$ conversion during the 6 days in which the other parameters were examined. There was a more pronounced decrease in the CO conversion of $\sim 18 \%$ from $\sim 28 \%$ CO conversion to $23 \%$ CO conversion when the $\mathrm{CO}_{2}$ was eliminated from the syngas. There also was a slight increase in the selectivity to $\mathrm{C}_{2}+$ oxygenates of about $1 \%$ between the two data sets collected using the syngas containing $\mathrm{CO}_{2}$, followed by an average increase of about $6 \%$ from about $47.8 \%$ to an average $50.7 \%$ for the next three data sets when $\mathrm{CO}_{2}$ was eliminated from the syngas as shown in Figure 3.22. Interestingly, the latter three data sets showed a significant increase in selectivity to methane that is mainly at the expense of 
lower selectivity to the hydrocarbon gases. The $\mathrm{C}_{2}+$ oxygenate STY generally followed the same trend as the $\mathrm{CO}$ conversion with an average decrease of about $14 \%$ in the $\mathrm{STY}$ when $\mathrm{CO}_{2}$ was eliminated from the syngas as shown in Figure 3.23.

A second test run was conducted using the $1.5 \mathrm{X}$ baseline RhMnIr, $0.06 \% \mathrm{Mg}$ on the Merck Grade 7734 silica support. This test was similar except that the testing temperature was $260^{\circ} \mathrm{C}$ and the order of obtaining samples with each syngas was different from that used with the previous catalyst. The first and last sample sets were obtained while testing with the syngas containing $\mathrm{CO}_{2}$. Samples for the in-between tests were taken when the syngas did not contain $\mathrm{CO}_{2}$. The first two of the in-between sets of samples were taken immediately following the test with syngas that contained $\mathrm{CO}_{2}$. Samples from two more test conditions (at $275^{\circ} \mathrm{C}$ and $280^{\circ} \mathrm{C}$ ) were next obtained, followed by the third set of samples obtained at $265^{\circ} \mathrm{C}$, still using the syngas without $\mathrm{CO}_{2}$. This was immediately followed by the second set of samples using the syngas containing $\mathrm{CO}_{2}$. Similar trends (not shown) were observed in terms of $\mathrm{CO}$ conversion selectivity and STYs as were seen in the previous test series with the Davisil 645 silica-supported catalyst, except the effects were more modest $(\sim 0.2 \%$ decrease in CO conversion, $\sim 3 \%$ increase in the selectivity to $\mathrm{C}_{2}+$ oxygenates, and $\sim 10 \%$ increase in the $\mathrm{C}_{2}+$ Oxygenate $\mathrm{STY}$ ) when $\mathrm{CO}_{2}$ was eliminated from the syngas.

These results suggest that overall there appears to be an increase in the selectivity to $\mathrm{C}_{2}+$ oxygenates accompanied by an offsetting decrease in the $\mathrm{STY}$ when $\mathrm{CO}_{2}$ is reduced from $4 \%$ to $0 \%$ in the syngas.

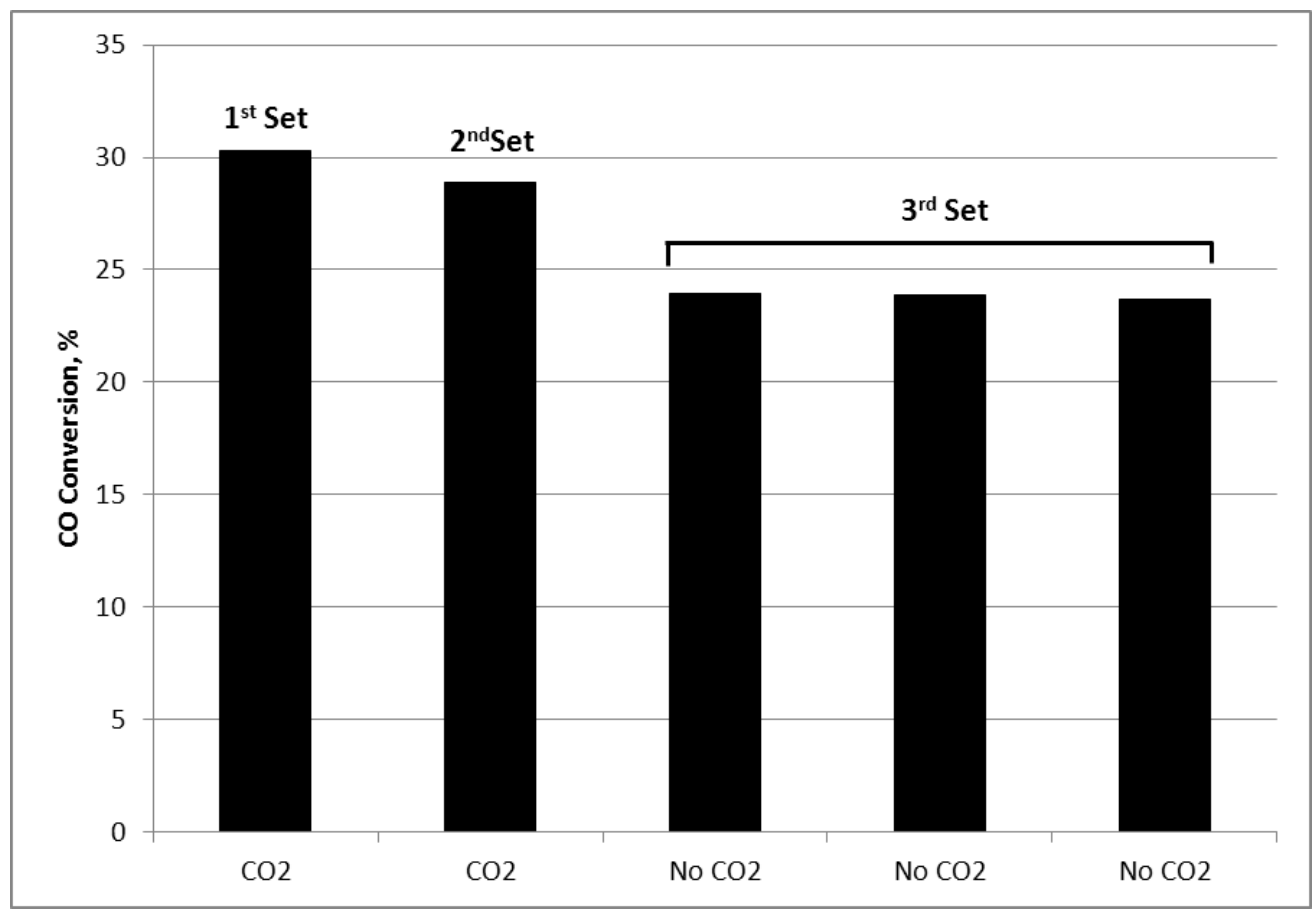

Figure 3.21. Effect of $\mathrm{CO}_{2}$ in Syngas on $\mathrm{CO}$ Conversion for a $1 \mathrm{X} \mathrm{RhMnIr}, 0.04 \% \mathrm{Mg} /$ Davisil Silica-Supported Catalyst at $265^{\circ} \mathrm{C}$ 


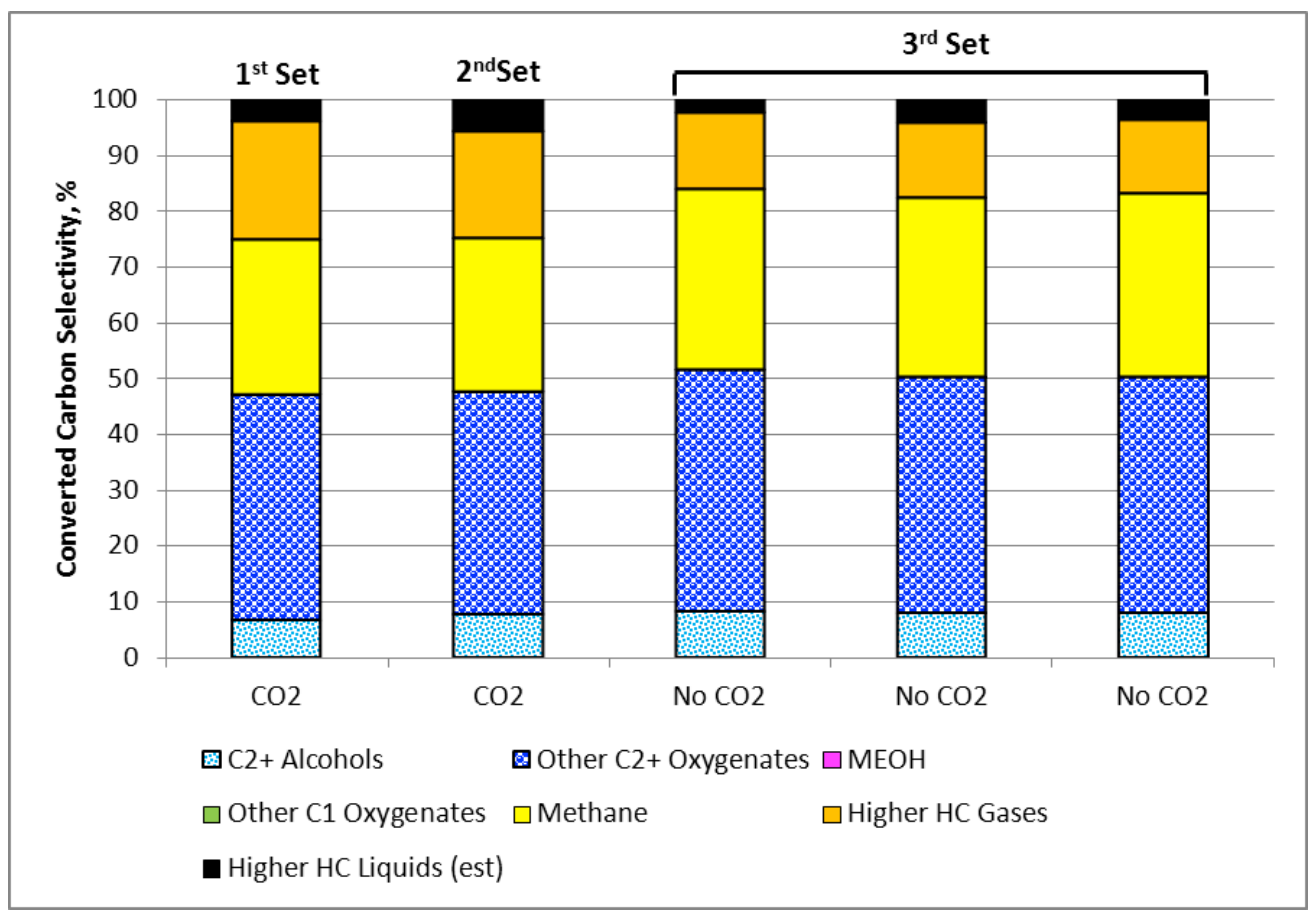

Figure 3.22. Effect of $\mathrm{CO}_{2}$ in Syngas on Selectivity of the Oxygenates to $\mathrm{C}_{2}+$ Alcohols for a $1 \mathrm{X} \mathrm{RhMnIr,} 0.04 \% \mathrm{Mg} /$ Davisil Silica-Supported Catalyst at $265^{\circ} \mathrm{C}$

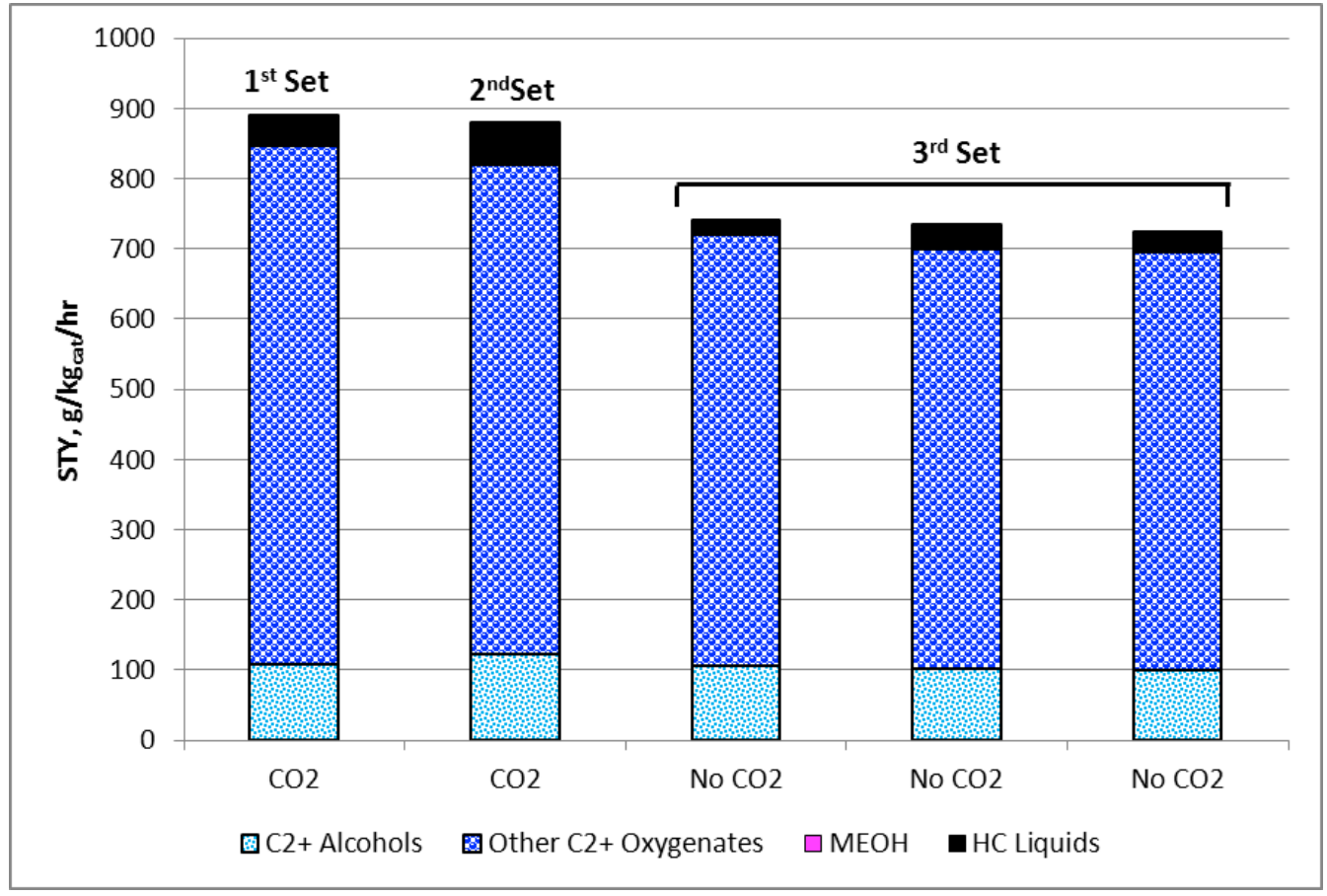

Figure 3.23. Effect of $\mathrm{CO}_{2}$ in Syngas on STYs for a $1 \mathrm{X}$ RhMnIr, $0.04 \% \mathrm{Mg} /$ Davisil Silica-Supported Catalyst at $265^{\circ} \mathrm{C}$ 


\subsection{Carbon-Supported Catalysts}

Tests performed during FY 2012 using carbon-supported RhMnIr catalysts fell into five general areas: re-examination of the performance of select carbon supports using alternative impregnation solutions, further examination of the total metals concentration on the Hyperion CS-02C-63 carbon support, further evaluation and optimization of promising third metal and third and fourth metal combinations added to the RhMnIr catalysts, and examination of operating pressure and the syngas composition on catalyst performance.

\subsubsection{Alternative Carbon Nanotube Supports and Impregnation Solutions}

A series of tests were performed to re-examine the performance of the $2.11 \mathrm{X}$ baseline $\mathrm{RhMnIr}$ catalysts on the three Hyperion carbon nanotube supports: CS-02C-63, CS-05C-63, and CS-07C-63. In addition, the effect of adding $10 \% \mathrm{MeOH}$ in the impregnation solution was evaluated. The results are shown in Figure 3.24 and Figure 3.25. The three tests conducted using the CS-02C-063 carbon support without $\mathrm{MeOH}$ in the impregnation solution had a $\mathrm{C}_{2}+$ oxygenate STY range from 535 to $685 \mathrm{~g} / \mathrm{kg}_{\text {cat }} / \mathrm{hr}$, with an average of about $600 \mathrm{~g} / \mathrm{kg}_{\text {cat }} / \mathrm{hr}$ (Figure 3.24). This produced a range of $+14 \%$ to $-11 \%$ around the average STY value, which is considered to be reasonable based on previous experience with these catalysts. The Hyperion CS-02C-63-supported catalyst prepared using $\mathrm{MeOH}$ in the impregnation solution had a $\mathrm{C}_{2}+$ oxygenate STY value that was $27 \%$ greater than the average of the three prepared without $\mathrm{MeOH}$ and $13 \%$ greater than the upper end of the range of STYs for the catalysts prepared without $\mathrm{MeOH}$. This suggests that there is a modest improvement in the STYs when $\mathrm{MeOH}$ is used in the impregnation solution. The Hyperion CS-05C-63- and CS-07C-63-supported catalysts prepared without $\mathrm{MeOH}$ appear to have significantly improved STYs over that achieved by similarly prepared catalysts using the Hyperion CS-02C-63 support although more tests would be needed to ascertain the scatter in the data for both catalysts. Both the Hyperion CS-05C-63- and CS-07C-63-supported catalysts also experienced significantly improved STYs (25\% and $42 \%$, respectively) when prepared with $\mathrm{MeOH}$ in the impregnation solution. Inspection of Figure 3.25 suggests that there was relatively little scatter in the overall selectivity to $\mathrm{C}_{2}+$ oxygenates for the catalysts prepared on the CS-02C-63 support, including the catalyst prepared with $\mathrm{MeOH}$ in the impregnation solution. The levels of selectivity to $\mathrm{C}_{2}+$ oxygenates for the catalysts prepared with the CS-05C-63- and CS-07C-63 supports also appeared to be unaffected by the presence of $\mathrm{MeOH}$ in the impregnation solution. The levels of selectivity for both catalysts prepared on the CS-05C-63 support were significantly lower than those prepared on the other two supports, however. 


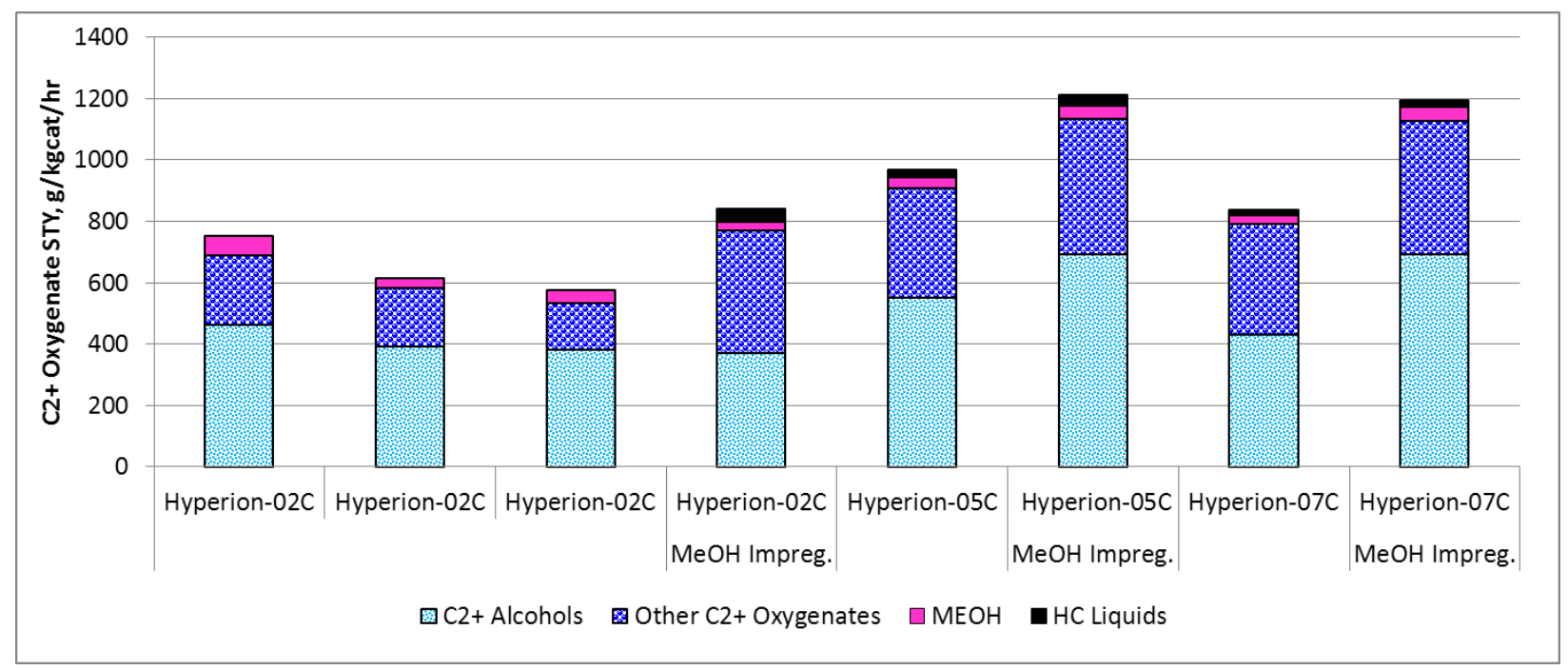

Figure 3.24. Effect of Impregnation using $10 \% \mathrm{MeOH}$ Solution on Converted Carbon Selectivity for 2.11X RhMnIr on Various Carbon Supports at $275^{\circ} \mathrm{C}, 1200 \mathrm{psig}$, and $7500 \mathrm{~g} / \mathrm{kg}_{\mathrm{cat}} \mathrm{hr}$

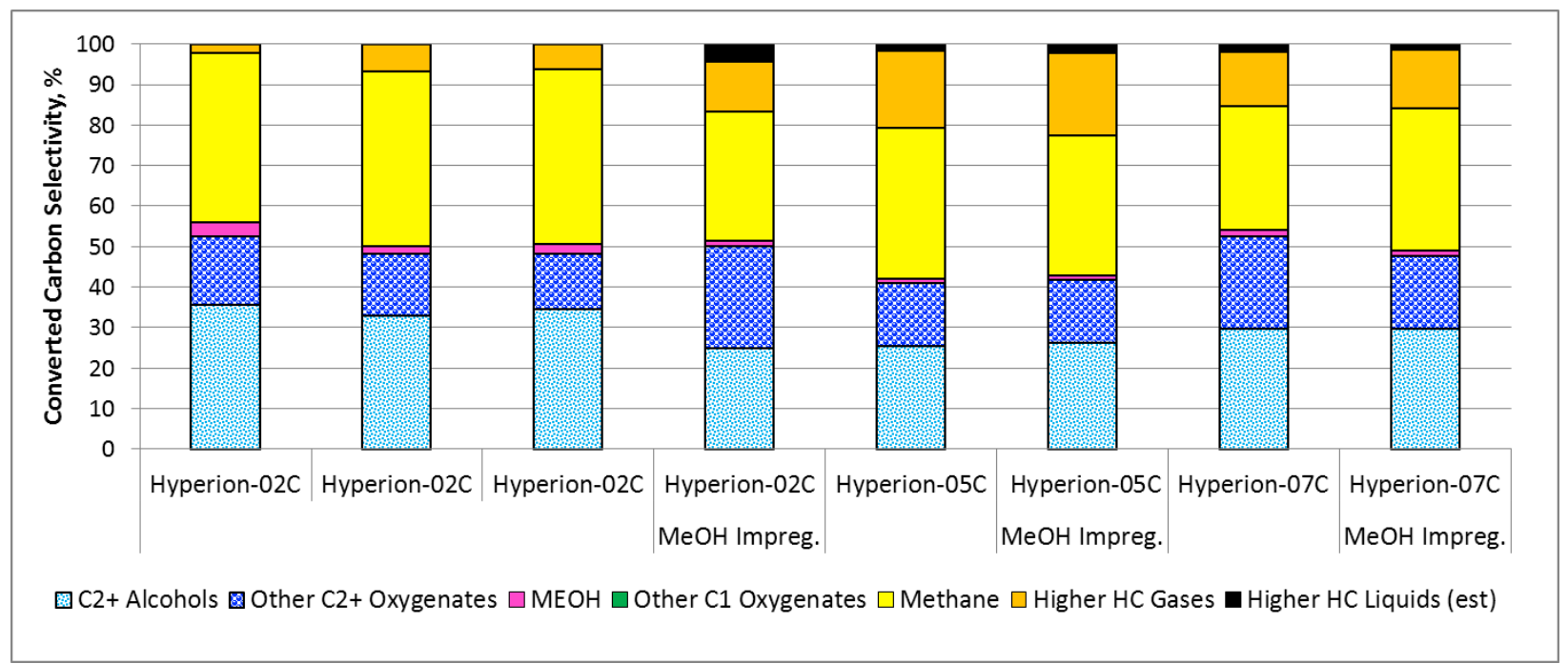

Figure 3.25. Effect of Impregnation using $10 \% \mathrm{MeOH}$ Solution on STY for 2.11X RhMnIr on Various Carbon Supports at $275^{\circ} \mathrm{C}, 1200 \mathrm{psig}$, and $7500 \mathrm{~g} / \mathrm{kg}_{\mathrm{cat}} / \mathrm{hr}$

\subsubsection{Effect of Metal Concentrations}

Several test series were conducted to further evaluate the effect of the concentrations of primarily Rh and Ir on catalyst performance. Earlier research using $1.5 \mathrm{X}$ baseline concentrations of $\mathrm{Rh}$ and $\mathrm{Mn}$ indicated that increasing Ir concentration to higher levels than $1.5 \mathrm{X}$ would further increase the $\mathrm{C}_{2}+$ oxygenate STY while at least maintaining the selectivity to $\mathrm{C}_{2}+$ oxygenates. These tests were conducted to find a preferred set of temperature and GHSV to obtain an optimum $\mathrm{C}_{2}+$ oxygenate STY and selectivity. Consequently, a single common set of operating conditions was not obtained for all of the tests, making direct comparisons more qualitative in nature. Figure 3.26 and Figure 3.27 show the STYs and converted carbon levels of selectivity, respectively for three tests at $275^{\circ} \mathrm{C}$ using $2.11 \mathrm{X}$ baseline concentrations for $\mathrm{Rh}, \mathrm{Mn}$, and Ir, which provides an indication of the scatter in the data for tests using 
the same metals concentrations at a common testing temperature. The average and range of values for the $\mathrm{C}_{2}+$ oxygenates were described in the previous section.

A fourth test used the same baseline concentrations of $\mathrm{Rh}$ and $\mathrm{Mn}$ but increased the Ir concentration to $3.64 \mathrm{X}$ the baseline concentration of $1.03 \%$. This catalyst was very reactive, achieving a $\mathrm{C}_{2}+$ oxygenate STY of nearly $2400 \mathrm{~g} / \mathrm{kg}_{\text {cat }} / \mathrm{hr}$ at $275^{\circ} \mathrm{C}$, but using a $12,000 \mathrm{~L} / \mathrm{L}_{\text {cat }} / \mathrm{hr}$ GHSV because of the very high CO conversion rate of $68 \%$ (Figure 3.26). Even with this high $\mathrm{CO}$ conversion, the selectivity to $\mathrm{C}_{2}+$ oxygenates was very comparable to that achieved at the same temperature and lower GHSV using the 2.11X baseline catalyst as shown in Figure 3.27.

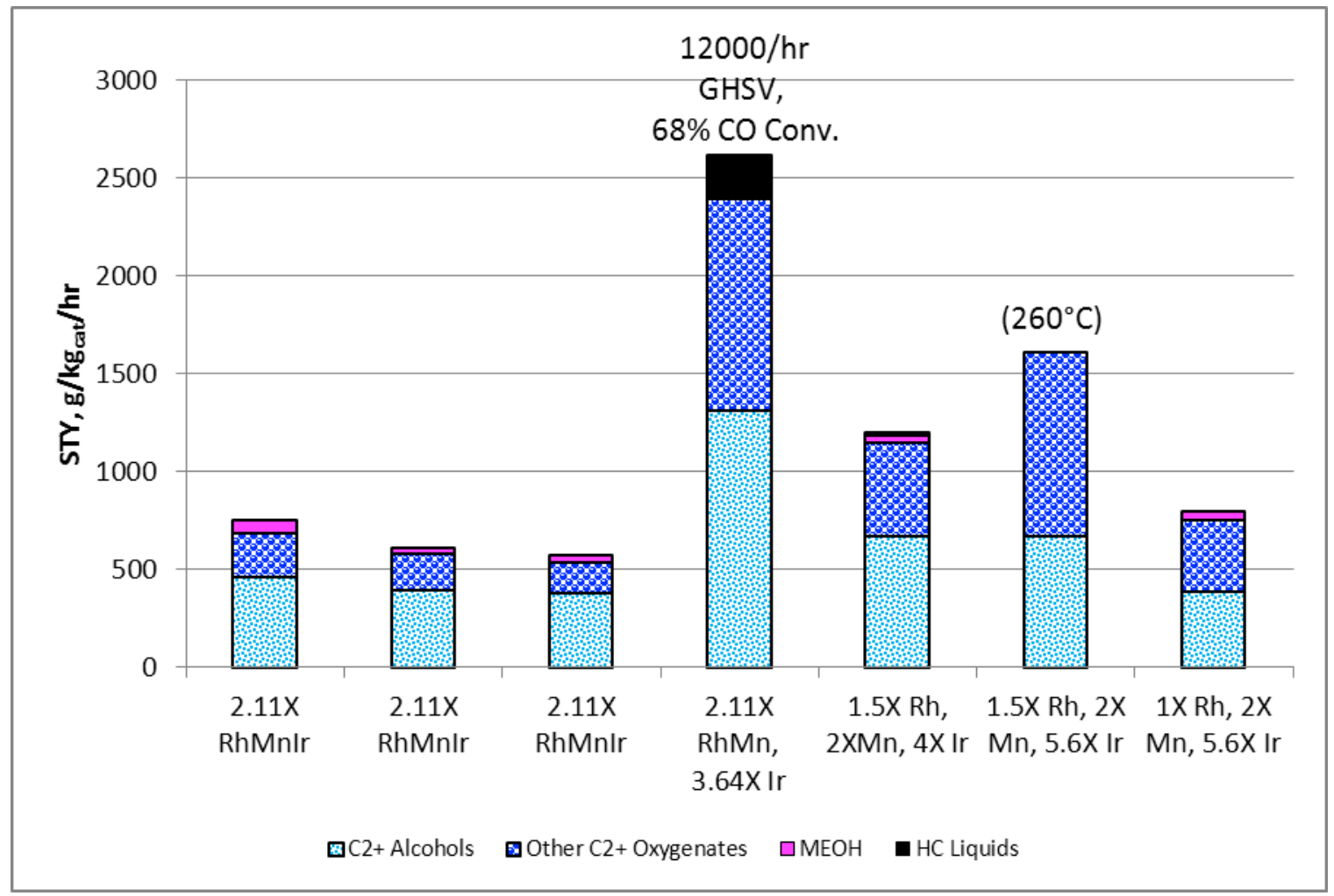

Figure 3.26. Effect of Metal Concentrations on STYs for RhMnIr/Hyperion CS-02C-63 Catalysts at $275^{\circ} \mathrm{C}, 1200 \mathrm{psig}$, and $7500 \mathrm{~g} / \mathrm{kg}_{\mathrm{cat}} / \mathrm{hr}$ 


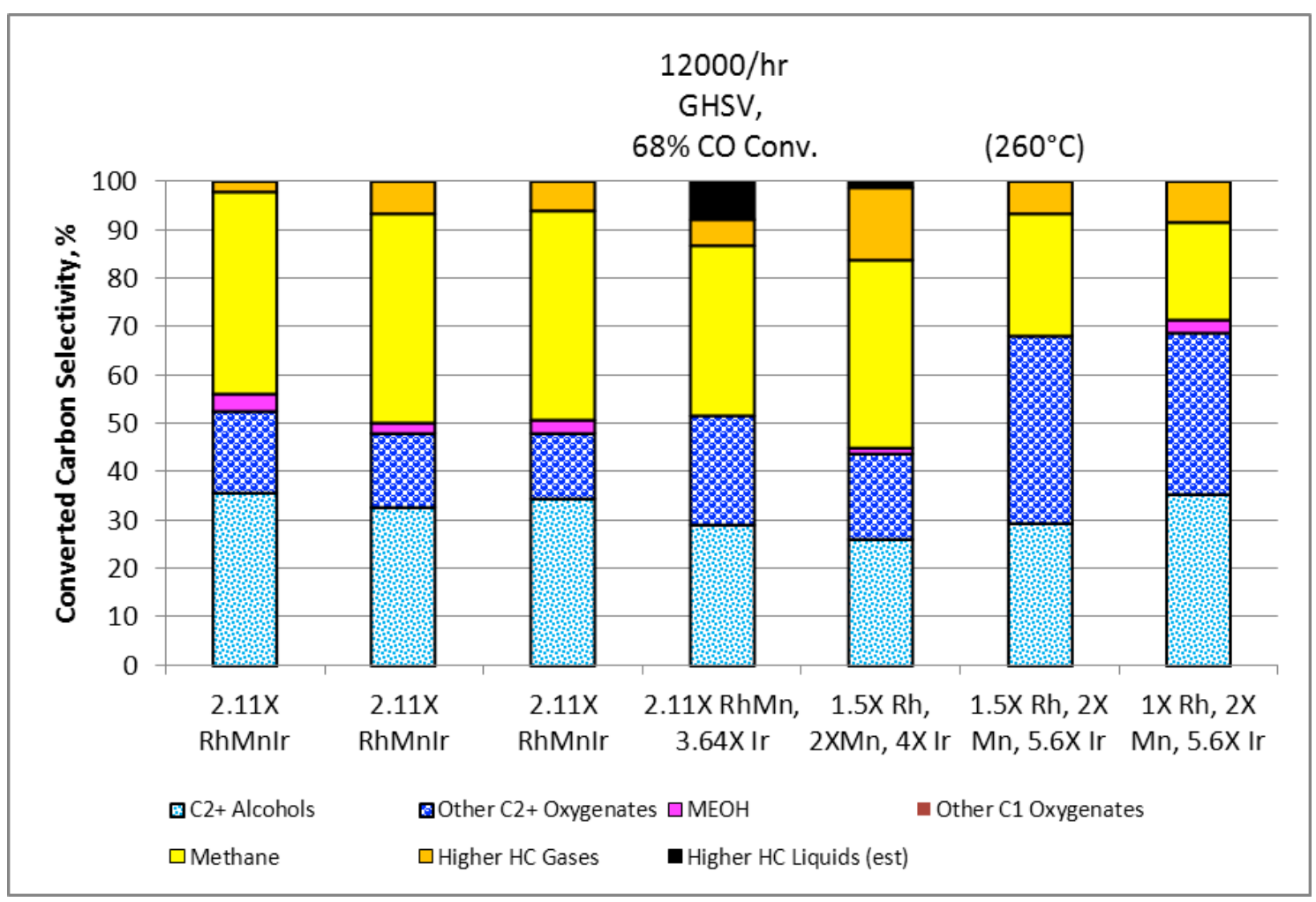

Figure 3.27. Effect of Metal Concentrations on Converted Carbon Selectivity for RhMnIr/Hyperion CS- $02 \mathrm{C}-63$ Catalysts at $275^{\circ} \mathrm{C}, 1200 \mathrm{psig}$, and $7500 \mathrm{~g} / \mathrm{kg}_{\text {cat }} / \mathrm{hr}$

Lowering the $\mathrm{Rh}$ concentration to $1.5 \mathrm{X}$ the baseline concentration while maintaining approximately the same concentrations of $\mathrm{Mn}$ and $\mathrm{Ir}$ (2X and 4X, respectively) resulted in a significantly reduced STY and a slightly reduced selectivity to $\mathrm{C}_{2}+$ oxygenates. The converted carbon selectivity to $\mathrm{C}_{2}+$ oxygenates also was significantly lower than that with the $2 \mathrm{X}$ baseline RhMnIr catalyst. Further increasing the Ir concentration to 5.6X the baseline concentration while maintaining 1.5X Rh and $2 \mathrm{X} \mathrm{Mn}$ baseline concentrations resulted in a significant improvement in both the $\mathrm{C}_{2}+$ oxygenate STY even though the testing temperature was only $260^{\circ} \mathrm{C}$, while also improving the selectivity. Maintaining the $\mathrm{Mn}$ and Ir concentrations at $2 \mathrm{X}$ and 5.6X their baseline concentrations, respectively, while further reducing the $\mathrm{Rh}$ to $1 \mathrm{X}$ its baseline concentration resulted in a lower $\mathrm{C}_{2}+$ oxygenate $\mathrm{STY}$, but maintained the selectivity at that achieved with the $2 \mathrm{X}$ baseline $\mathrm{Rh}$ concentration.

Figure 3.28 provides a comparison of the converted carbon levels of selectivity to $\mathrm{C}_{2}+$ oxygenates as a function of their $\mathrm{C}_{2}+$ oxygenate STYs for a broader set of test conditions using the catalysts with the different metal concentrations. As seen in the figure, catalysts containing 1.5X Rh, 2X Mn, and 5.6X Ir baseline concentrations achieved a level of selectivity of $\sim 70 \%$ over a range of test conditions while achieving STYs that were comparable to the $2.11 \mathrm{X}$ RhMnIr catalysts. Further reducing the $\mathrm{Rh}$ concentration to $1 \mathrm{X}$ the baseline value also achieved very high converted carbon level of selectivity to $\mathrm{C}_{2}+$ oxygenates at up to $750 \mathrm{~g} / \mathrm{kg}_{\mathrm{cat}} / \mathrm{hr}_{2}+$ oxygenate STYs. These results strongly suggest that further increasing the Ir concentration relative to the $\mathrm{Rh}$ and $\mathrm{Mn}$ concentrations over that used in a $2.11 \mathrm{X} \mathrm{RhMnIr}$ composition can significantly improve both the $\mathrm{C}_{2}+$ oxygenate STYs and level of selectivity. Reducing the Rh concentration while maintaining the $\mathrm{Mn}$ and Ir concentrations reduces the STY, but the selectivity may not necessarily be reduced by a significant amount. 


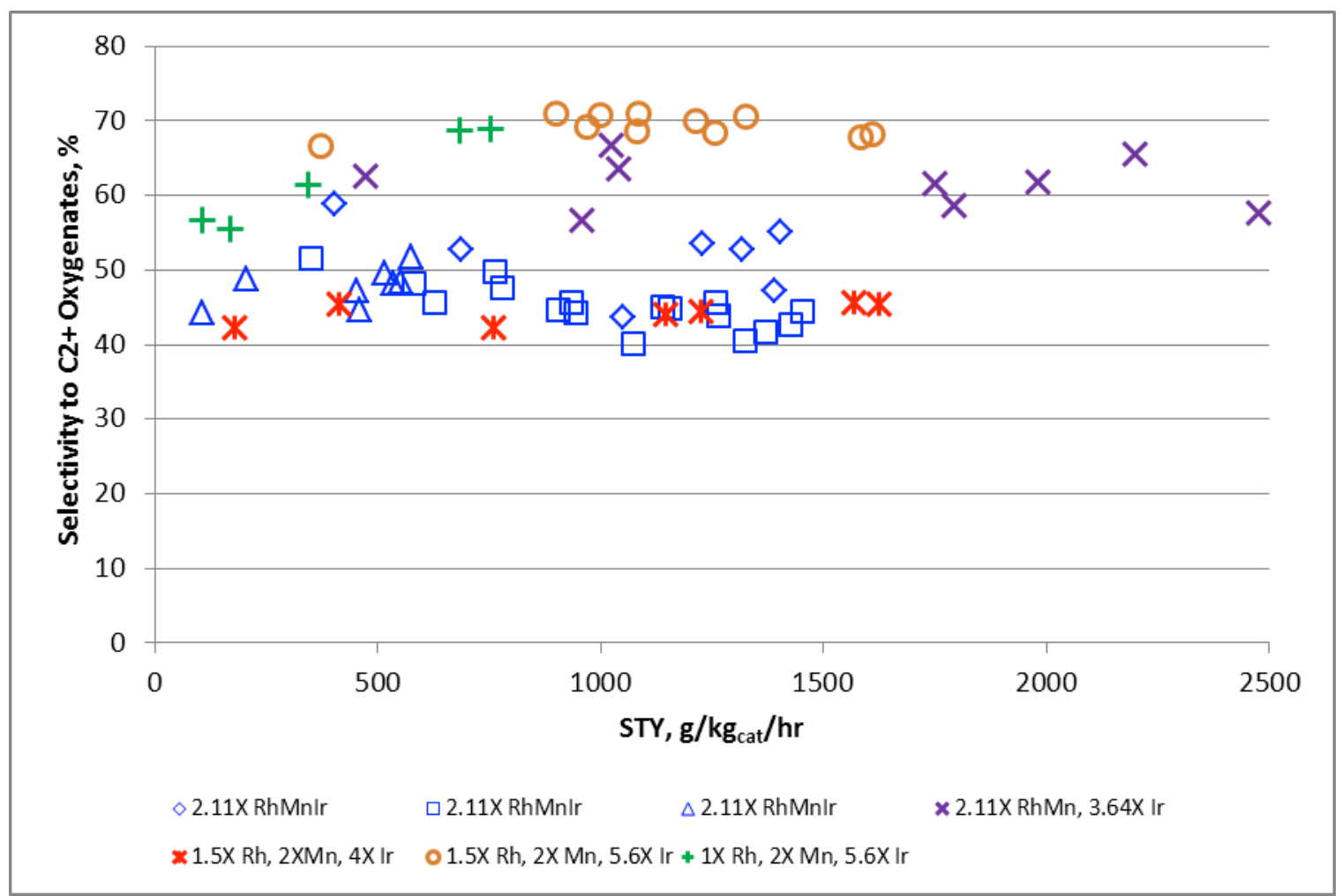

Figure 3.28. Comparison of the $\mathrm{C}_{2}+$ Oxygenates versus $\mathrm{C}_{2}+$ Oxygenate $\mathrm{STY}$ s for Tests Conducted with Catalysts Containing Different Metal Concentrations on Hyperion CS-02C-063 Carbon Supports

\subsubsection{Additional Promoters}

Several test runs were performed to investigate the addition of select promoters to a partially optimized RhMnIr catalyst, containing 2.11X baseline concentrations of Rh and Mn and 3.64X baseline concentrations of Ir. The promoters considered included:

- $0.04 \% \mathrm{~B}$

- $0.01 \% \mathrm{Ga}$

- $0.12 \%$ Zn plus $0.20 \% \mathrm{Pd}$

- $0.12 \%$ Zn plus $0.10 \% \mathrm{Fe}$

- $1.1 \%$ praseodymium $(\operatorname{Pr})$.

The first four promoters had been previously tested on similar catalysts containing the same $\mathrm{Rh}$ and Mn concentrations but a lower $2.11 \mathrm{X}$ baseline Ir concentration. Pr had not been previously evaluated.

Figure 3.29, Figure 3.30, and Figure 3.31 compare the CO conversions, STYs, and converted carbon levels of selectivity of the promoted and unpromoted catalysts at a common testing condition of $260^{\circ} \mathrm{C}$, $1200 \mathrm{psig}, 12,000 \mathrm{~L} / \mathrm{L}_{\mathrm{cat}} / \mathrm{hr}$, except for the Pr-promoted catalyst, which was tested at a GHSV of $7500 \mathrm{~L} / \mathrm{L}_{\text {cat }} / \mathrm{hr}$. Also, because the unpromoted catalyst was not tested at $260^{\circ} \mathrm{C}$, data for tests at $256^{\circ} \mathrm{C}$ and $275^{\circ} \mathrm{C}$ are presented to bracket the anticipated performance at the common temperature. The $\mathrm{B}, \mathrm{Ga}$, 
and $\mathrm{Zn}+\mathrm{Pd}$ promoters had $\mathrm{CO}$ conversions similar to that of the unpromoted catalyst tested at $256^{\circ} \mathrm{C}$, while the $\mathrm{CO}$ conversion of the $\mathrm{Zn}+$ Fe-promoted catalyst was about one-third that of the unpromoted catalyst. The Pr-promoted catalyst cannot be directly compared because it was evaluated at a lower GHSV.

Both of the B- and Ga-promoted catalysts had converted carbon levels of selectivity to $\mathrm{C}_{2}+$ oxygenates that were comparable to that of the unpromoted catalyst at $256^{\circ} \mathrm{C}$, followed by the $\mathrm{Pr}$ promoted catalyst (about 13\% lower), the $\mathrm{Zn}+\mathrm{Pd}$-promoted catalyst (about $21 \%$ lower), and the $\mathrm{Zn}+\mathrm{Fe}-$ promoted catalyst (about 60\% lower). (Comparison of the promoted catalyst level of selectivity to the selectivity of the unpromoted catalyst at $275^{\circ} \mathrm{C}$ is not meaningful because of the unusually high [78\%] $\mathrm{CO}$ conversion of the latter that typically results in reduced selectivity.)

The ranking of the $\mathrm{C}_{2}+$ oxygenate STYs (Figure 3.31) generally followed the CO conversion for the promoted catalysts except for the Pr-promoted catalyst, which had a substantially lower STY because it was tested at a lower GHSV. The B- and Ga-promoted catalysts had STYs that were significantly greater than the unpromoted catalyst at $256^{\circ} \mathrm{C}$, of which a portion could be attributed to the slightly higher testing temperature. The Pr- and $\mathrm{Zn}+\mathrm{Pd}$-promoted catalysts had comparatively lower STYs than the unpromoted catalyst at $256^{\circ} \mathrm{C}$. However, both still had a very high STYs of $\sim 1260$ and $1495 \mathrm{~g} / \mathrm{kg}_{\text {cat }} / \mathrm{hr}$, respectively, at $260^{\circ} \mathrm{C}$.

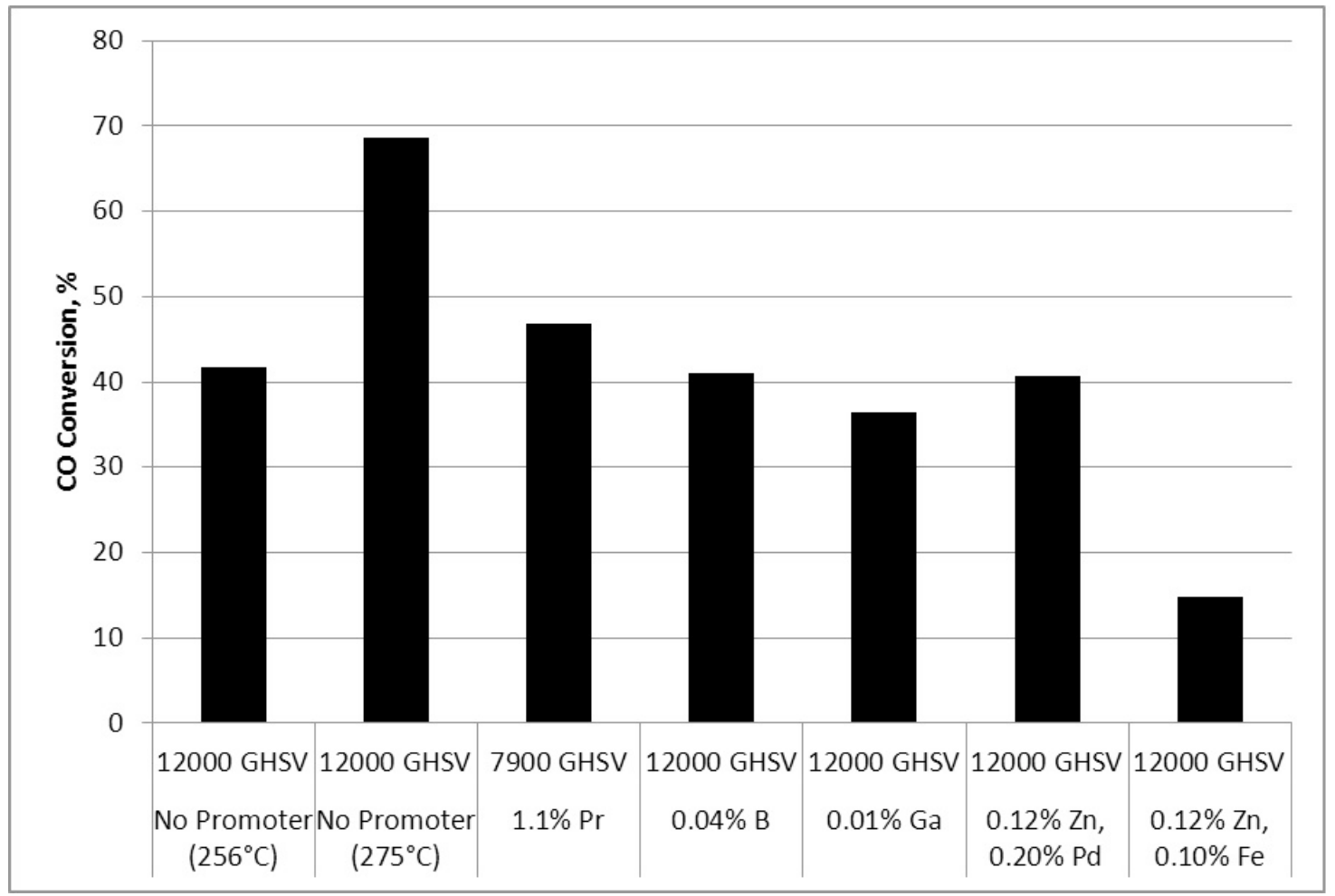

Figure 3.29. Effect of Promoters on CO Conversion for RhMnIr Catalysts on Hyperion CS-02C-063 Carbon Supports at $260^{\circ} \mathrm{C}$ and $1200 \mathrm{psig}$ 


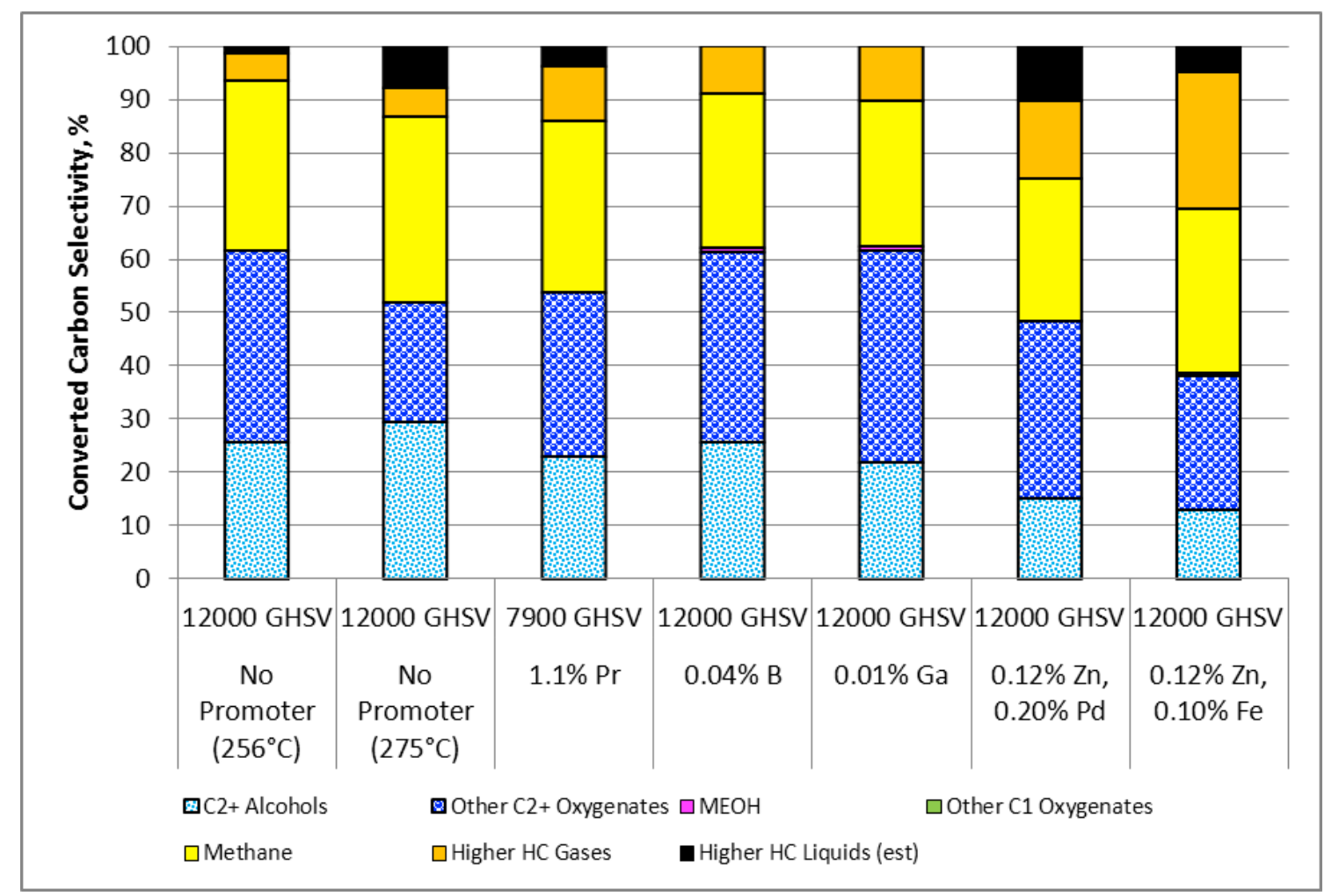

Figure 3.30. Effect of Promoters on Converted Carbon Selectivity for RhMnIr Catalysts on Hyperion CS-02C-063 Carbon Supports at $260^{\circ} \mathrm{C}, 1200$ psig, and $7500 \mathrm{GHSV}$

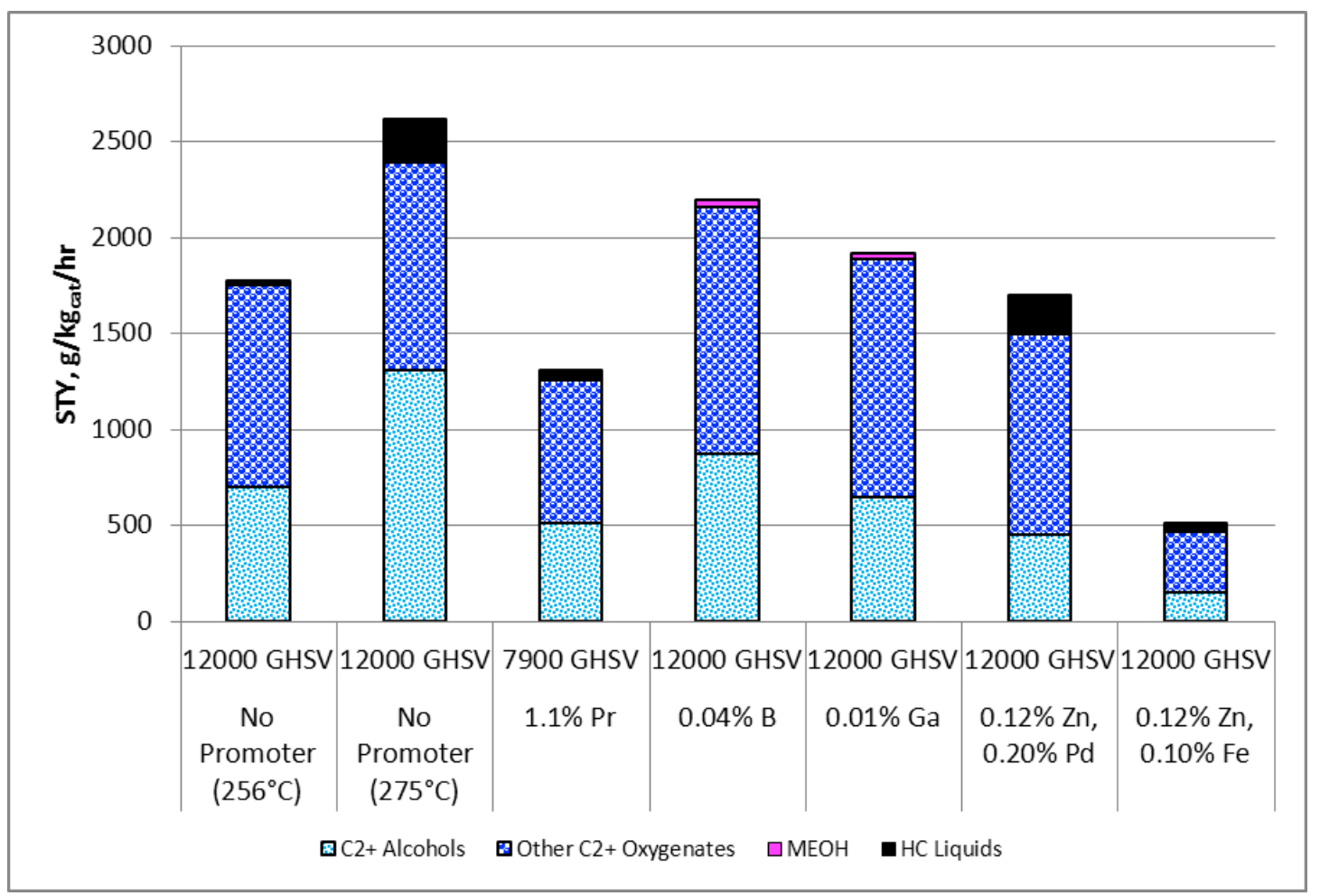

Figure 3.31. Effect of Promoters on STYs for RhMnIr Catalysts on Hyperion CS-02C-063 Carbon Supports at $260^{\circ} \mathrm{C}, 1200 \mathrm{psig}$, and $7500 \mathrm{GHSV}$ 
Figure 3.32 provides a comparison of the converted carbon level of selectivity to $\mathrm{C}_{2}+$ oxygenates as a function of their $\mathrm{C}_{2}+$ oxygenate STYs for a broader set of test conditions using the catalysts with the different metal concentrations. It can be seen that the B- and Ga-promoted catalysts compare very favorably with the unpromoted catalyst. The main difference between these promoted catalysts and the unpromoted catalyst is that they both appear to be more active than the unpromoted catalyst at similar temperatures, as indicated in the figure with the temperatures labels of selected data points for the various catalysts. The Pr-promoted catalyst is consistently less active than the unpromoted catalyst, although its selectivity to $\mathrm{C}_{2}+$ oxygenates is comparable at the lower temperatures. The $\mathrm{Zn}+\mathrm{Pd}$ catalyst appears to be less selective than any of the other catalysts over the range of conditions tested.

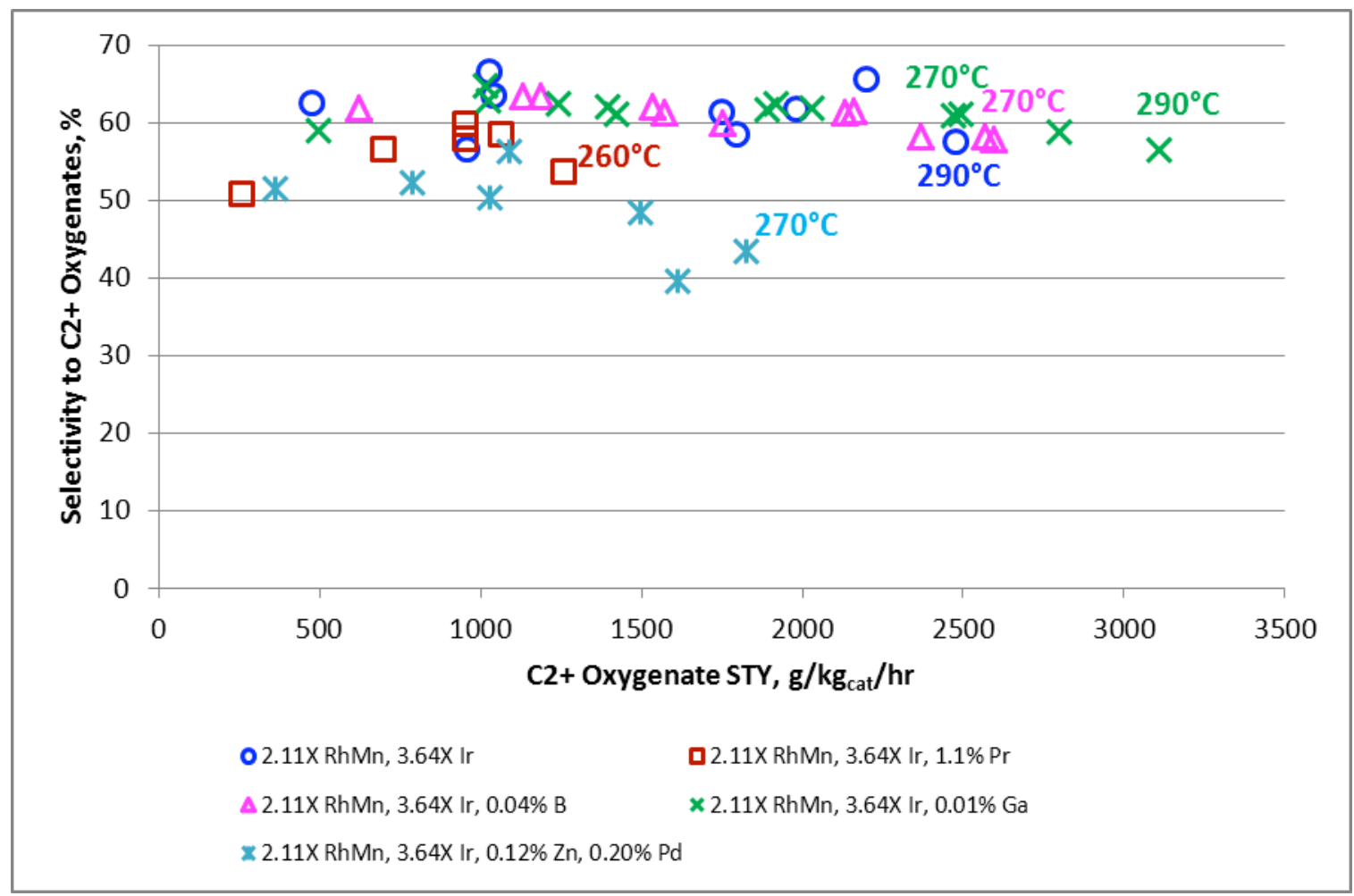

Figure 3.32. Comparison of the $\mathrm{C}_{2}+$ Oxygenates versus $\mathrm{C}_{2}+$ Oxygenates STYs for Tests Conducted with Catalysts Containing Different Promoters (temperatures indicated for selected data points for each catalyst)

\subsubsection{Syngas Pressure}

A series of test conditions were conducted to examine the effect of the syngas pressure on the performance of a $1 \mathrm{X} \mathrm{Rh}, 2 \mathrm{X} \mathrm{Mn}, 5.6 \mathrm{X}$ Ir catalyst on a Hyperion CS-02C-063 carbon support. The test conditions were $256^{\circ} \mathrm{C}, 7500 \mathrm{~L} / \mathrm{L}_{\text {cat }} / \mathrm{hr} \mathrm{GHSV}$, and syngas containing $4 \% \mathrm{CO}_{2}, 4 \% \mathrm{~N}_{2}$, and the balance being $\mathrm{H}_{2}$ and $\mathrm{CO}$ in a 2:1 $\mathrm{H}_{2}: \mathrm{CO}$ ratio. The pressures examined were $400,500,800$, and $1200 \mathrm{psig}$.

Figure 3.33 shows the effect of pressure on $\mathrm{CO}$ conversion. A power-law trend line fitted to the data using Microsoft Excel showed that the CO conversion was approximately 0.4-order with respect to pressure. Figure 3.34 shows the effect of pressure on the converted carbon selectivity. Between 1200 psig and 500 psig, there was a gradual decrease in the total $\mathrm{C}_{2}+$ oxygenate selectivity with 
decreasing pressure accompanied by a gradual increase in selectivity to hydrocarbons. Within the $\mathrm{C}_{2}+$ oxygenates, the decrease mainly was the result of a decrease in selectivity to the nonalcoholic (other) oxygenates. Within the hydrocarbon categories, the increase mainly resulted from an increase in the higher hydrocarbon gases. Between $500 \mathrm{psig}$ and $400 \mathrm{psig}$ the selectivity to the total $\mathrm{C}_{2}+$ oxygenates continued to decrease, but the $\mathrm{C}_{2}+$ alcohols underwent a significant increase with decreasing pressure over this range. Similarly, there was a measurable quantity of methanol produced at $400 \mathrm{psig}$ that was not present at $500 \mathrm{psig}$. It is noteworthy that the increase in the selectivity to $\mathrm{MeOH}$ was accompanied by a significant decrease in selectivity to methane at $400 \mathrm{psig}$.

The $\mathrm{C}_{2}+$ oxygenate STY decreases in a manner very similar to the CO conversion, with decreasing pressure as shown in Figure 3.35, because of the relatively modest effects of pressure on selectivity to the total $\mathrm{C}_{2}+$ oxygenates over the pressure range considered. A power-law trend line fitted to the data using Microsoft Excel showed that the STY was approximately 0.6-order with respect to pressure.

The $\mathrm{C}_{2}+$ alcohols account for more than half of the total oxygenates as shown in Figure 3.36. It is noteworthy that this fraction increases from $\sim 52$ to $60 \%$ with a decrease in syngas pressure from 1200 to 400 psig.

A second set of tests were performed using the same set of test conditions with a catalyst containing 2.11X RhMn, 3.64\% Ir, and promoted with 1.1\% Pr to further investigate the effect of pressure on catalyst performance. The results are summarized in Figure 3.37, Figure 3.38, Figure 3.39, Figure 3.40, and Figure 3.40. Comparisons of these figures to those for the $1 \mathrm{X} \mathrm{Rh}, 2 \mathrm{X} \mathrm{Mn}, 5.6 \mathrm{X}$ Ir catalyst (as shown in Figure 3.33 through Figure 3.36) show very similar behavior with respect to pressure. The main differences are that $\mathrm{MeOH}$ was not produced at any of the pressures in the catalyst containing $\mathrm{Pr}$, and the absolute values of the various parameters are different.

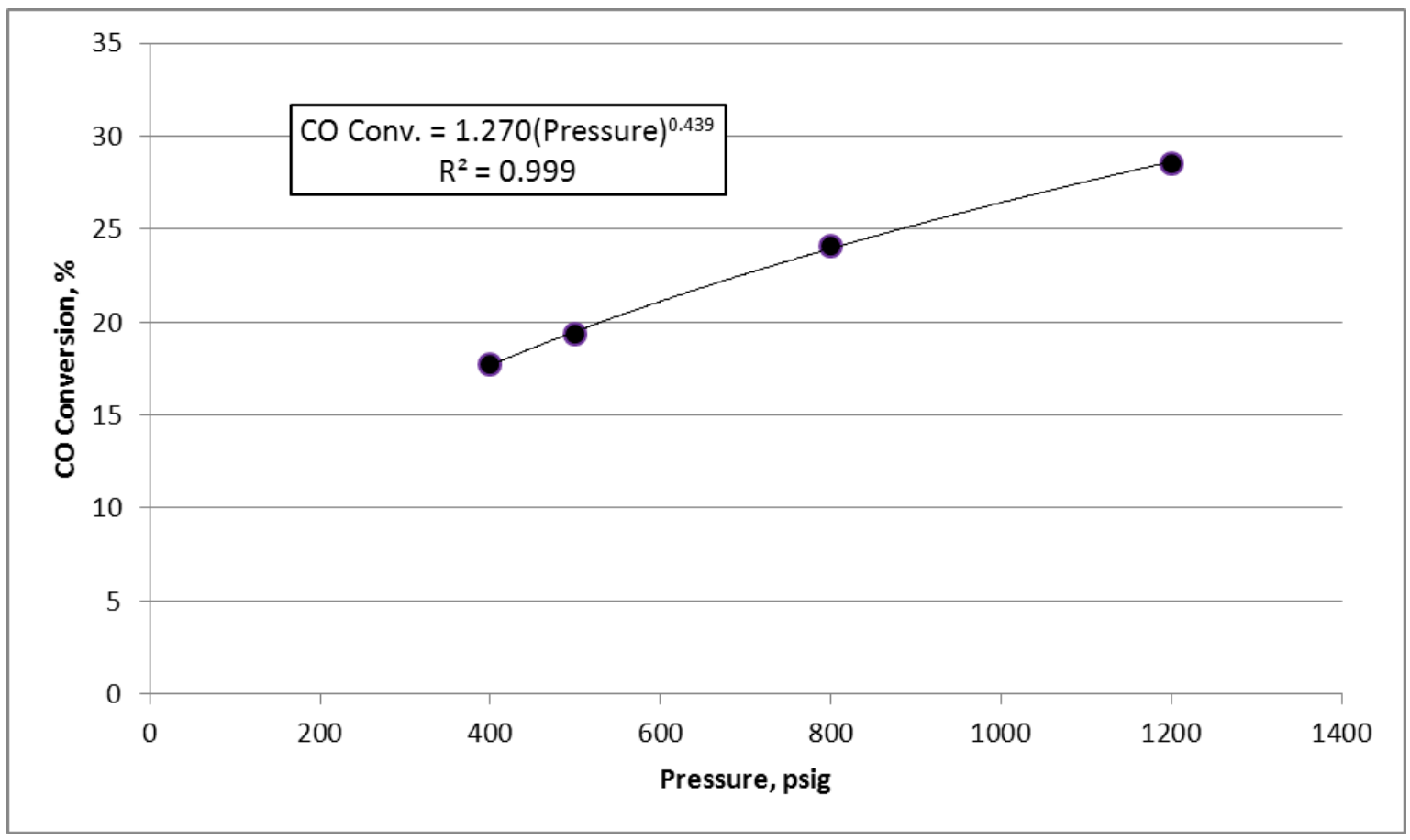

Figure 3.33. Effect of Syngas Pressure on CO Conversion for a 1.5X Rh, 2X Mn, 5.6X Ir/Hyperion CS-02C-063 Carbon-Supported Catalyst at $256^{\circ} \mathrm{C}$ 


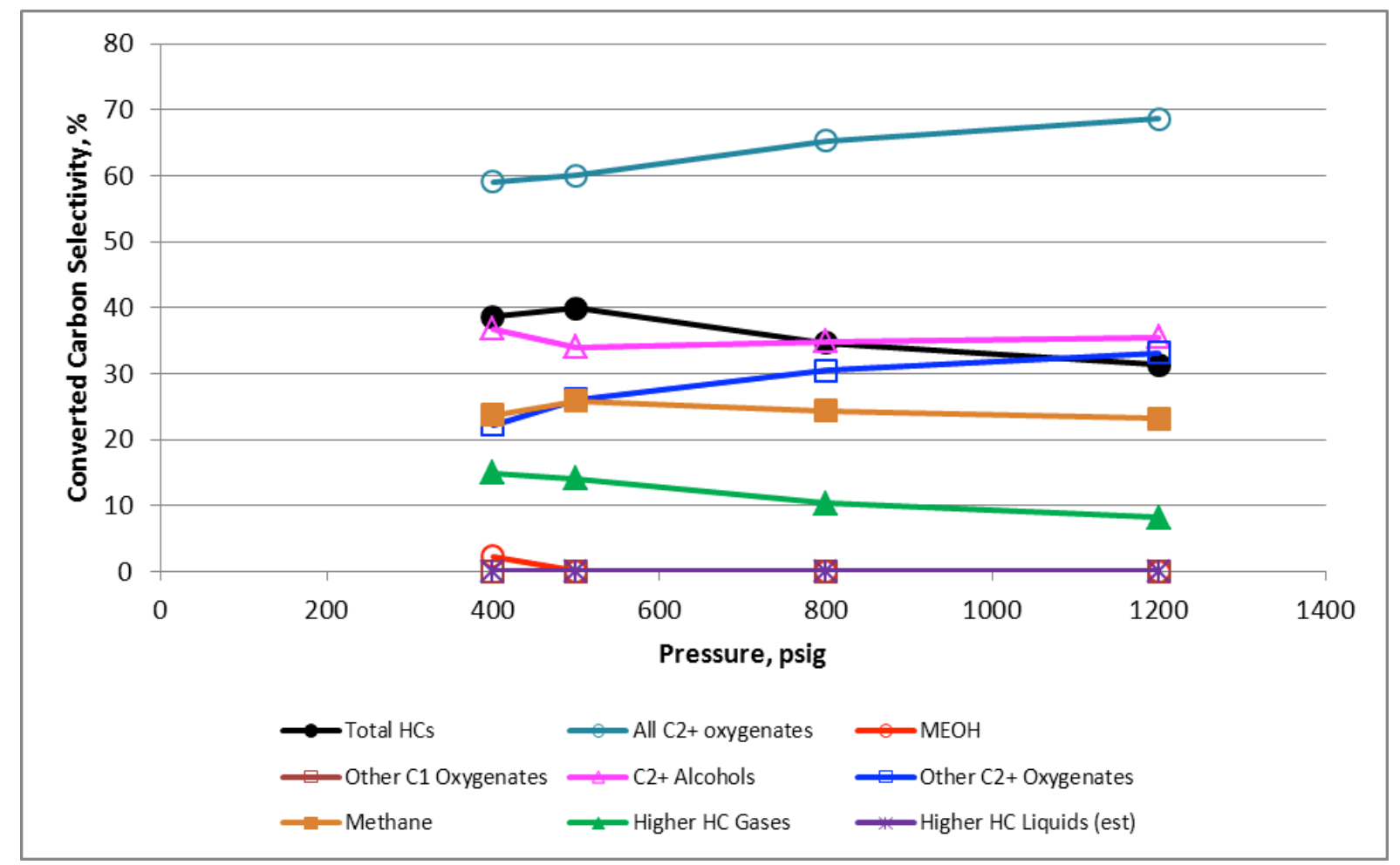

Figure 3.34. Effect of Syngas Pressure on Converted Carbon Selectivity for a $1.5 \mathrm{X} \mathrm{Rh}, 2 \mathrm{X} \mathrm{Mn}$, 5.6X Ir/Hyperion CS-02C-063 Carbon-Supported Catalyst at $256^{\circ} \mathrm{C}$

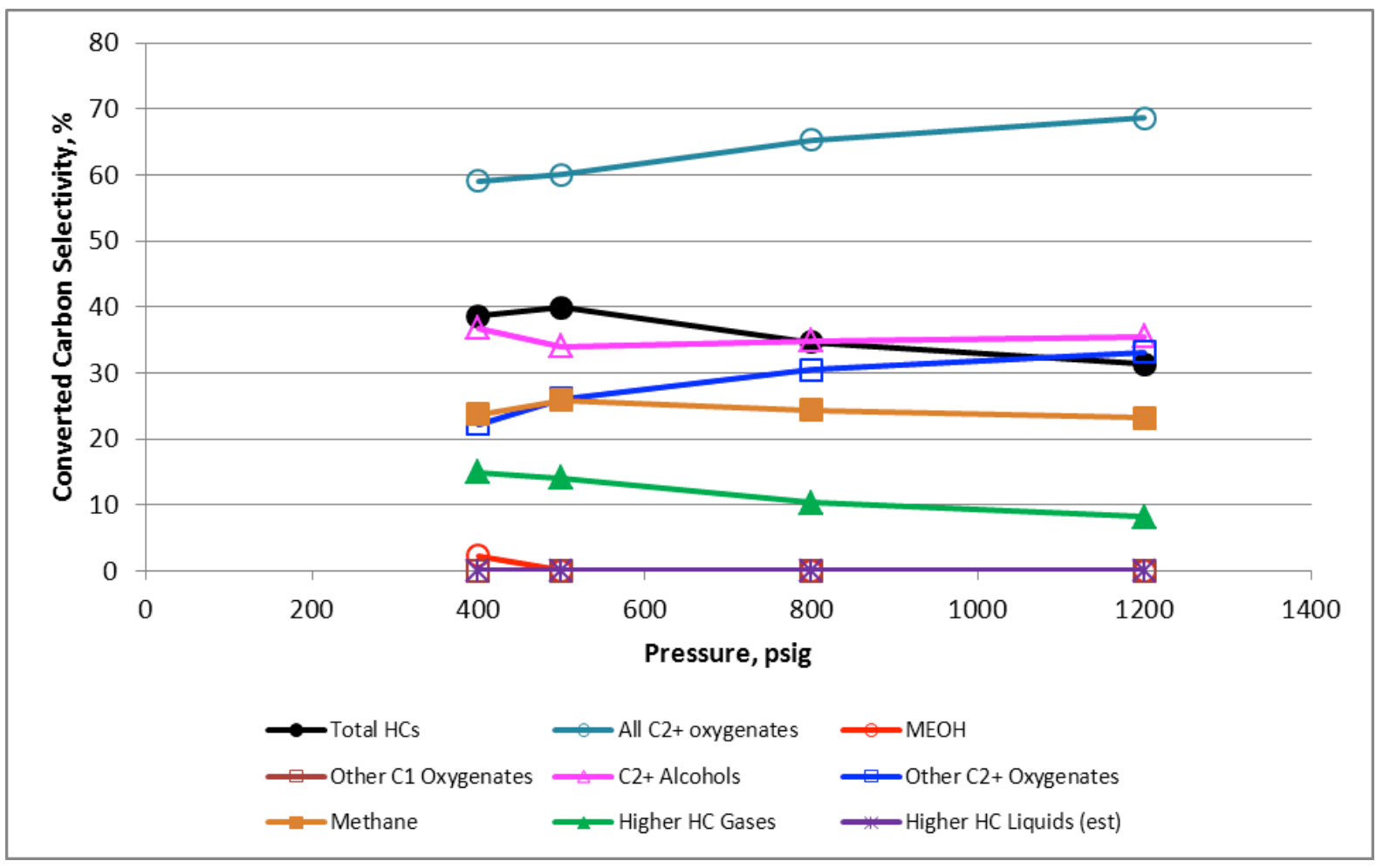

Figure 3.35. Effect of Syngas Pressure on Converted Carbon Selectivity for a 1.5X Rh, $2 \mathrm{X} \mathrm{Mn}$, 5.6X Ir/Hyperion CS-02C-063 Carbon-Supported Catalyst at $256^{\circ} \mathrm{C}$ 


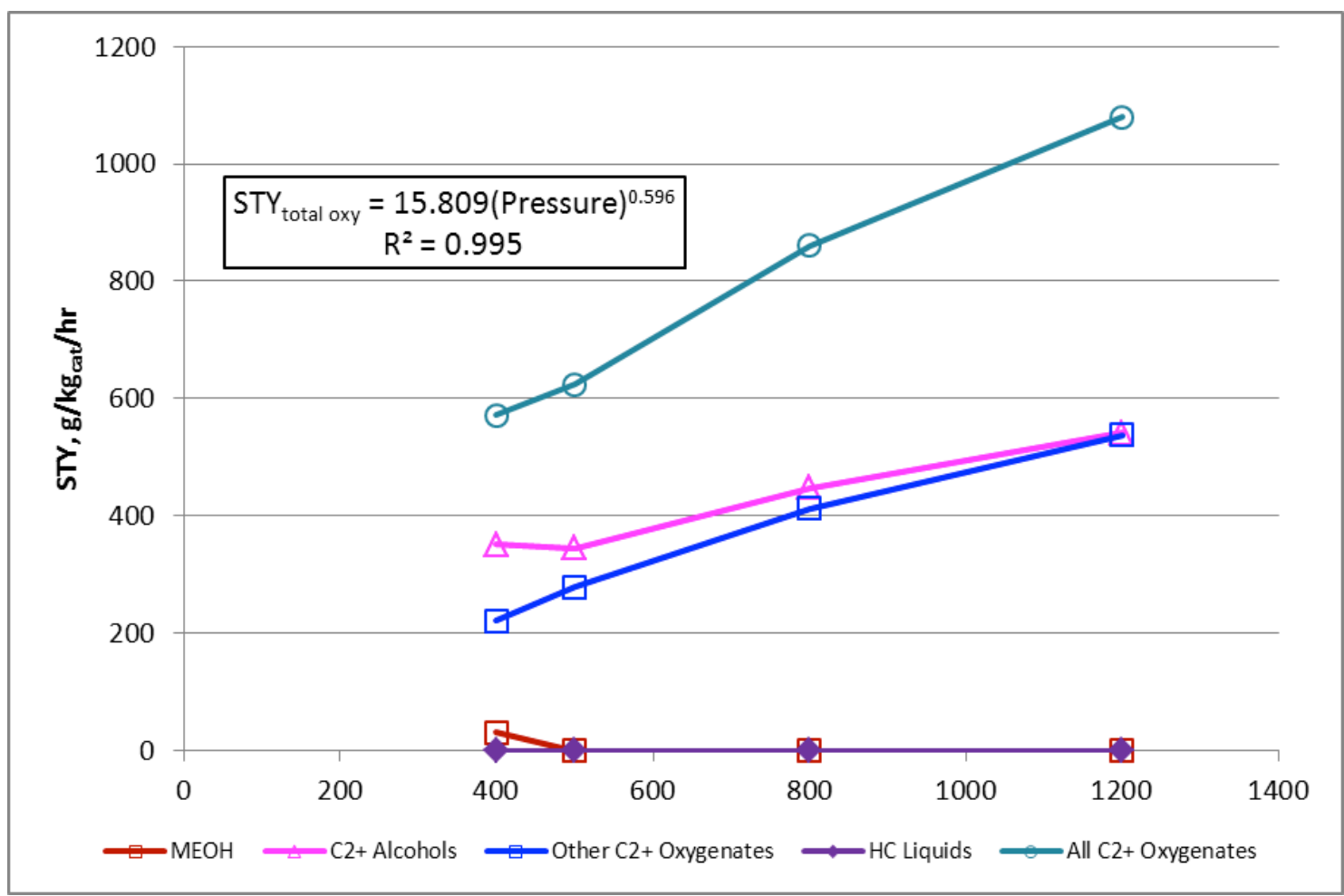

Figure 3.36. Effect of Syngas Pressure on STYs for a 1.5X Rh, 2X Mn, 5.6X Ir/Hyperion CS-02C-063 Carbon-Supported Catalyst at $256^{\circ} \mathrm{C}$

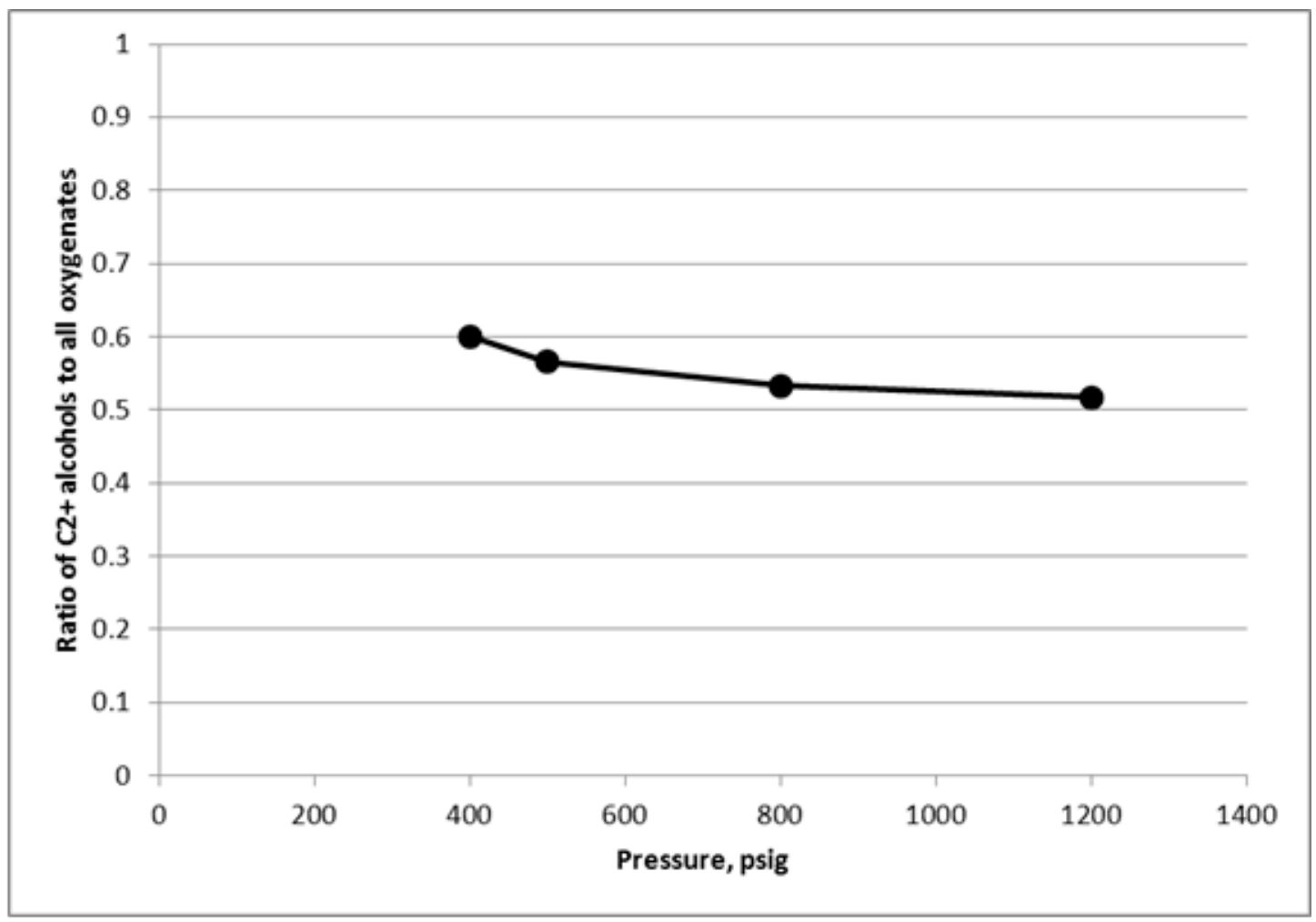

Figure 3.37. Effect of Syngas Pressure on Selectivity of the Oxygenates to $\mathrm{C}_{2}+$ Alcohols for a $1.5 \mathrm{X} \mathrm{Rh}$, 2X Mn, 5.6X Ir/Hyperion CS-02C-063 Carbon-Supported Catalyst at $256^{\circ} \mathrm{C}$ 


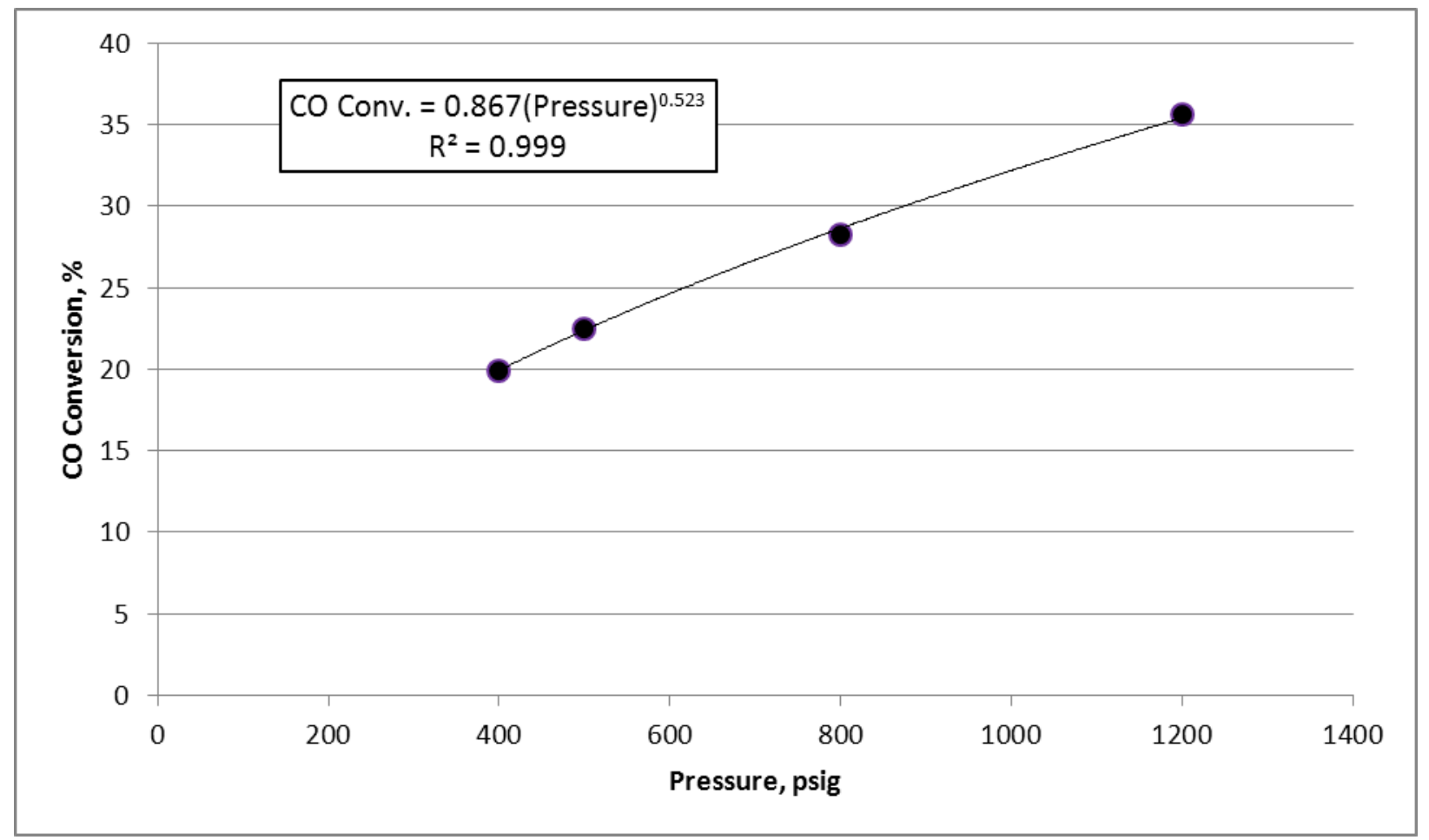

Figure 3.38. Effect of Syngas Pressure on Selectivity of the Oxygenates to $\mathrm{C}_{2}+$ Alcohols for a 2.11X RhMn, 3.64X Ir, 1.1\% Pr/Hyperion CS-02C-063 Carbon-Supported Catalyst at $256^{\circ} \mathrm{C}$

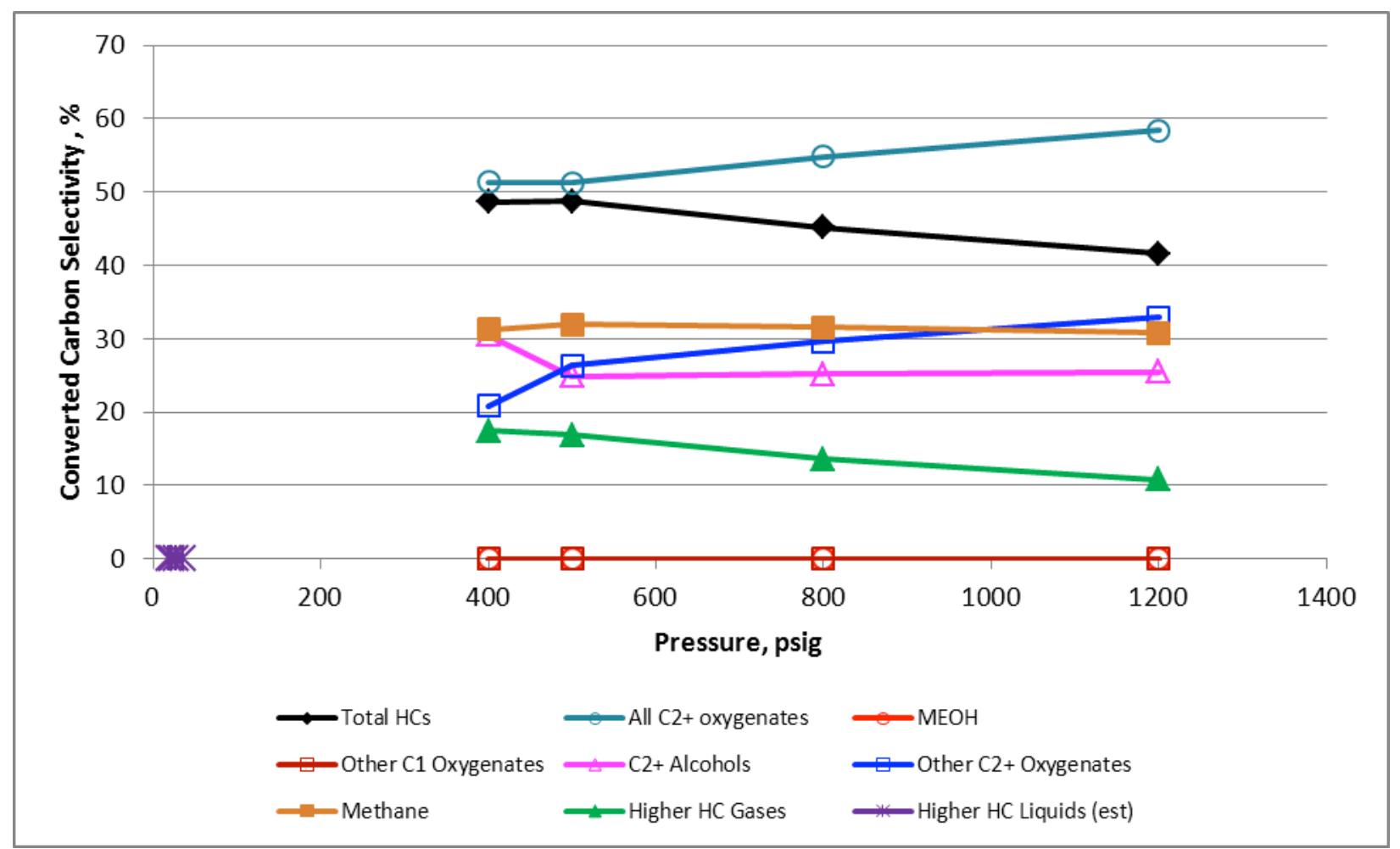

Figure 3.39. Effect of Syngas Pressure on Converted Carbon Selectivity for a 2.11X RhMn, 3.64X Ir, $1.1 \% \mathrm{Pr} /$ Hyperion CS-02C-063 Carbon-Supported Catalyst at $256^{\circ} \mathrm{C}$ 


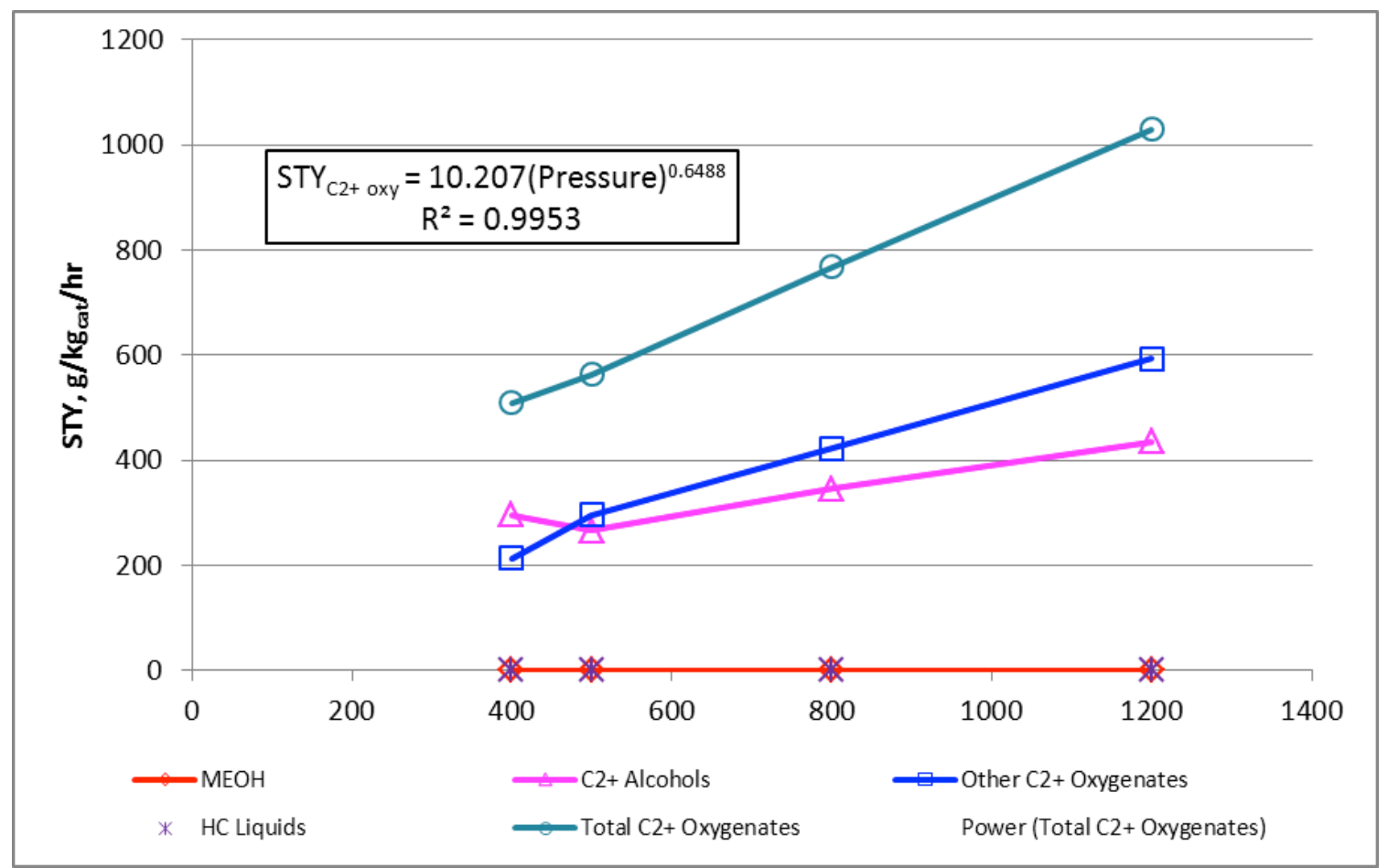

Figure 3.40. Effect of Syngas Pressure on STYs for a 2.11X RhMn, 3.64X Ir, 1.1\% Pr/Hyperion CS-02C-063 Carbon-Supported Catalyst at $256^{\circ} \mathrm{C}$

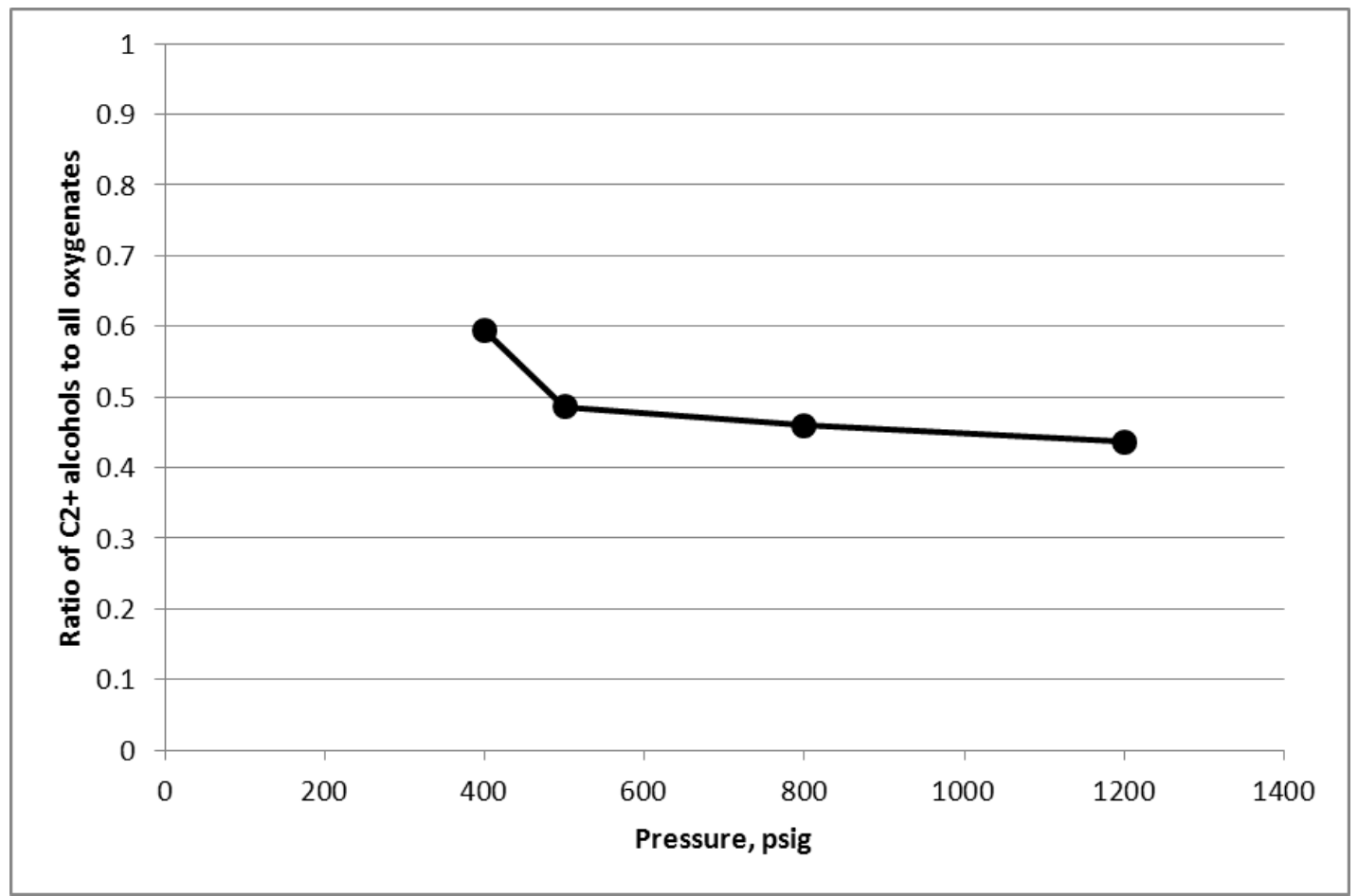

Figure 3.41. Effect of Syngas Pressure on Selectivity of the Oxygenates to $\mathrm{C}_{2}+$ Alcohols for a 2.11X RhMn, 3.64X Ir, 1.1\% Pr/Hyperion CS-02C-063 Carbon-Supported Catalyst at $256^{\circ} \mathrm{C}$ 


\subsection{5 $\quad \mathrm{H}_{2}$ : $\mathrm{CO}$ Ratio}

Two test series were conducted to investigate the effect of the $\mathrm{H}_{2}$ : $\mathrm{CO}$ ratio on the performance of catalysts containing 2.11X the baseline concentrations of $\mathrm{Rh}$ and $\mathrm{Mn}$ and 3.64X the baseline concentration of Ir. One test involved a catalyst promoted with $0.04 \%$ B, and the other catalyst was promoted with $0.01 \% \mathrm{Ga}$. The test series were conducted at $256^{\circ} \mathrm{C}$ and $1200 \mathrm{psig}$ total system pressure using a mixture of the standard syngas $\left(\mathrm{H}_{2}: \mathrm{CO}\right.$ ratio $\left.=2,4 \% \mathrm{~N}_{2}+4 \% \mathrm{CO}_{2}\right)$ and pure $\mathrm{CO}$ gas to achieve $\mathrm{H}_{2}: \mathrm{CO}$ ratios of $2: 1,1.5: 1$ and 1.3:1. The flow rate of the feed gas mixture was adjusted so the $\mathrm{CO}$ GHSV remained at the same value as previous tests using only the syngas with a total feed gas GHSV of $1200 \mathrm{~L} / \mathrm{L}_{\text {cat }} / \mathrm{hr}\left(\mathrm{CO}\right.$ GHSV $\left.=6000 \mathrm{~L} / \mathrm{L}_{\text {cat }} / \mathrm{hr}\right)$. The $\mathrm{CO}_{2}$ and $\mathrm{N}_{2}$ in the syngas were reduced by $9 \%$ and $14 \%$ in the feed gas mixture for the mixtures with $1.5: 1$ and $1.3: 1 \mathrm{H}_{2}: \mathrm{CO}$ ratios, respectively.

Figure 3.42 and Figure 3.43 show the results for the B-promoted catalyst, while Figure 3.44 and Figure 3.45 show the results for the Ga-promoted catalyst. Both catalysts behaved similarly with a decrease in the $\mathrm{H}_{2}: \mathrm{CO}$ ratio. The converted carbon selectivity to $\mathrm{C}_{2}+$ oxygenate increased by $\sim 3 \%$ from $\sim 60 \%$ to $63 \%$ for the B-promoted catalyst and by $\sim 4 \%$ from $\sim 62 \%$ to $66 \%$ for the Ga-promoted catalyst. The $\mathrm{C}_{2}+$ oxygenate STYs decreased by $\sim 24 \%$ from 1750 to $1330 \mathrm{~g} / \mathrm{kg}_{\text {cat }} / \mathrm{hr}$ for the B-promoted catalyst and by $\sim 18 \%$ from 1240 to $1020 \mathrm{~g} / \mathrm{kg}_{\text {cat }} / \mathrm{hr}$ for the Ga-promoted catalyst. Decreasing the $\mathrm{H}_{2}$ :CO ratio also decreased the selectivity of the oxygenate products to $\mathrm{C}_{2}+$ alcohols, suggesting that hydrogenation of the other oxygenates to alcohols is lower with the reduced hydrogen concentration in the gas.

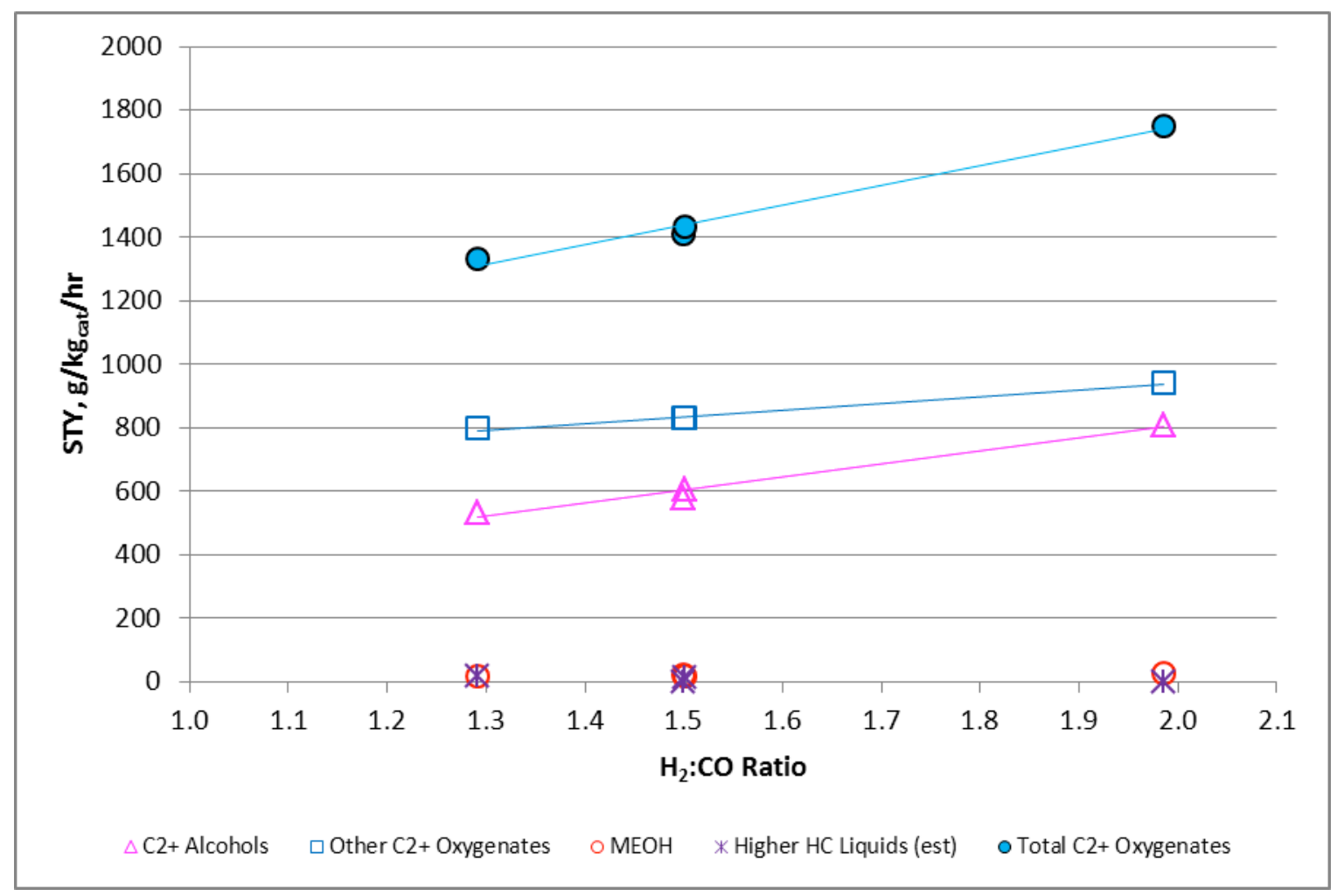

Figure 3.42. Effect of the $\mathrm{H}_{2}$ :CO Ratio on the STYs for a 2.11X RhMn, 3.64X Ir, 0.04\% B/Hyperion CS-02C-063 Catalyst (constant CO GHSV basis) 


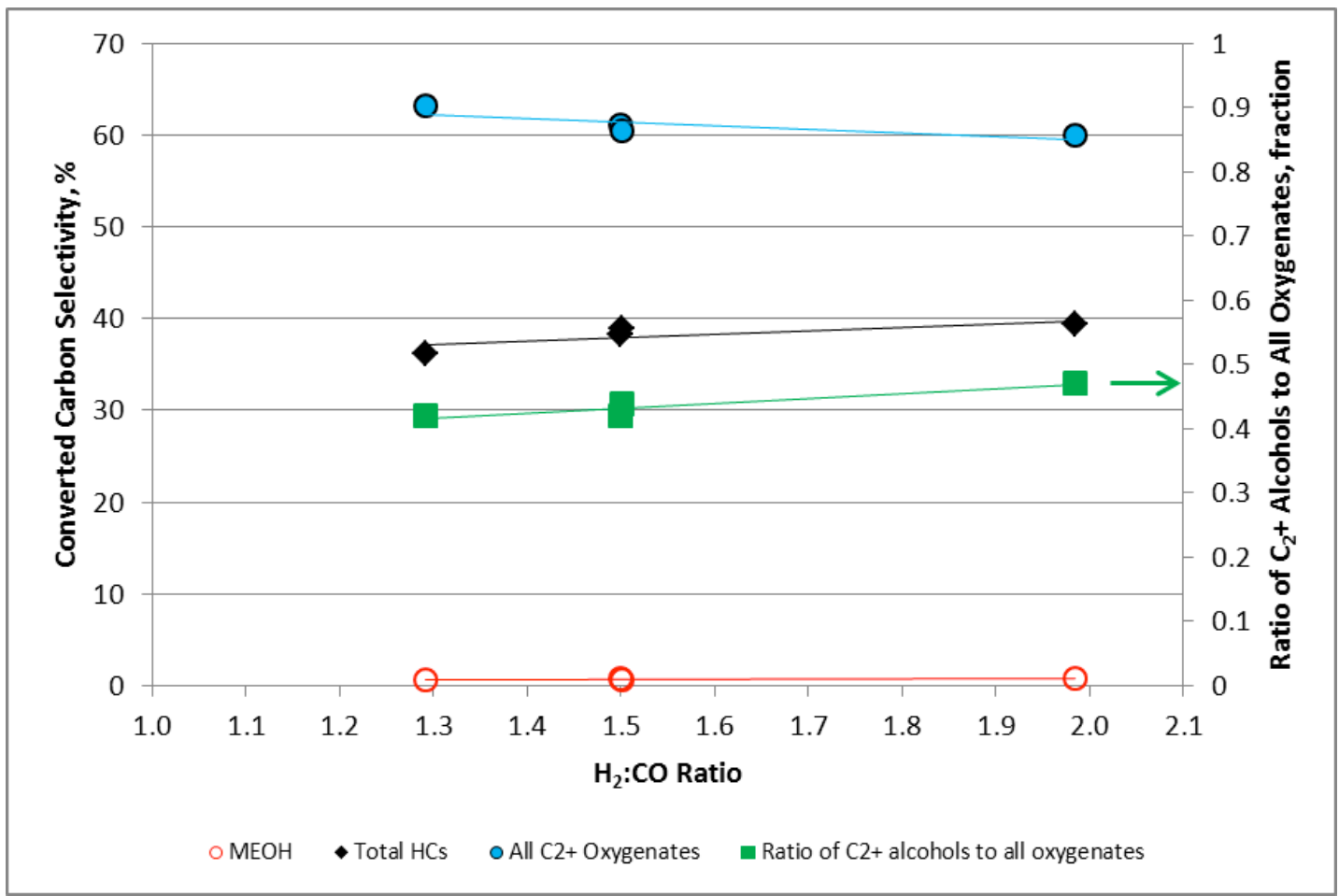

Figure 3.43. Effect of the $\mathrm{H}_{2}$ : $\mathrm{CO}$ Ratio on the Converted Carbon Selectivity to $\mathrm{C}_{2}+$ Oxygenates and the Oxygenate Selectivity to $\mathrm{C}_{2}+$ Alcohols for a 2.11X RhMn, 3.64X Ir, 0.04\% B/Hyperion CS-02C-063 Catalyst (constant CO GHSV basis)

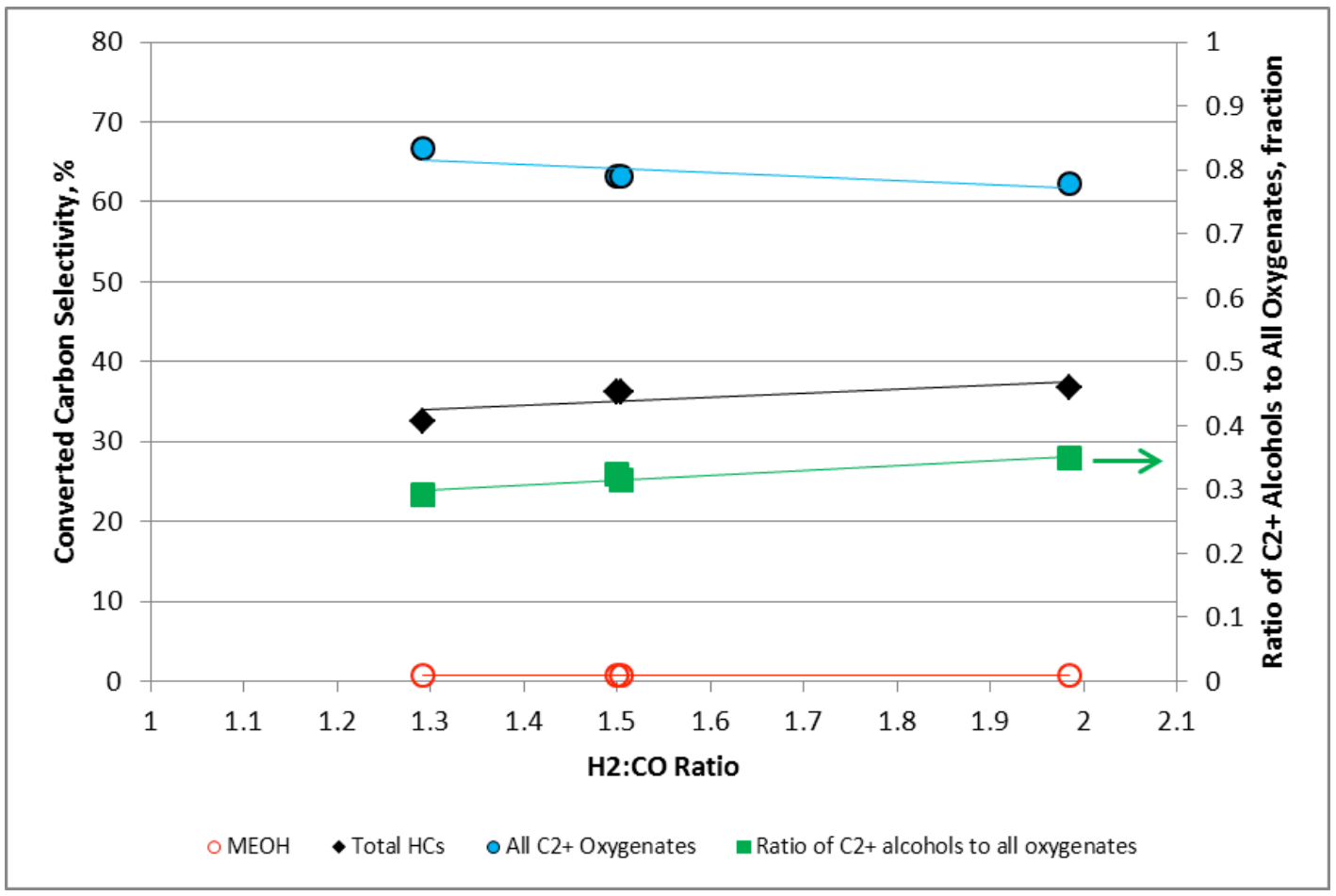

Figure 3.44. Effect of the $\mathrm{H}_{2}$ : $\mathrm{CO}$ Ratio on the Converted Carbon Selectivity to $\mathrm{C}_{2}+$ Oxygenates and the Oxygenate Selectivity to $\mathrm{C}_{2}+$ Alcohols for a 2.11X RhMn, 3.64X Ir, 0.01\% Ga Hyperion CS-02C-063 Catalyst (constant CO GHSV basis) 


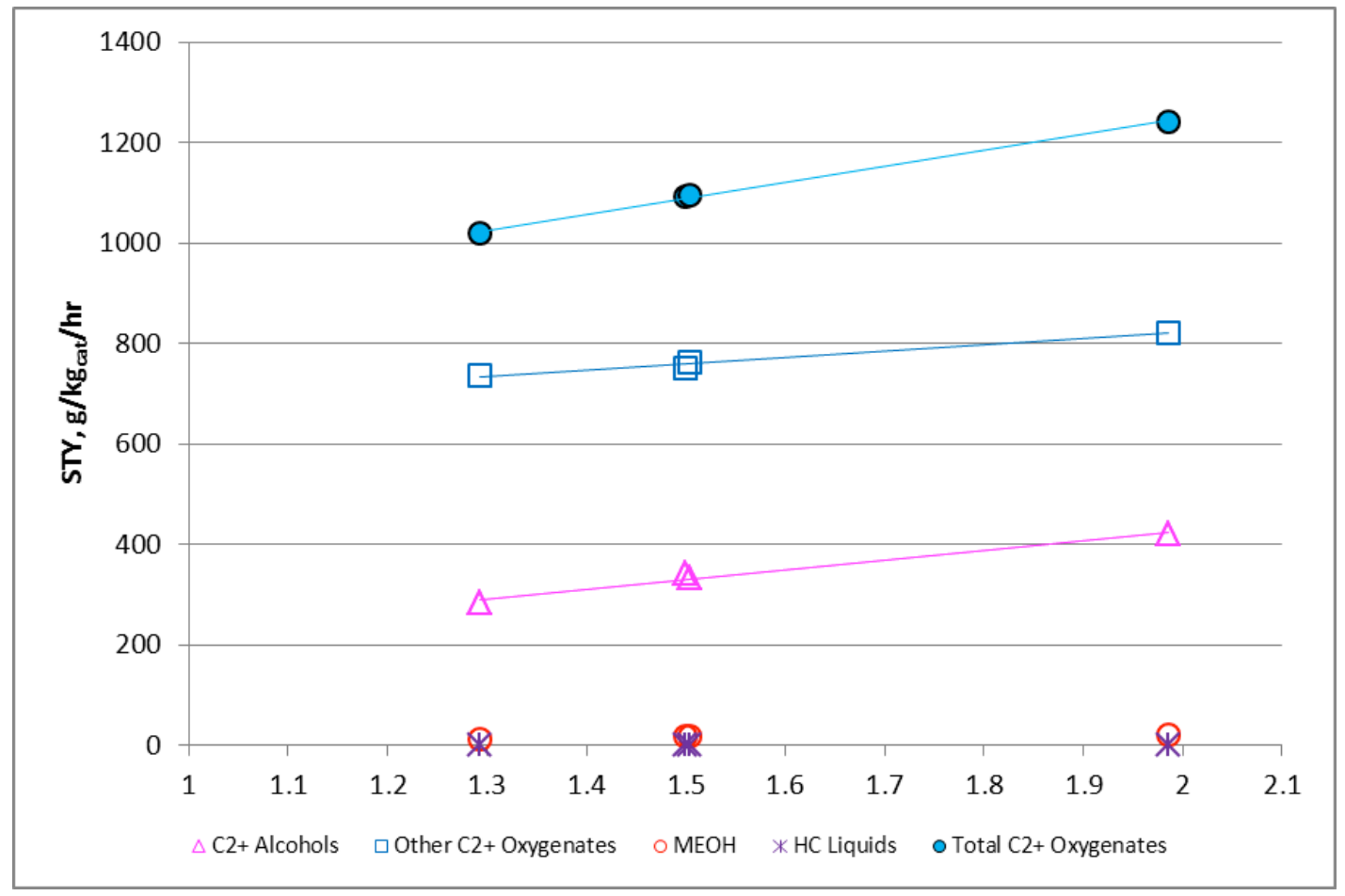

Figure 3.45. Effect of the $\mathrm{H}_{2}$ :CO Ratio on the STYs for a 2.11X RhMn, 3.64X Ir, $0.01 \% \mathrm{Ga} / \mathrm{Hyperion}$ CS-02C-063 Catalyst (constant CO GHSV basis) 


\subsection{Conclusions}

Tests were continued during FY 2012 to further improve the Ir-promoted RhMn catalysts on both silica and carbon supports for producing mixed oxygenates from syngas. This research re-examined selected alternative silica and carbon supports to follow up on some uncertainties in the results with previous test results. Additional, tests were conducted to further optimize the total and relative concentrations of Rh, Mn, and Ir on selected silica and carbon supports, and to examine selected promoters and promoter combinations based on earlier results. The effects of key operating parameters, pressure, and feed gas composition also were evaluated to establish the optimum operating conditions. Based on the results of these tests, a number of general conclusions can be reached. These general conclusions are presented in this chapter.

\subsection{Catalyst Supports}

Re-examination of several alternative silica supports showed that, while baseline RhMnIr catalysts supported on several of the alternative silicas could achieve $\mathrm{C}_{2}+$ oxygenate STYs comparable to those achieved with the Davisil 645 silica-supported catalyst, none achieved a level of selectivity that were as good. However, the Perlkat 97-1 silica-supported catalyst, which was much less active than the Davisil 645 silica-supported catalyst (having a $\mathrm{C}_{2}+$ oxygenate STY that was only about $25 \%$ of that achieved by a Davisil silica-supported catalyst at a $275^{\circ} \mathrm{C}$ operating temperature), had significantly higher selectivity ( $\sim 60 \%$ versus $\sim 50 \%$ ). Its performance was comparable to Merck Grade 7734 silica-supported catalysts evaluated earlier under similar conditions (Gerber et al. 2011). Earlier testing with the Merck Grade 7734 silica-supported catalyst suggested that it could achieve very good STYs by using $1.5 \mathrm{X}$ the baseline concentrations of the Rh, Mn, and Ir used in these tests while retaining or improving upon the higher levels of selectivity achieved with this support.

With continued progress in the improvement of the Hyperion CS-02C-063, carbon nanotubesupported RhMnIr catalysts, tests were conducted to re-examine the other two Hyperion nanotube supports and to investigate any effects of including $\mathrm{MeOH}$ in the impregnation solution on catalyst performance. Although there was considerable scatter in the STYs of repeat tests using the Hyperion CS-02C-063 support, it appears that both the CS-05C-063 and CS-07C-063 supports can attain significantly higher STYs when compared at a common set of test conditions. Furthermore, it appears that including $\mathrm{MeOH}$ in the impregnation solution further improved the STYs for all three supported catalysts. Including $\mathrm{MeOH}$ in the impregnation solution did not significantly affect the converted carbon selectivity to $\mathrm{C}_{2}+$ oxygenates for any of the supported catalysts. However, the CS-05C-063-supported catalysts prepared using both solutions had levels of selectivity that were significantly lower than those achieved with the other two Hyperion nanotube supports.

\subsection{Effect of Metals Concentrations}

Because earlier tests using double-impregnated metals (i.e., Rh and Mn co-impregnation followed by Ir impregnation with drying between impregnations) suggested possible improved performance, the effect of the total metals content was examined for the Davisil 645, Merck Grade 7734, and Merck Grade 7754 silica-supported catalysts and the Hyperion CS-02C-063 carbon nanotube-supported catalysts containing co-impregnated Rh, Mn, and Ir metals; however, there was too much scatter in the data for the results to 
be conclusive. In addition, testing in FY 2012 focused on lower temperatures to avoid the effects of thermal excursions that could affect performance through sintering of the metal clusters.

Test results with the Davisil 645 showed that increasing the total metals content of $\mathrm{Rh}, \mathrm{Mn}$, and $\mathrm{Ir}$ beyond their baseline concentrations $(5.56 \% \mathrm{Rh}, 1.69 \% \mathrm{Mn}$, and $1.03 \% \mathrm{Ir})$ to $1.5 \mathrm{X}$ and $2 \mathrm{X}$ the baseline concentrations would produce significantly increased $\mathrm{C}_{2}+$ oxygenate STYs $(\sim 400, \sim 550$, and $\sim 500 \mathrm{~g} / \mathrm{kg}_{\text {cat }} / \mathrm{hr}$, respectively) but at the expense of significant decreases in the converted carbon level of selectivity to $\mathrm{C}_{2}+$ oxygenates $\left(\sim 50 \%, \sim 43 \%\right.$, and $\sim 30 \%$, respectively), even when evaluated at $256^{\circ} \mathrm{C}$ $\left(250^{\circ} \mathrm{C}\right.$ for the catalyst with $2 \mathrm{X}$ baseline concentrations).

Previous research showed that the Merck Grade 7734 silica-supported catalysts were significantly less active than the Davisil-supported catalysts, so tests were conducted using catalysts with $1.5 \mathrm{X}$ and $2 \mathrm{X}$ baseline metals concentrations. Reasonably high $\mathrm{C}_{2}+$ oxygenate STYs could be obtained at $275^{\circ} \mathrm{C}$ operating temperatures with both catalysts $\left(\sim 700 \mathrm{~g} / \mathrm{kg}_{\text {cat }} / \mathrm{hr}\right.$ for both), while the level of selectivity to $\mathrm{C}_{2}+$ oxygenates decreased from $\sim 68 \%$ to $\sim 58 \%$. These results suggest that $1.5 \mathrm{X}$ the baseline total metals loading for the Merck Grade 7734 silica-supported catalyst can be tolerated because of the lower activity of catalysts made with this support while still retaining the high level of selectivity also characteristic of catalysts made with this support. Tests conducted with Merck Grade 7754 silica-supported catalysts suggest that catalysts made with this support are not as selective as comparable catalysts made with the Merck Grade 7734 silica. Comparisons of STYs and corresponding level of selectivity over a range of testing temperatures for all of the catalysts tested suggest that $1.5 \mathrm{X}$ the baseline RhMnIr Merck Grade 7734 catalyst had the overall best performance.

Earlier research with carbon-supported catalysts showed that both $\mathrm{C}_{2}+$ oxygenates selectivity and STYs could be improved with increasing total metals concentrations up to $2.11 \mathrm{X}$ baseline concentrations, which was the highest considered for the catalysts. The earlier research also showed that the upper limit for Ir was not attained when evaluating catalysts with $1.5 \mathrm{X}$ baseline concentrations of Rh and Mn. The effects of Mn concentration had not been evaluated in RhMnIr catalysts. Testing during FY 2012 further examined the effects of Rh and Ir concentrations in RhMnIr/Hyperion CS-02C-063 carbons supports. The test results showed that increasing the Ir concentration can significantly improve both $\mathrm{C}_{2}+$ oxygenate STYs and level of selectivity when Rh and Mn are maintained at constant concentrations. Alternatively, it appears that increasing the Ir concentration while decreasing the Rh concentration in appropriate amounts can significantly increase the selectivity while maintaining the STY at comparable levels. Comparisons the STYs and corresponding levels of selectivity over a range of testing temperatures for all of the catalysts tested suggest that the $1.5 \mathrm{X}$ baseline $\mathrm{Rh}$ and $\mathrm{Mn}$ concentrations along with a 5.6X baseline Ir concentration had the best overall performance on the Hyperion CS-02C-063 carbon support.

\subsection{Evaluation of Promoters for the RhMnIr Catalysts}

The results of an evaluation of the effect of $\mathrm{Mg}$ as a promoter for RhMnIr catalysts supported on both the Davisil 645 and Merck Grade 7734 indicated that the addition of Mg significantly increased CO conversion. However, the effect of $\mathrm{Mg}$ addition on $\mathrm{C}_{2}+$ oxygenate STYs was more difficult to ascertain because there was considerable scatter in these results when repeat tests were made using different batches of catalysts. The differences appeared to be the result of an interchange between the selectivity to $\mathrm{C}_{2}+$ hydrocarbon gases and liquids and the nonalcoholic $\mathrm{C}_{2}+$ oxygenates. One clear difference was that, when $\mathrm{Mg}$ was added to the catalyst, a separate organic liquid fraction, presumed to be mainly 
hydrocarbons, was produced. GC-MS analysis of organic liquid samples produced from Mg-promoted catalysts on both supports showed that about $70 \%$ of the organic liquid species were oxygenated species, mainly consisting of $\mathrm{C}_{2}$ to $\mathrm{C}_{10}$ aldehydes and $\mathrm{C}_{4}$ to $\mathrm{C}_{20}$ acetates derived from $\mathrm{C}_{2}$ to $\mathrm{C}_{10}$ alcohols, with lesser quantities of $\mathrm{C}_{2}$ to $\mathrm{C}_{6}$ alcohols and $\mathrm{C}_{6}$ to $\mathrm{C}_{8}$ acetals, the latter derived from $\mathrm{C}_{2}$ to $\mathrm{C}_{4}$ aldehydes and alcohols. These results at least partially explain why a decrease in the organic liquids is accompanied by an increase in oxygenates in the aqueous phase.

$\mathrm{Pr}, \mathrm{B}, \mathrm{Ga}, \mathrm{Zn}+\mathrm{Pd}$, and $\mathrm{Zn}+\mathrm{Fe}$ were examined as promoters on a partially optimized Hyperion CS-02C-063 carbon-supported RhMnIr catalyst, containing 2.11X of the baseline concentrations of Rh and $\mathrm{Mn}$, and 3.64X the baseline concentration of Ir. The results showed that B- and Ga-promoted catalysts compare very favorably with the unpromoted catalyst. The main difference between them and the unpromoted catalyst is that they both appear to achieve higher $\mathrm{C}_{2}+$ oxygenate STYs than the unpromoted catalyst at similar temperatures, while attaining comparable levels of selectivity to $\mathrm{C}_{2}+$ oxygenates. The catalysts promoted with $\mathrm{Zn}+\mathrm{Pd}$ and $\mathrm{Zn}+\mathrm{Fe}$ were not as good, both suffering from lower levels of selectivity at comparable conditions, although the STYs for the Zn + Pd-promoted catalysts compared favorably at comparable temperatures.

\subsection{Pressure Effects}

Three sets of tests were conducted with silica- and carbon-supported RhMnIr catalysts to investigate the effects of operating pressure on catalyst performance. The silica-supported catalyst was promoted with $\mathrm{Mg}$ (1X the baseline RhMnIr, $0.04 \% \mathrm{Mg}$ ) and used a Davisil 645 silica support. One of the two Hyperion CS-02C-063 carbon-supported catalysts had a 1.5X Rh, 2X Mn, 5.6X Ir baseline concentration. The other had a 1.1\% Pr-promoted 2.11X RhM and, 3.64X Ir baseline concentrations. The behavior of all four catalysts was generally similar. Carbon conversion underwent a regular decrease as the pressure decreased from 1200 to $400 \mathrm{psig}$, with the silica-supported catalyst undergoing approximately a $65 \%$ decrease in carbon conversion and the two carbon-supported catalysts undergoing approximately a $40 \%$ decrease. The selectivity to $\mathrm{C}_{2}+$ oxygenates decreased several percentage points with decreasing pressure over the entire pressure range, although very little change was observed with the silica-supported catalysts over the 1200 to 700 psig pressure range. The STYs generally followed the same trends as the CO conversion for all three catalysts. The $\mathrm{C}_{2}+$ alcohols made up a greater fraction of the total oxygenates as the pressure decreased over the entire range. Based on these results, it appears that higher pressure is preferred for STY and selectivity, although some decrease in pressure (perhaps as low as $800 \mathrm{psig}$ ) might be tolerated with relatively little effect on selectivity.

\subsection{Gas Composition Effects}

Two test series were conducted to investigate the effect of the $\mathrm{H}_{2}$ :CO ratio on the performance of two carbon-supported catalysts containing 2.11X the baseline concentrations of Rh and $\mathrm{Mn}$ and 3.64X the baseline concentration of Ir. One catalyst was promoted with $0.04 \% \mathrm{~B}$, and the other was promoted with $0.01 \% \mathrm{Ga}$. Changing the $\mathrm{H}_{2}$ :CO ratio from $2: 1$ to $1.3: 1$ produced a $\sim 3$ to $\sim 4 \%$ increase in the converted carbon selectivity to $\mathrm{C}_{2}+$ oxygenates, while the $\mathrm{C}_{2}+$ oxygenate STYs decreased between 18 and $24 \%$. Decreasing the $\mathrm{H}_{2}: \mathrm{CO}$ ratio also decreased the selectivity of the oxygenate products to $\mathrm{C}_{2}+$ alcohols, suggesting that hydrogenation of the other oxygenates to alcohols is lower with the reduced hydrogen concentration in the feed gas. 
Two tests were conducted to investigate the effect of $4 \% \mathrm{CO}_{2}$ in the syngas using a Davisil 645 silicasupported catalyst containing $1 \mathrm{X}$ the baseline concentrations of $\mathrm{Rh}, \mathrm{Mn}$, and $\mathrm{Ir}$, and $0.04 \% \mathrm{Mg}$ and a Merck Grade 7734 silica-supported catalyst containing 1.5X the baseline concentrations of Rh, Mn, and $\mathrm{Ir}$, and $0.06 \% \mathrm{Mg}$. The results suggested that, when $\mathrm{CO}_{2}$ is reduced from 4 to $0 \%$ in the syngas, there appears to be a very modest 3 to $6 \%$ increase in the selectivity to $\mathrm{C}_{2}+$ oxygenates accompanied by an offsetting 10 to $14 \%$ decrease in the STY. 


\subsection{References}

Gerber MA, JF White, and DJ Stevens. 2007. Mixed Alcohol Synthesis Catalyst Screening.

PNNL-16763, Pacific Northwest National Laboratory, Richland, Washington.

Gerber MA, JF White, MJ Gray, and DJ Stevens. 2008. Evaluation of Promoters for Rhodium-Based Catalysts for Mixed Alcohol Synthesis. PNNL-17857, Pacific Northwest National Laboratory, Richland, Washington.

Gerber MA, MJ Gray, DJ Stevens, JF White, and BL Rummel. 2010. Optimization of Rhodium-Based Catalysts for Mixed Alcohol Synthesis - 2009 Progress Report. PNNL-20115, Pacific Northwest National Laboratory, Richland, Washington.

Gerber MA, MJ Gray, KO Albrecht, JF White, BL Rummel, and DJ Stevens. 2012a. Optimization of Rhodium-Based Catalysts for Mixed Alcohol Synthesis - 2010 Progress Report. PNNL-22081, Pacific Northwest National Laboratory, Richland, Washington.

Gerber MA, MJ Gray, KO Albrecht, and BL Rummel. 2012b. Optimization of Rhodium-Based Catalysts for Mixed Alcohol Synthesis - 2011 Progress Report. PNNL-22078, Pacific Northwest National Laboratory, Richland, Washington.

Vassiliki-Alexandra G, JE Jaffe, R Rousseau, D Mei, SM Kathmann, KO Albrecht, MJ Gray, and MA Gerber. 2012. "The Role of Ir in Ternary Rh-Based Catalysts for Syngas Conversion to $\mathrm{C}_{2}+$ Oxygenates." Topics in Catalysis 55(7-10):595-600. 



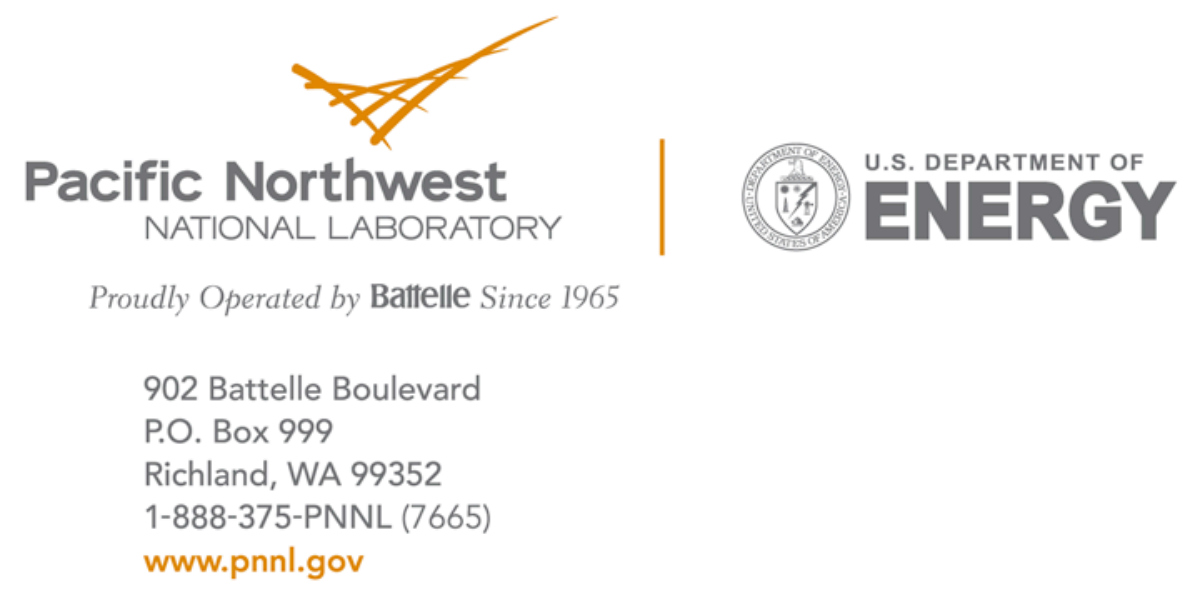

